ROSANA SOUZA THURLER DOS SANTOS

Avaliação da inibição da atividade das ciclooxigenases 1 e 2 e da eficácia analgésica da dipirona em equinos.

São Paulo 
ROSANA SOUZA THURLER DOS SANTOS

\section{Avaliação da inibição da atividade das ciclooxigenases 1 e 2 e da eficácia analgésica da dipirona em equinos.}

Dissertação apresentada ao Programa de Pós-Graduação em Clínica Cirúrgica Veterinária da Faculdade de Medicina Veterinária e Zootecnia da Universidade de São Paulo para a obtenção do título de Mestre em Ciências

Departamento:

Departamento de Cirurgia

Área de concentração:

Clínica Cirúrgica Veterinária

Orientador:

Prof ${ }^{\underline{a}}$. Dr ${ }^{\mathrm{a}}$. Denise Tabacchi Fantoni

São Paulo 
Autorizo a reprodução parcial ou total desta obra, para fins acadêmicos, desde que citada a fonte.

\section{DADOS INTERNACIONAIS DE CATALOGAÇÃO NA PUBLICAÇÃO}

(Biblioteca Virginie Buff D'Ápice da Faculdade de Medicina Veterinária e Zootecnia da Universidade de São Paulo)

Santos, Rosana Souza Thurler dos

Avaliação da inibição da atividade das ciclooxigenases 1 e 2 e da eficácia analgésica da dipirona em equinos / Rosana Souza Thurler dos Santos. - 2017.

$107 \mathrm{f}$ : : il.

Dissertação (Mestrado) - Universidade de São Paulo. Faculdade de Medicina Veterinária e Zootecnia. Departamento de Cirurgia, São Paulo, 2018.

Programa de Pós-Graduação: Clínica Cinúrgica Veterinária.

Área de concentração: Clínica Cirúrgica Veterinánia.

Orientadora: Profa. Dra. Denise Tabacchi Fantoni.

1. Dor. 2. Equinos. 3. Dipirona. 4. Prostaglandina E2. 5. Tromboxano B2. I. Título. 
UNIVERSIDADE DE SÃo PAULO

\section{CERTIFICADO}

Certificamos que a proposta intitulada "AVALIAÇĀO DOS EFEITOS DA DIPIRONA NA MUCOSA GÁSTRICA E NA CURVA DE PROSTAGLANDINA EM EQUINOS- MODELO EXPERIMENTAL", protocolada sob o CEUA $n^{2} \mathbf{8 8 6 2 0 2 0 7 1 5}$, sob a responsabilidade de Denise Tabacchi Fantoni e equipe; Rosana Souza Thurler dos Santos - que envolve a produção, manutenção e/ou utilização de animais pertencentes ao filo Chordata, subfilo Vertebrata (exceto o homem), para fins de pesquisa cientifica ou ensino - está de acordo com os preceitos da Lei 11.794 de 8 de outubro de 2008, com o Decreto 6.899 de 15 de julho de 2009, bem como com as normas editadas pelo Conselho Nacional de Controle da Experimentação Animal (CONCEA), e foi aprovada pela Comissão de Ética no Uso de Animais da Faculdade de Medicina Veterinária e Zootecnia da Universidade de São Paulo (CEUA/FMVZ) na reuniāo de 02/12/2016.

We certify that the proposal "EVALUATION OF EFFECTS OF DIPYRONE IN GASTRIC MUCOSA AND PROSTAGLANDIN CURVE IN EQUINE EXPERIMENTAL MODEL ", utilizing 8 Equines ( 8 females), protocol number CEUA 8862020715 , under the responsibility of Denise Tabacchi Fantoni and team; Rosana Souza Thurler dos Santos - which involves the production, maintenance and/or use of animals belonging to the phylum Chordata, subphylum Vertebrata (except human beings), for scientific research purposes or teaching - is in accordance with Law 11.794 of October 8, 2008, Decree 6899 of July 15, 2009, as well as with the rules issued by the National Council for Control of Animal Experimentation (CONCEA), and was approved by the Ethic Committee on Animal Use of the School of Veterinary Medicine and Animal Science (University of São Paulo) (CEUA/FMVZ) in the meeting of 12/02/2016.

Finalidade da Proposta: Pesquisa

Vigência da Proposta: de 08/2015 a 10/2015 Área: Cirurgia

\begin{tabular}{|c|c|c|c|c|c|}
\hline Origem: & HOVET/FMVZ/USP & & & & \\
\hline Espécie: & Equideos & sexo: Fêmeas & idade: & 1 a 4 & $\mathrm{~N}:$ \\
\hline Linhagem: & arabe & & Peso: & 300 a 500 & \\
\hline
\end{tabular}

Resumo: Nos equinos, são diversos os mecanismos de formação de úlceras gástricas, podendo-se citar o estresse, exercícios em demasia, a diminuição da camada protetora gástrica, a redução do fluxo sanguíneo para a mucosa, dentre outros. Dos fatores exógenos, os antinflamatórios não esteroidais (AINES) representam um dos fatores de maior relevância para indução de ulcerações gástricas. Por esta razão, e levando-se em conta o provável mecanismo de ação da dipirona, este estudo tem o objetivo de avaliar se o uso de Dipirona nas doses de $15 \mathrm{mg} / \mathrm{Kg}$ e $20 \mathrm{mg} / \mathrm{Kg}$, de $12 \mathrm{em} 12$ horas, durante 7 dias tem o poder de lesionar a mucosa gástrica de equinos da raça Árabe, machos e fêmeas.

Local do experimento: HOVET - Equinos

São Paulo, 07 de novembro de 2017

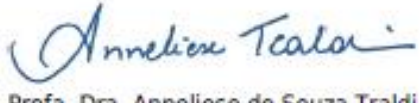

Profa. Dra. Anneliese de Souza Trald Presidente da Comissão de Ética no Uso de Animais Faculdade de Medicina Veterinária e Zootecnia da Universidade Faculdade de Medicina Veterinária e Zootecnia da Universidade de São Paulo

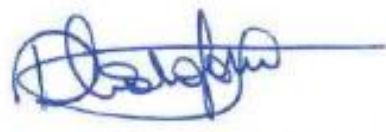

Roseli da Costa Gomes Secretária Executiva de Sāo Paulo 
Universidade de SÃo Paulo

IImo(a). Sr(a).

Responsável: Denise Tabacchi Fantoni

Área: Cirurgia

Denise Tabacchi Fantoni (orientador)

Título da proposta: "AVALIAÇÃ̃o dOS EFEITOS DA DIPIRONA NA MUCOSA GÁSTRICA E NA CURVA DE PROSTAGLANDINA EM EQUINOS- MODELO EXPERIMENTAL".

\section{Parecer Consubstanciado da Comissão de Ética no Uso de Animais FMVZ/USP}

A Comissão de Ética no Uso de Animais da Faculdade de Medicina Veterinária e Zootecnia da Universidade de São Paulo, no cumprimento das suas atribuiçōes, analisou e APROVOU a Notificaçāo (versão de 09/maio/2017) da proposta acima referenciada.

Resumo apresentado pelo pesquisador: "Seguindo sugestōes dadas pela banca de qualificação, resolveu-se então adicionar a fase 2 no projeto de pesquisa. Esta fase consiste na avaliação da efiććcia analgésica da dipirona para o procedimento de orquiectomia eletiva em cavalos, quando comparado com o protocolo mais utilizado nesta espécie (flunixin Melgumine). Espera-se com este projeto encontrar na dipirona um analgésico para dor leve à moderada que traga menores efeitos deletérios na espécie equina."

Comentário da CEUA: "Este projeto apresenta um aditivo para a incorporação de uma segunda fase, que consiste na avaliação da efićcía analgésica da dipirona para o procedimento de orquiectomia eletiva em cavalos, quando comparado com o protocolo mais utilizado nesta espécie (flunixin Melgumine). Foi apresentado um TCLE para que proprietários cedam equinos para esta nova fase do estudo, já que a primeira fase consistiu em animais patrimoniados do Hovet.".

$$
\text { Mnneliese Tealar. }
$$

Profa. Dra. Anneliese de Souza Traldi Presidente da Comissão de Ética no Uso de Animais Faculdade de Medicina Veterinária e Zootecnia da Universidade de São Paulo

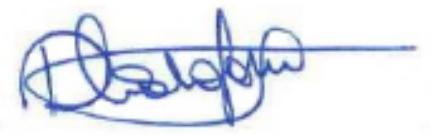

Roseli da Costa Gomes Secretária Executiva

Faculdade de Medicina Veterinária e Zootecnia da Universidade de São Paulo 


\section{FOLHA DE AVALIAÇÃO}

Autor: SANTOS, Rosana Souza Thurler dos.

Título: Avaliação da inibição da atividade das ciclooxigenases 1 e 2 e da eficácia analgésica da dipirona em equinos.

Dissertação apresentada ao Programa de Pós-Graduação em Clínica Cirúrgica Veterinária da Faculdade de Medicina Veterinária e Zootecnia da Universidade de São Paulo para obtenção do titulo de Mestre em Ciências

Data:

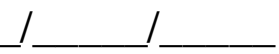

\section{Banca Examinadora}

Prof. Dr.

Instituição:

Julgamento:

Prof. Dr.

Instituição:

Julgamento:

Prof. Dr.

Instituição:

Julgamento: 


\section{DEDICATÓRIA}

Dedico este trabalho a todos meus pacientes e animais que participaram do meu experimento pois sem eles nada disso valeria a pena ou mesmo seria possível. Que nosso esforço seja recompensado com a melhora no tratamento da dor e atendimento em equinos.

Dedico também todo meu esforço e trabalho para minhas avós: vovó Maria (in memoriam) e vovó Altiva (in memoriam), que sempre foram minhas estrelas e me passaram todo o amor que eu tenho pelos animais. 


\section{AGRADECIMENTOS}

Só tenho a agradecer por todo amor que tive a oportunidade de receber de tantas pessoas nessa fase. Agradeço a Deus pela oportunidade de poder seguir a minha vocação e ser extremamente realizada! Obrigada por todos os seres de luz que o Senhor envia para me guiarem nessa jornada da vida! Eu nunca fui muito boa com palavras, sempre achei um desafio transcrever conhecimentos e, principalmente, sentimentos. Para mim nenhum texto que eu faça será capaz de descrever o que foram esses quase três anos morando em São Paulo. O crescimento profissional e pessoal foram absurdos, e me fizeram ser uma pessoa melhor e com mais maturidade....e talvez alguns fios de cabelo branco a mais para colocar na conta da 'experiência de vida'.

Falando daquela que dedicou o melhor sorriso, as melhores brincadeiras, o melhor abraço, assim como corpo, alma, mente e tudo mais para poder fornecer à minha irmã e a mim o melhor possível. MÃE, nunca serei capaz de achar as palavras certas para te agradecer por tudo o que você foi e é para mim. Se hoje me consideram uma guerreira, foi te olhando que eu aprendi a ser assim. Se eu sei algo sobre resiliência, foi vendo você se reinventar a cada situação difícil que eu aprendi. Obrigada por ser mãe, mentora, amiga, companheira e comediante. Te amo com um amor mais profundo que eu já senti na vida. Obrigada, minha rainha, eu nada seria sem seu apoio.

Sheila, minha irmã e primeira melhor amiga. Obrigada pelos conselhos, por todo apoio e toda ajuda nos momentos de crise. Obrigada por ajudar a mami a cuidar das crianças com tanto carinho (Guto Maurício, Lion Jorge, Melissa Maria- mamãe ama vocês demais). Te amo, mimã!

Papis, Huguinho e Ju, obrigada pelo apoio, cuidado, abrigo por me ajudarem no momento de conturbação de mudança de Cidade, pós e mestrado. Amo vocês. Família Thurler, família Souza, obrigada pelo carinho, pelo apoio e pelo orgulho que vocês sentem de mim, amo vocês. Quero agradecer também às famílias dos meus amigos que me acolheram nesse período! Eu tenho muita sorte de ter vocês, Famílias Nogueira, Ribeiro, Amador Pereira, Seidel. Vocês têm um lugar especial no meu coração!

Aos amigos, seria impossível eu passar por todo esse turbilhão sem vocês. Cada um sabe a importância do carinho no momento certo que vocês me deram. Artemis, Renata, Celle, Naty, Marcola, Xuh, aos meus colegas de profissão e amigos da PAV XI, são muitos nomes, mas quero deixar meu profundo agradecimento e amor por cada momento! Agradeço aos amigos do Team Fantoni, que me ajudaram demais! Agradeço também ao grupo de anestesia de equinos e à Profa Aline Ambrósio, por me dar conselhos, me defender quando eu pedi e por me ensinar tantas coisas e aos professores Luis Cláudio e Romero, por me ajudarem, confiarem em mim e me fazerem rir!!

Quero agradecer à equipe do EVET, por ter me acolhido nesse último ano. Obrigada por todas as trocas e experiência e por se tornarem parte do meu grupo de amigos. "Somos amados e perfeitos como somos". Agradeço ao pessoal do hospital veterinário e da pós da FMVZ-USP: Livia, Flôr, Julio, aos residentes de equinos de 2017, obrigada aos enfermeiros, ao pessoal da limpeza. Obrigada a todos que direta ou indiretamente me ajudaram a evoluir neste processo.

Cléber (Mozi), obrigada por me tratar com carinho, por me inserir na sua maravilhosa família (um beijo enorme para todos vocês!) e por me ajudar e me acalmar em cada crise minha: seu lugar no céu está reservadíssimo!!! Te amo TANTO! Obrigada por ser esse homem incrível e por me fazer tão feliz de uma maneira que eu nunca achei que fosse se concretizar!

Por último, gostaria de agradecer à minha orientadora. Não é a toa que você, prof ${ }^{a}$ Denise Fantoni, é conhecida nacional e internacionalmente. Não é fácil ser mulher no nosso mundo, no nosso país, no nosso meio. Você é simplesmente uma das principais responsáveis pela total mudança de rumo na anestesia veterinária no Brasil. Uma mulher pequenininha de altura, mas grandiosa de espírito, que ousou falar sobre dor em animais, ousou brigar para que o tratamento analgésico fosse realizado corretamente nos animais, principalmente nos cavalos. Obrigada por cada gota de conhecimento, obrigada por cuidar de mim e por ser minha Mamis de São Paulo. Obrigada pelo carinho, pelas risadas e pelos fofos puxões de orelha. Obrigada por aceitar o desafio de me orientar nessa jornada do mestrado...espero que nossos caminhos se cruzem muito mais! Seu lugar no meu coração está guardado pra sempre! 
"Onde houver ódio, que eu leve o amor."

São Francisco de Assis

"O que mais me atrai nos animais é que eles não usam palavras, eles usam sentimentos".

Chico Xavier 


\section{RESUMO}

SANTOS, R. S. T. dos. Avaliação da inibição da atividade das ciclooxigenases 1 e 2 e da eficácia analgésica da dipirona em equinos. [Evalution of ciclooxygenases 1 and 2 and the analgesic efficacy of dipyrone in horses]. 2017. 107 f. Dissertação [Mestrado em Ciências] - Faculdade de Medicina Veterinária e Zootecnia, Universidade de São Paulo, São Paulo, 2017.

O controle da dor nos animais tem sido objeto de inúmeros estudos na atualidade, tanto por razões de cunho humanitário, quanto pela influência que a dor não controlada exerce sobre os parâmetros fisiológicos de todas as espécies animais, o que invariavelmente causa prejuízos ao bem-estar e aos índices produtivos dos animais, sejam estes empregados na produção, esporte ou companhia. Os antiinflamatórios não esteroidais (AINEs) são os fármacos mais comumente empregados para o controle da dor em equinos, porém podem ocasionar vários efeitos adversos, entre eles gastrite ou agravar um quadro pré-existente, pois atuam inibindo a ciclooxigenase 1, que é a principal enzima responsável pela produção não só de mediadores inflamatórios, mas também da camada protetora estomacal. A dipirona, embora não seja um AINE clássico, pode também promover inibição da COX-1, como já comprovada em humanos e ratos. A presente pesquisa teve como objetivo avaliar o efeito da administração de dipirona pela via intravenosa na dose de $15 \mathrm{mg} / \mathrm{Kg}$, a cada 12 horas, em 12 equinos da raça Árabe, sem distinção de sexo ou idade, durante 24 horas. Foram avaliadas as concentrações da prostaglandina E2 e de tromboxano B2 nos tempos Basal (TB, antes da administração de dipirona) e decorridas 2 (T2), 8 (T8), 12 (T12) e 24 (T24) horas após a administração de dipirona. Na segunda fase do estudo foi realizada a avaliação da analgesia promovida pela dipirona em 15 equinos submetidos ao procedimento de orquiectomia eletiva, na qual um dos grupos recebeu no pósoperatório, dipirona $15 \mathrm{mg} / \mathrm{Kg}$, a cada 12 horas e outro grupo recebeu flunixin meglumine $1,1 \mathrm{mg} / \mathrm{Kg}$ a cada 24 horas, ambos pela via intravenosa. A dipirona promoveu inibição em COX-1 de 97,76\% \2,02 em T2 ( $\mathrm{P}<0,0001)$, não promoveu inibição em COX-2, porém mostrou-se eficaz como único analgésico pós-operatório 
para orquiectomia eletiva em equinos saudáveis, podendo ser uma opção para tratamento de dor leve à moderada em cavalos.

Palavras-chave: Dor. Equinos. Dipirona. Prostaglandina $\mathrm{E}_{2}$. Tromboxano $\mathrm{B}_{2}$. 


\begin{abstract}
SANTOS, R. S. T. dos. Avaliação da inibição da atividade das ciclooxigenases 1 e 2 e da eficácia analgésica da dipirona em equinos. [Evalution of ciclooxygenases 1 and 2 and the analgesic efficacy of dipyrone in horses]. 2017. 107 f. Dissertação [Mestrado em Ciências] - Faculdade de Medicina Veterinária e Zootecnia, Universidade de São Paulo, São Paulo, 2017.
\end{abstract}

The pain control in animals has been the subject of numerous studies nowadays, both for humanitarian reasons, and for the influence that uncontrolled pain exerts on the physiological parameters of all animal species, which invariably causes harm to the welfare and productive ratings of the animals, whether they are production, sport or company animals. Non-steroidal anti-inflammatory drugs (NSAIDS) are the most commonly used drugs in horses, but may cause several side effects, including gastritis, or aggravating a preexisting condition, as it inhibits cyclooxygenase 1, which is the main responsible enzyme for producing not only inflammatory mediators, but also the stomach protective layer. Although dipyrone is not a classic NSAID, it may also promotes the inhibition of COX-1, already proven in humans and rats. Therefore, the present study aimed to evaluate the effect of intravenous administration of dipyrone at the dose of $15 \mathrm{mg} / \mathrm{kg}$, every 12 hours, in 12 Arabian horses, regardless of sex or age, for 24 hours. It was evaluated the concentrations of prostaglandin $\mathrm{E}_{2}$ and thromboxane $\mathrm{B}_{2}$ at basal times (TB, prior to the administration of dipyrone) and so on 2 (T2), 8 (T8), 12 (T12) and 24 (T24) hours later after the administration of dipyrone. In the second phase of the study, the assessment was conducted to evaluate the analgesia provided by dipyrone in 15 horses submitted to elective orchiectomy procedure, in which one of the groups received, postoperatively, dipyrone $15 \mathrm{mg} / \mathrm{kg}$, every 12 hours, and the other group received flunixin meglumine $1.1 \mathrm{mg} / \mathrm{kg}$ every 24 hours, both intravenously. Dipyrone promoted inhibition in COX-1 of $97.76 \% \pm 2.02$ in T2 $(\mathrm{P}<0.0001)$ and did not induce inhibition in COX-2, although it was effective as the sole analgesic for elective orchiectomy in healthy horses, and may be an option for mild to moderate pain management in horses.

Keywords: Pain. Horses. Dipyrone. Prostaglandine $E_{2}$. Tromboxane $B_{2}$. 


\section{LISTA DE FIGURAS}

Figura 01 - Esquematização de alguns efeitos adversos provenientes da inibição COX-1/ COX-2..

Figura 02 - Delineamento experimental das coletas de sangue para mensuração da concentração de $\mathrm{PGE}_{2}$ e $\mathrm{TXB}_{2}$ de 12 cavalos distribuídos aleatoriamente nos 2 grupos do estudo - FMVZ - São Paulo 2017 41

Figura 03 - Delineamento experimental dos momentos de avaliação dos escores de dor, sedação e ataxia de 15 cavalos distribuídos aleatoriamente nos 2 grupos do estudo - $\quad$ FMVZ $\quad-\quad$ São $\quad$ Paulo 2017 


\section{LISTA DE TABELAS}

Tabela 1 - Média e desvio padrão da porcentagem de mudança das concentrações de Tromboxano B2 (TXB2), representando a atividade da cicloxigenase 1 (COX-1) em comparação com o valor imediatamente anterior à administração da medicação (Basal: valor considerado como 100\%), dos 12 cavalos distribuídos aleatoriamente nos 2 grupos do estudo durante os momentos avaliados na fase 01- FMVZ - São Paulo - 2017 .50

Tabela 2 - Média e desvio padrão da porcentagem de mudança das concentrações de Prostaglandina E2 (PGE2), representando a atividade da ciclooxigenase 2 (COX-2) em comparação com o valor imediatamente anterior à administração da medicação referente ao grupo (Basal: valor considerado como 100\%), dos 12 cavalos distribuídos aleatoriamente nos 2 grupos do estudo durante os momentos avaliados na fase 01 - FMVZ - São Paulo - 2017 .51

Tabela 3 - Média e desvio padrão do tempo cirúrgico dos 15 cavalos distribuídos aleatoriamente nos 2 grupos do estudo durante os momentos avaliados na fase 02 - FMVZ - São Paulo - 2017 .54 


\section{LISTA DE GRÁFICOS}

Gráfico 01 - Gráfico Boxplot da porcentagem de mudança na concentração de Tromboxano B2 (TXB2), representando a atividade da ciclooxigenase 1 (COX-1), em comparação com o valor imediatamente anterior à administração da medicação referente ao grupo (Basal: valor considerado como 100\% [linha pontilhada horizontal]) de 12 cavalos distribuídos aleatoriamente nos 2 grupos do estudo durante os momentos avaliados na fase 01-FMVZ-USP - São Paulo - 2017.....50

Gráfico 02 - Gráfico Boxplot da porcentagem de mudança na concentração de Prostaglandina E2 (PGE2), representando a atividade da cicloxigenase 2 (COX-2), em comparação com o valor imediatamente anterior à administração da medicação referente ao grupo (Basal: valor considerado como 100\% [linha pontilhada horizontal]) de 12 cavalos distribuídos aleatoriamente nos 2 grupos do estudo durante os momentos avaliados na fase 01-FMVZ-USP - São Paulo - 2017.....52

Gráfico 03 - Gráfico Boxplot da variação da idade em anos e do peso em quilogramas dos 15 cavalos distribuídos aleatoriamente nos 2 grupos do estudo durante os momentos avaliados na fase 02- FMVZ-USP - São Paulo - 2017....53

Gráfico 04 - Gráfico Boxplot da variação do tempo cirúrgico dos 15 cavalos distribuídos aleatoriamente nos 2 grupos do estudo durante os momentos avaliados na fase 02- FMVZ-USP - São Paulo - 2017.

Gráfico 05 - Gráfico Boxplot das médias \pm desvio padrão da frequência cardíaca (FC), em batimentos por minuto, de 15 cavalos distribuídos aleatoriamente nos 2 grupos do estudo durante os momentos avaliados na fase 02- FMVZ-USP - São Paulo - 2017 .55

Gráfico 06 - Gráfico Boxplot das médias \pm desvio padrão da frequência respiratória (FR), em movimentos por minuto, de 15 cavalos distribuídos aleatoriamente nos 2 grupos do estudo durante os momentos avaliados na fase 02- FMVZ-USP - São Paulo - 2017 . 56 
Gráfico 07 - Gráfico Boxplot das médias \pm desvio padrão da temperatura retal, em graus Celsius $\left({ }^{\circ} \mathrm{C}\right)$ nos momentos avaliados de 15 cavalos distribuídos aleatoriamente nos 2 grupos do estudo durante os momentos avaliados na fase 02- FMVZ-USP - São Paulo - 2017.

Gráfico 08 - Gráfico Boxplot de médias \pm desvio padrão dos escores de dor, em centímetros, obtidos pela Escala Analógica Visual (EAV) de 15 cavalos distribuídos aleatoriamente nos 2 grupos do estudo durante os momentos avaliados na fase 02- FMVZ-USP - São Paulo - 2017 .58

Gráfico 09 - Gráfico Boxplot de médias \pm desvio padrão dos escores de dor obtidos pela Escala Multidimensional da UNESP-Botucatu de 15 cavalos distribuídos aleatoriamente nos 2 grupos do estudo durante os momentos avaliados na fase 02- FMVZ-USP - São Paulo - 2017. .59

Gráfico 10 - Gráfico Boxplot médias \pm desvio padrão dos escores de dor obtidos pela Escala Facial de 15 cavalos distribuídos aleatoriamente nos 2 grupos do estudo durante os momentos avaliados na fase 02- FMVZ-USP - São Paulo 2017. 60

Gráfico 11 - Gráfico Boxplot médias \pm desvio padrão dos escores de sedação obtidos pela Escala de Sedação de 15 cavalos distribuídos aleatoriamente nos 2 grupos do estudo durante os momentos avaliados na fase 02- FMVZ-USP - São Paulo - 2017. .61

Gráfico 12 - Gráfico Boxplot médias \pm desvio padrão dos escores de sedação obtidos pela Escala de Sedação de 15 cavalos distribuídos aleatoriamente nos 2 grupos do estudo durante os momentos avaliados na fase 02- FMVZ-USP - São Paulo - 2017. 62 
SUMÁRIO

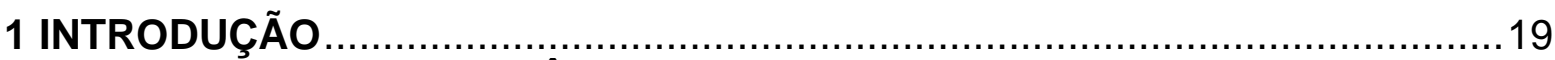

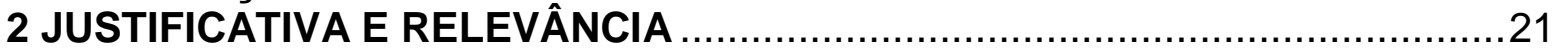

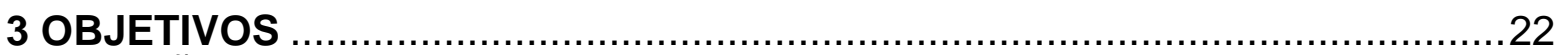

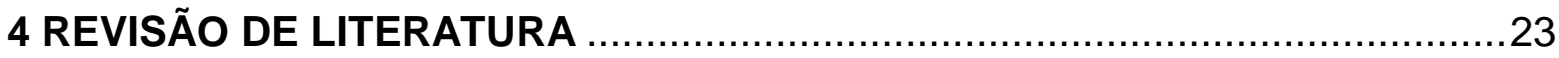

4.1 DOR

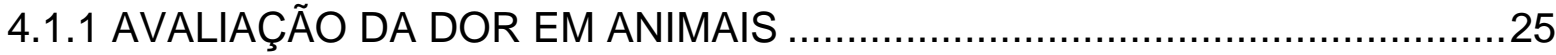

4.1.2 TRATAMENTO DA DOR EM ANIMAIS ….......................................27

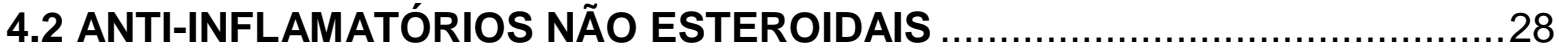

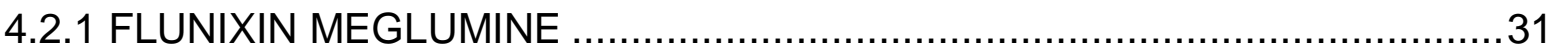

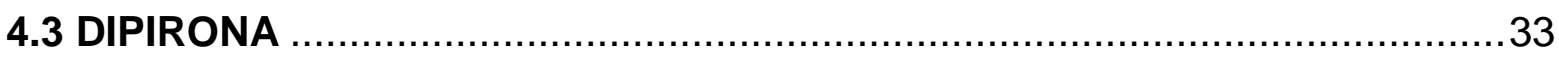

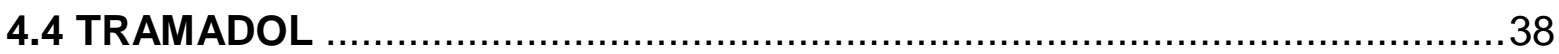

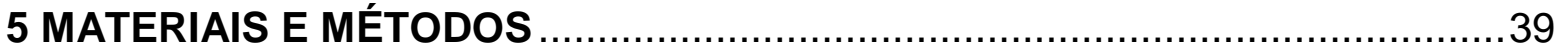

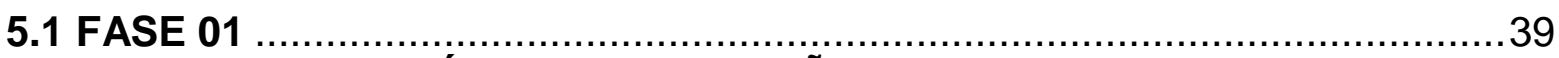

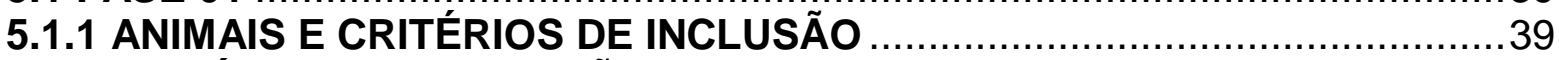

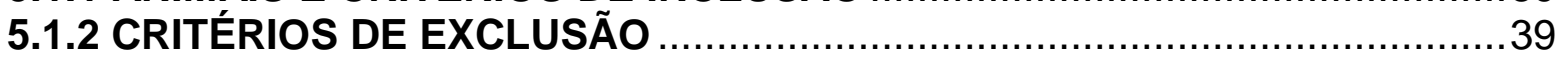

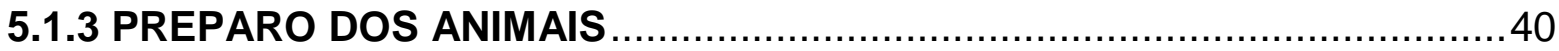

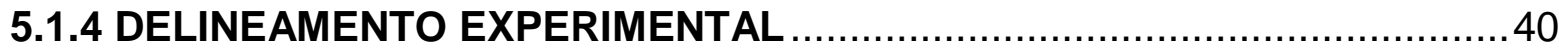

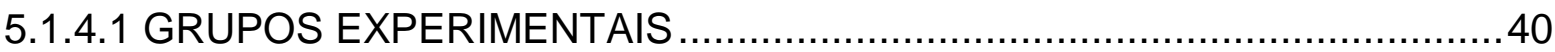

5.1.4.2 DETERMINAÇÃO EX VIVO DA CONCENTRAÇÃO DE TXB ${ }_{2} \mathrm{E} \mathrm{PGE}_{2} \ldots \ldots .41$

5.1.4.2.1 AVALIAÇÃO DA CONCENTRAÇÃO DE TROMBOXANO B $B_{2} \ldots \ldots \ldots \ldots \ldots . . . . .42$

5.1.4.2.2 AVALIAÇÃO DA CONCENTRAÇÃO DE PROSTAGLANDINA $E_{2} \ldots \ldots \ldots . . .43$

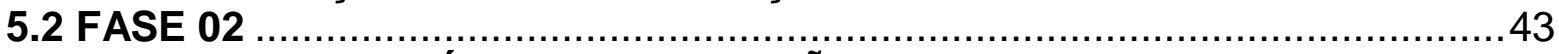

5.2.1 ANIMAIS E CRITÉRIOS DE INCLUSÃO …........................................... 44

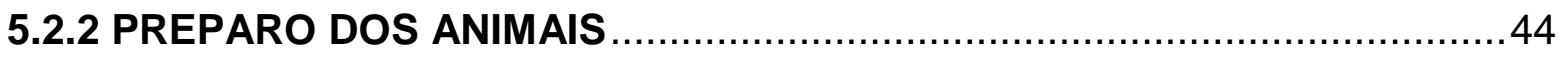

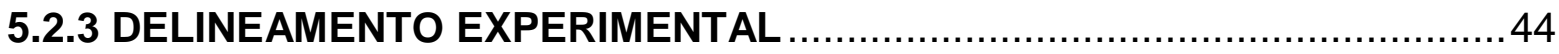

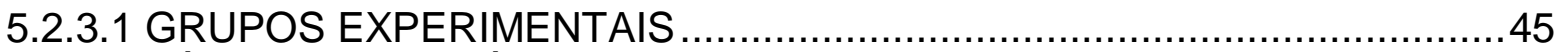

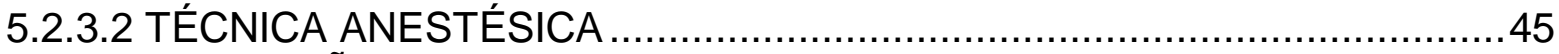

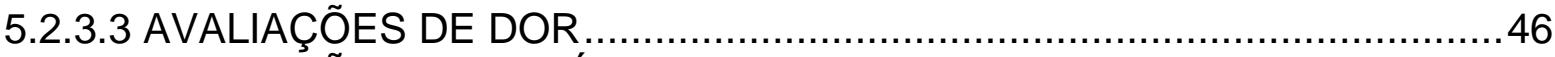

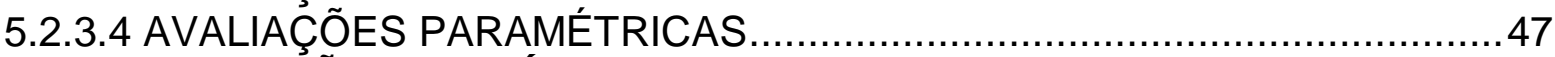

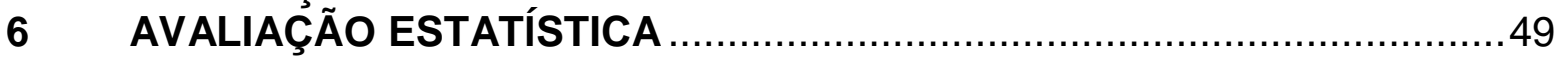

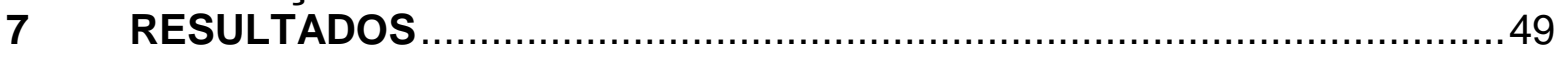

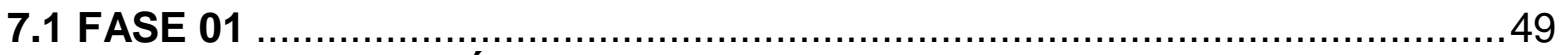

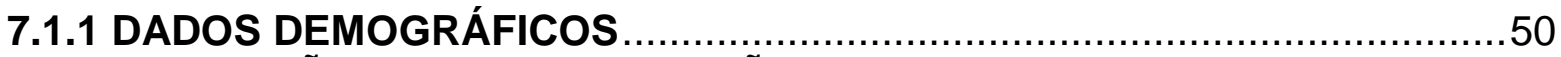

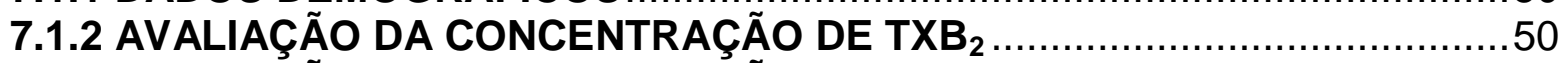

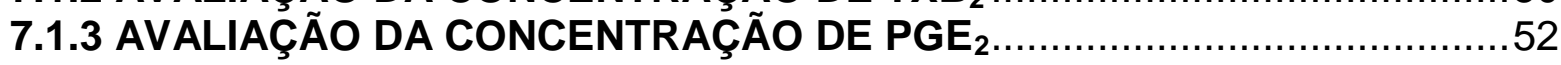

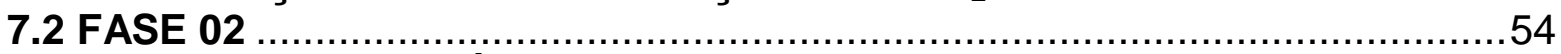

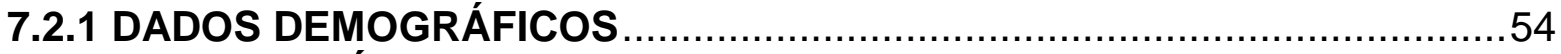

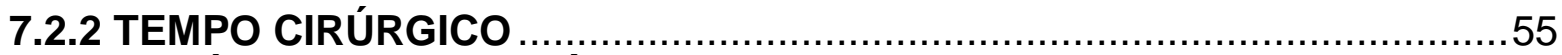

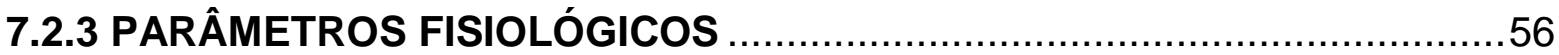

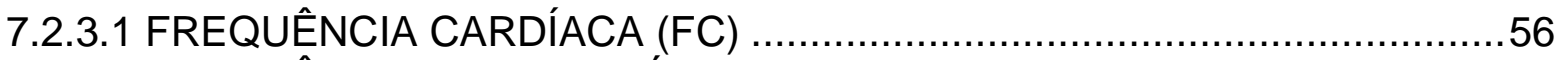

7.2.3.2 FREQUÊNCIA RESPIRATÓRIA (FR) .............................................

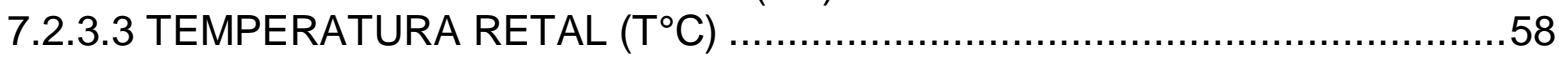

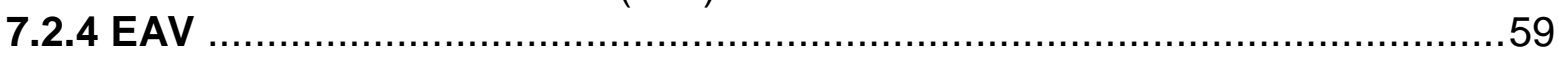

7.2.5 ESCALA MULTIDIMENSIONAL DA UNESP-BOTUCATU.......................60

7.2.6 ESCALA MULTIDIMENSIONAL DE EXPRESSÕES FACIAIS PARA

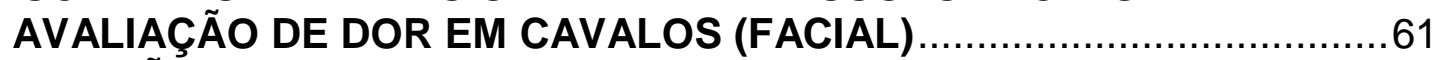


7.2.8 ATAXIA

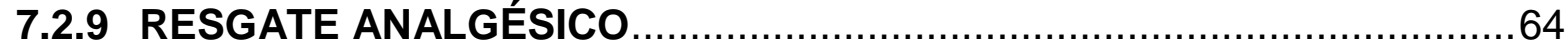

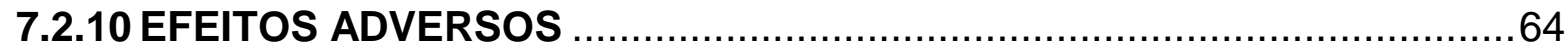

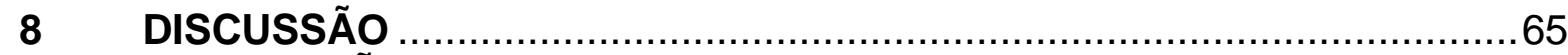

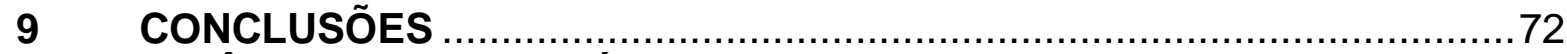

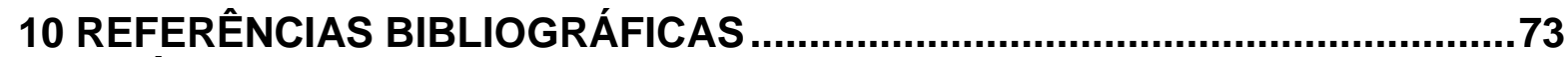

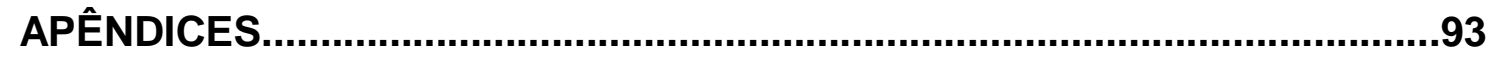

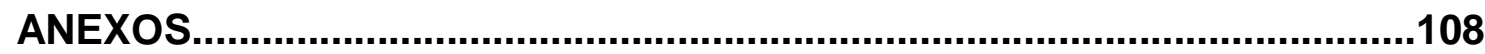




\section{INTRODUÇÃO}

Considerada o $5^{\circ}$ sinal vital na medicina humana (EPSTEIN et al., 2015), a dor é um dos sinais mais comumente encontrados tanto nos homens como nos animais. No entanto, o tratamento da dor ainda é inadequado na maioria dos casos (ROBERTSON, 2010), e isto pode ser atribuído em parte à dificuldade no reconhecimento da dor na maioria das espécies. Ingwersen et al. (2012) atribuem às diferenças no ensino da Medicina Veterinária entre as gerações, assim como insegurança em utilizar analgésicos como as principais causas do tratamento inadequado da dor. A dor aguda pós-operatória possui o potencial risco de cronicidade caso não seja adequadamente tratada, podendo piorar a recuperação e a qualidade de vida do paciente (JR et al., 2014). Seu tratamento deve ser realizado com bastante cautela, pois há influência direta na qualidade de recuperação pós-cirúrgica. O período pós-operatório traz consigo alterações fisiológicas resultantes do estresse, das lesões teciduais e da anestesia propriamente dita, portanto, o tratamento da dor pós-operatória torna-se indispensável para que o paciente recupere suas funções rapidamente, reduzindo assim a morbidade e a mortalidade (XU \& BRENNAN, 2011).

Para que se estabeleça adequadamente a terapia analgésica pós-operatória, deve-se conhecer o comportamento natural da espécie e sua interação com seres humanos e com outros indivíduos da mesma espécie para se realizar uma avaliação mais fidedigna da dor (ROBERTSON, 2008). Vários tipos de escalas para avaliação de dor são utilizadas atualmente (ROBERTSON, 2008) sendo empregadas com sucesso para a avaliação da dor pós-operatória.

Quando se trata do controle da dor aguda pós-operatória, podem-se eleger diversas classes farmacológicas para seu tratamento, sendo que os opioides, os anti-inflamatórios não esteroidais (AINES) e os analgésicos constituem a base do tratamento da dor aguda nociceptiva. (SCHATZMANN, 2002).

Em equinos os AINES são amplamente utilizados, pois promovem controle efetivo da dor em diversas condições/afecções que cursam com inflamação. Entretanto, devido ao seu mecanismo de ação, podem ocasionar efeitos adversos como ulceração gastrointestinal, insuficiência renal, alterações da coagulação dentre outras (MACALLISTER et al., 1997; MURRAY, M.J., 2002; CHATTERJEE et al., 2012). A possibilidade dos AINES de causarem efeitos adversos, está 
relacionada à maior ou menor capacidade destes agentes em bloquearem as enzimas ciclooxigenases 1 e/ou 2 (COX-1 e COX-2). O bloqueio mais consistente da COX-1 acarreta maiores alterações a curto prazo, ao passo que com a COX-2, as alterações são mais insidiosas ou até mesmo ausentes (FANTONI \& MASTROCINQUE, 2002; WARNER \& MITCHELL, 2004). Agentes corriqueiramente utilizados nos equinos como a fenilbutazona e o flunixin meglumine são mais seletivos para a COX-1 enquanto que o meloxicam é mais seletivo para a COX-2. (BERETTA et al., 2005).

A dipirona (ou metamizole), embora seja classificada como anti-inflamatório não esteroidal por alguns autores na literatura (BATU \& EROL, 2007; DOMÍNGUEZ-RAMÍREZ et al., 2010), não apresenta seu mecanismo de ação completamente elucidado até o presente momento. Acredita-se que seja bloqueadora de uma terceira ciclooxigenase (COX-3) que estaria presente apenas no cérebro, motivo pelo qual, se explicaria a ação analgésica da dipirona e a pouca ação anti-inflamatória. Este provável mecanismo de ação também seria o responsável pela menor incidência de efeitos adversos gástricos e da coagulação no homem (CHANDRASEKHARAN et al., 2002; SCHATZMANN, 2002; MUÑOZ et al., 2010).

Assim, o objetivo do presente trabalho foi de avaliar a influência da dipirona nas curvas de tromboxano (ação em COX-1) e prostaglandina (ação em COX-2), assim como se o uso pós-operatório para orquiectomia eletiva promove analgesia suficiente quando comparada a administração de flunixin meglumine em equinos saudáveis. 


\section{JUSTIFICATIVA E RELEVÂNCIA}

A indústria do cavalo no Brasil é um setor que sofreu um crescimento aproximado de 12\% entre 2006 e 2016, gerando um grande impacto na economia, representando em 2016, o $7^{\circ}$ lugar no PIB brasileiro considerando-se 0 agronegócio (Brasil, 2017). Consequentemente, a demanda de serviços veterinários para tratamento da espécie equina vem aumentando. Os antiinflamatórios não esteroidais (AINES) são os fármacos mais utilizados nesta espécie para o tratamento da dor. Embora a dipirona seja amplamente utilizada em várias espécies animais, existem poucos estudos científicos na espécie equina. Alguns autores a consideram com efeito anti-inflamatório, outros a consideram apenas um analgésico e antitérmico. Apesar dos estudos em humanos e ratos terem comprovado a inibição das ciclooxigenases (COX) 1 e 2 pela dipirona, não existe comprovação científica se este efeito anti-inflamatório é significativo clinicamente e se na espécie equina se comporta da mesma maneira. 


\section{OBJETIVOS}

Objetivou-se com este trabalho avaliar a ação analgésica e o efeito da dipirona e do flunixin meglumine, na inibição das ciclooxigenases 1 e 2 em equinos.

Para tanto, em um grupo de equinos saudáveis foram mensuradas as concentrações de tromboxano B2 e prostaglandina E2, tratados com dipirona ou flunixin meglumine.

Num segundo grupo de animais analisou-se a ação analgésica de ambos os fármacos após orquiectomia eletiva por meio de avaliações de dor durante 24 horas após o procedimento cirúrgico. 


\section{REVISÃO DE LITERATURA}

\subsection{DOR}

Quase todo indivíduo, humano ou animal, apresentará dor em algum momento da vida. $\mathrm{O}$ tratamento da dor tem se tornado assunto relevante no mundo por seu impacto social e financeiro e, cada vez mais, busca-se a abordagem mais adequada. A dor é definida pela IASP (International Association for the Study of Pain) como uma experiência emocional e sensorial desagradável, associada à lesão tecidual real ou potencial (LOESER \& TREEDE, 2008; IASP, 2014). Um indivíduo com dor possui alterações fisiológicas, comportamentais e psíquicas importantes, e devido a esta função incapacitante, atualmente a dor é considerada o quarto sinal vital, atrás apenas da frequência cardíaca, respiratória e temperatura retal. (AAHA/AAFP, 2015)

Demonstrando a importância do controle da dor, sabe-se que pacientes que não recebem tratamento adequado da dor aguda sofrerão uma variedade de alterações sistêmicas deletérias, além de possível evolução para dor crônica (MEISSNER et al., 2015; KAYE et. al, 2017). Em relação aos procedimentos cirúrgicos, resta claro que um protocolo de analgesia peri operatória bem realizado produz impacto que vai muito além do pós-operatório imediato, por isso o manejo adequado da dor não deve ser encarado apenas como função do anestesista e restrito ao procedimento anestésico-cirúrgico, mas sim realizado como parte corriqueira do manejo clínico (HELLYER et. al, 2013). A associação farmacológica de analgésicos opioides e não opioides, com ou sem bloqueio local, agem nos diferentes mecanismos desde a transdução até a percepção da dor, trazendo assim um sinergismo na analgesia (MEISSNER et al., 2015).

$O$ ato cirúrgico desencadeia eventos que possuem o objetivo de evitar a propagação do dano tecidual, combater infecções e dar início ao processo de cicatrização. Estes eventos são relacionados com a nocicepção e inflamação, portanto, um tratamento adequado da dor será realizado quando o avaliador entende as alterações fisiológicas resultantes da dor. Além de alterações fisiológicas utilizadas como parâmetros para avaliar a dor, sabe-se que a dor 
desencadeia uma resposta simpática decorrente do estresse como aumento de cortisol, catecolaminas e glucagon circulantes, assim como citocinas, que são importantes mediadores inflamatórios liberados por células do sistema imune. Como consequência, há aumento do metabolismo basal, do trabalho cardíaco, da resistência vascular periférica e do consumo de oxigênio pelo miocárdio (CARDOZO, 2013). Vale dizer que mudanças nas variáveis fisiológicas e neuroendócrinas (adrenalina, noradrenalina, cortisol e $\beta$-endorfinas) que também são consideradas indicativos de dor (Oliveira et al., 2011), podem ser influenciadas por outros fatores, como estresse (SMITH et al., 1996).

Quanto aos tipos de dor, existem diversas classificações adotadas na literatura, que podem ser quanto à origem (visceral ou somática), quanto à duração (crônica ou aguda) e por fim quanto à etiopatogenia (aguda, neuropática e psicogênica) (FANTONI \& MASTROCINQUE, 2002).

Em relação aos receptores nociceptivos, ou nociceptores, estão presentes em fibras A-delta (mielinizadas, de condução rápida e mais relacionadas com dor aguda) e C (amielinizada, de condução mais lenta). Por sua vez, estas fibras estão presentes por todo o organismo animal inervando tanto a pele (dor superficial) como estruturas mais profundas (dor profunda). São ativados por estímulos físicos, químicos ou térmicos, sendo alguns receptores polimodais, e alguns específicos. $A$ atividade destes receptores é modulada por várias substâncias químicas, denominadas alogênicas, liberadas em decorrência de processos inflamatórios, traumáticos e/ou isquêmicos, reduzindo sensivelmente então o limiar de alguns tipos de nociceptores, o que os faz passar a responder a certos tipos de estímulos térmicos e mecânicos- o que explica a hiperalgesia primária induzida pela inflamação. (FANTONI \& MASTROCINQUE, 2002; HELLYER et al., 2013).

A lesão de células sanguíneas, como neutrófilos, mastócitos, plaquetas e de moléculas livres nos vasos sanguíneos estão relacionadas com a liberação de substâncias alogênicas, podendo-se citar acetilcolina, prostaglandinas, histamina, serotonina, bradicinina, leucotrieno, substância $P$, tromboxano, fator de ativação plaquetário e íons potássio. O impulso gerado por estes receptores (transdução) é levado ao corno dorsal da medula espinhal (transmissão) aonde ocorre o processamento para supressão ou amplificação do estímulo (modulação) e por sua vez, levado ao córtex cerebral para integração da dor (percepção). É no córtex que 
a dor recebe suas características físicas e emocionais, devido à ação, dentre outras estruturas, do tálamo (FANTONI \& MASTROCINQUE, 2002).

\subsubsection{AVALIAÇÃO DA DOR EM ANIMAIS}

A avaliação da dor em animais tem aspectos muito particulares, pois é subjetiva, e depende da perícia humana para realizá-la. Devem ser levados em conta aspectos como gênero, idade, espécie, raça, linhagem e ambiente. Ainda, a incapacidade de se comunicar verbalmente, traz a possibilidade de que um animal que esteja sentindo dor e necessite de tratamento adequado para aliviá-la, não tenha sua necessidade corretamente interpretada e atendida. Cabe salientar, que a percepção de dor é acompanhada por sentimentos de ansiedade, medo e pânico, e promove alterações biológicas e/ou comportamentais, podendo alterar características específicas e cada espécie. (HELLYER et al., 2013).

O não tratamento ou mesmo terapia inadequada, ineficiente, pode transformar uma dor aguda, que tem como serventia a proteção do organismo, é fisiológica e se caracteriza por ser o sintoma de alguma lesão, em dor crônica, doença propriamente dita, de difícil controle, sendo necessária a associação de vários tipos de terapias farmacológicas e não farmacológicas. (HELLYER et al., 2013). Por isso, as escalas de dor surgem como ferramenta para tornarmos a avaliação de dor nos animais cada vez mais acurada. As escalas são diferenciadas de acordo com a espécie, pois se leva muito em consideração o comportamento natural da espécie, se a dor é aguda ou crônica e se é ortopédica ou visceral (HELLYER et al., 2013). As escalas podem ser descritivas simples, como por exemplo, a escala analógica visual (EAV), bastante utilizada na rotina clínica de cães e gatos (ROBERTSON, 2008), ou multidimensionais, que incluem a avaliação comportamental e interação com o paciente para aumentar a sensibilidade da avaliação de dor.

Existem diversas escalas descritas em literatura para avaliação da dor aguda em cavalos, como por exemplo, a escala facial (DALLA COSTA et al., 2014 ), a escala Multidimensional da UNESP-Botucatu (TAFFAREL et al., 2015), escala para dor ortopédica (BUSIÈRES et al., 2008) e escalas para dor visceral (VAN 
LOON et al., 2010; VAN LOON \& VAN DIERENDONCK, 2015; GRAUW \& VAN LOON, 2016), assim como alguns estudos que comparam sua utilização (SUTTON et al., 2013). A evolução nos estudos para confecção de escalas ao longo dos anos visa sempre minimizar a subjetividade e a discrepância inter-avaliadores, ou seja, objetiva-se sempre a moldagem de escalas que dependam menos possível da opinião do avaliador, e utilizem mais sinais característicos da espécie em questão frente ao estímulo de dor para melhor acurácia. Alguns trabalhos apresentam a preocupação com a redução da interferência inter-avaliadores (SUTTON et al., 2013; TAFFAREL et al., 2015; VAN LOON \& VAN DIERENDONCK, 2015).

É importante ressaltar que o uso das escalas de dor deve ser feito conforme a espécie para qual a escala em questão foi desenvolvida, assim como para a afecção que está causando dor naquele animal, como por exemplo a escala para avaliação de dor ortopédica de Busières et al. (2008) não trará uma avaliação correta se utilizada em um animal com dor pós operatória de celiotomia devido ao quadro de cólica. Epstein e seus colaboradores (2015) concluíram que é necessária a utilização de escalas distintas para dor aguda ou crônica e para caninos ou felinos com intuito de minimizar a subjetividade e a parcialidade dos observadores, sendo mais eficaz e conduzindo a uma melhor assistência ao paciente.

Parâmetros fisiológicos como a frequência cardíaca, frequência respiratória e temperatura são importantes de avaliarmos, apesar de sofrerem influência de fatores ambientais, temperatura, desidratação e doença cardíaca e/ou respiratória, situações de choque, dentre outras. (PRICE et al., 2003; DUJARDIN \& VAN LOON, 2011). Porém, escalas atualmente usadas incorporaram parâmetros fisiológicos com as alterações comportamentais demonstradas na dor (BUSIÈRES et al., 2008; TAFFAREL et al., 2015). A escala descrita por Sutton et al. (2013) avalia apenas a parte comportamental do cavalo com dor aguda abdominal devido ao quadro de síndrome cólica, considerando que parâmetros fisiológicos estarão alterados devido também ao processo de choque que o organismo destes animais sofre durante a síndrome. 


\subsubsection{TRATAMENTO DA DOR EM ANIMAIS}

A Organização Mundial de Saúde (OMS) protocola o tratamento da dor conforme uma escada, na qual quanto mais intensa a dor se torna, mais adições farmacológicas e não farmacológicas este tratamento ganha (SPAIN, 1987). Quando se trata do controle da dor em animais, podem-se eleger diversas classes farmacológicas para o tratamento, sendo que os opioides, os anti-inflamatórios não esteroidais (AINES) e os analgésicos constituem a base do tratamento da dor aguda nociceptiva (SCHATZMANN, 2002). Analgésicos compõem a classe de medicamentos cujo efeito principal é suprimir a dor ou produzir analgesia (HELLYER et al., 2013).

Os opioides atualmente são muito empregados em Medicina Veterinária, sendo indicados para o tratamento da dor em diferentes situações. Esses fármacos ligam-se de maneira reversível a receptores específicos no SNC e medula espinhal (pré e pós-sinápticos), alterando a nocicepção e a percepção da dor (FANTONI \& MASTROCINQUE, 2002; HELLYER et al., 2013). O sucesso dos opioides envolve a seleção adequada do fármaco e da dose, em função da espécie, para evitar efeitos adversos, como gastrointestinais, respiratórios, imunológicos, dentre outros (HELLYER et al., 2013).

Já os AINES (anti-inflamatórios não esteroidais) atuam principalmente na periferia, diminuindo a produção de substâncias alogênicas, em particular os prostanóides, que facilitam a geração e condução dos estímulos nociceptivos (HELLYER et al., 2013). Reduzindo a inflamação por bloquearem a enzima responsável pela transformação do ácido araquidônico em uma série de substâncias que desencadeiam o processo inflamatório, como prostaglandinas, tromboxanos e prostaciclinas. Este mecanismo explica como estes agentes promovem analgesia em processos que cursam com inflamação (FANTONI \& MASTROCINQUE, 2002).

Estes fármacos possuem grande utilidade devido aos seus efeitos na mediação ou modulação dos diferentes níveis que envolvem a transmissão do estímulo doloroso, que se inicia em nociceptores periféricos e progride até o cérebro pela medula espinhal. O uso de combinações destes analgésicos nãoopioides com os opioides em uma abordagem multimodal reduz o requerimento da 
dose de cada fármaco envolvido na terapia e assim, minimizam os efeitos de toxicidade de cada agente envolvido. (KAYE et. al, 2017).

\subsection{ANTI-INFLAMATÓRIOS NÃO ESTEROIDAIS}

Os anti-inflamatórios não esteroidais (AINES) são o grupo de medicamentos mais utilizados no mundo e desempenham um papel de destaque no controle/tratamento da dor. Há algumas centenas de anos, Hipócrates iniciou o tratamento de algumas feridas com extrato de salgueiro; anos depois, foi descoberta a presença da substância salicilina, um anti-inflamatório e analgésico no extrato do salgueiro. Quimicamente similar, em 1899 a farmacêutica Bayer desenvolveu o ácido acetilsalicílico, com o nome de aspirina (KAYE et al., 2017).

Desde sua purificação, em 1976, a COX-1 vem sendo apontada como uma das principais enzimas catalizadoras da síntese de prostanóides pelo ácido araquidônico. Cerca de 15 anos depois uma segunda isoforma - COX-2 - foi descoberta (BERETTA et. al, 2005). A ciclooxigenase 1 (COX-1) é constitutiva e é extremamente importante para funções fisiológicas normais, como por exemplo a vasodilatação renal $\left(\mathrm{PGE}_{2}\right)$, a proteção da mucosa gastrointestinal $\left(\mathrm{PGI}_{2}\right)$ e agregação plaquetária (tromboxano $\mathrm{B}_{2}$ ). Assim sendo, um agente que bloqueie COX-1 prejudica automaticamente estas funções. Por outro lado, a COX-2 é a forma induzível, sendo formada a partir de determinados estímulos, como presença de endotoxinas e estímulos inflamatórios que liberem citocinas, que por sua vez induzem a síntese da COX-2 por células como macrófagos, resultando na liberação de prostaglandinas inflamatórias. A liberação de prostaglandinas juntamente com proteases e outros mediadores inflamatórios resulta em inflamação (Figura 01), (FANTONI \& MASTROCINQUE, 2002; BERETTA et al., 2005). A homeostase entre as concentrações de $\operatorname{COX}-1$ e 2 não são bem definidas em nenhuma espécie veterinária, principalmente nos equinos (COLE, 2015).

Com o conhecimento das enzimas COX-1 e COX-2, facilitou-se a produção de fármacos com efeitos específicos (KAYE et al., 2017). Sabe-se que existem várias isoformas da COX, com diferentes papéis na fisiologia e patofisiologia dos 
organismos. Pelo menos 3 isoformas de COX são conhecidas atualmente. (ZIEGLER et al., 2017).

Figura 01: Esquematização de alguns efeitos adversos provenientes da inibição COX-1/ COX-2.

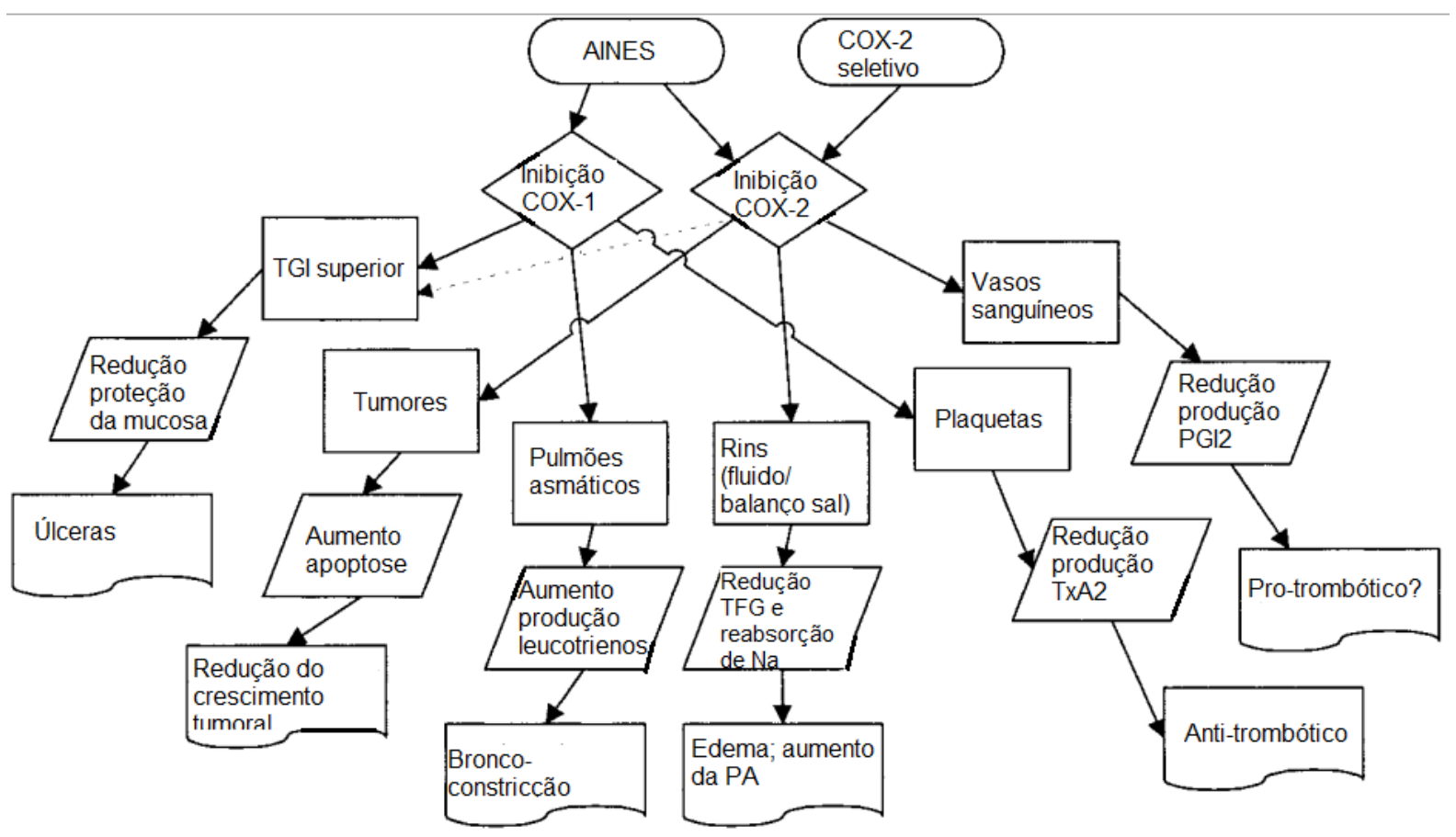

Fonte: Traduzido de WARNER \& MITCHELL (2004).

Em equinos os AINES são amplamente utilizados, pois promovem controle efetivo da dor em diversas condições/afecções que cursam com inflamação (SANCHEZ \& ROBERTSON, 2014). AINES geralmente agem como inibidores de ambas as isoformas COX, porém com a ciência de que a COX-2 desempenha um papel fundamental nos processos inflamatórios, agentes anti-inflamatórios seletivos para COX-2 foram desenvolvidos como alternativa à AINES não seletivos, devido aos menores efeitos deletérios apresentados, principalmente no trato gastrointestinal. Porém, o efeito total das isoformas COX não foi completamente elucidado em equinos, e mesmo fármacos ditos seletivos para COX-2, podem promover inibição em COX-1 quando em altas concentrações (COLE, 2015). A via da COX-2 pode ser interrompida em diversos níveis por antagonistas ou anticorpo para citocinas e mutógenos inibidores da indução da COX-2, como por exemplo, os 
glicocorticoides ou mesmo os inibidores seletivos de COX-2 (FANTONI \& MASTROCINQUE, 2002).

Sabe-se também, que a COX-1 é produtora de níveis fisiológicos de prostanóides, e a COX-2 responsável pela alta produção de prostanóides que ocorre nos sítios inflamatórios (WARNER \& MITCHELL, 2004). Portanto, a maior ou menor probabilidade de um AINE provocar efeitos adversos está condicionada à sua capacidade de inibir seletivamente apenas COX-2 ou inibir COX-1 conjuntamente (FANTONI \& MASTROCINQUE, 2002; WARNER \& MITCHELL, 2004). Os AINES apresentam efeito "teto", ou seja, o aumento da dose não gera aumento da ação analgésica ocorrendo aumento dos efeitos indesejados (SAKATA, 2001).

A seletividade de um AINE é derivada de algum estudo in vivo em que a inibição, normalmente expressa como a concentração suficiente para inibir $50 \%$ da atividade COX, é medida por meio de células que são os produtos da atividade destas enzimas. Ou seja, em um estudo com sangue total, a fonte de produtos de COX-1 são as plaquetas e a fonte de produtos de COX-2 são os leucócitos. A proporção é representada como COX-1/COX-2 e quanto mais acima de 1,0 o resultado, mais específico é o medicamento para inibição de COX-2 em comparação com COX-1 (PAPICH, M. G., 2008).

Um efeito adverso inesperado foi relacionado ao uso de COX-2 seletivos (ou poupadores de COX-1) em humanos. A inibição da COX-2 reduziu a concentração de prostaglandina $E_{2}$ (substância responsável pela vasodilatação), acarretando em efeitos cardiovasculares e tromboembolismo. A falta de inibição de COX-1 permite a continuação da produção da substância trombogênica tromboxano $A_{2}$ (ZIEGLER et al., 2017). Evidências mostram que COX-2 seletivos devem ser evitados em pacientes com distúrbios cardiovasculares (KAYE et al., 2017).

Cavalos aparentemente não são predispostos às mesmas alterações cardiovasculares vistas com o uso de COX-2 seletivos em humanos, sugerindo que o uso deste agente talvez seja seguro nesta espécie (ZIEGLER et al., 2017). Em equinos, o firocoxib é o único AINE seletivo para COX-2 licenciado para alívio da dor e inflamação (DUZ et al., 2015).

Por outro lado, os equinos são mais susceptíveis aos efeitos gástricos dos AINES. De fato, os anti-inflamatórios não esteroidais (AINES) representam um dos fatores de maior relevância para indução de ulcerações gástricas em equinos 
(MACALLISTER et al., 1997; MURRAY, M.J., 2002; CHATTERJEE et al., 2012). O uso em longo prazo reduz a formação da camada de muco que protege a mucosa gástrica. O desenvolvimento da úlcera ocorre devido ao desbalanço entre os fatores pró-inflamatórios e anti-inflamatórios do organismo (MURRAY, M.J., 2002; CHATTERJEE et al., 2012).

Os equinos são animais que possuem a característica de produzirem de maneira initerrupta ácido clorídrico, mesmo durante os períodos em que não estão se alimentando (MURRAY, M. J., 2002). Por outro lado, a porção glandular é responsável pela secreção de ácido clorídrico e pepsina, constituindo então sua mucosa por uma série de mecanismos protetores contra lesões. Porém, a porção aglandular não possui camada protetora contra a ação do ácido clorídrico (MURRAY, M. J., 2002). Dessa forma, essa anatomia diferenciada pode explicar a alta prevalência de úlceras gástricas nesta espécie (MACALLISTER et. al, 1997). A maioria das lesões se apresentam na porção aglandular do estômago, próxima à região da margo plicatus, ao longo da curvatura menor, como observado por Dionne et al. (2003). Lesões na porção glandular são mais comuns no antro em animais adultos, e na região do piloro em potros (MURRAY, M.J., 2002).

A prostaciclina produzida pela COX-2 nas células endoteliais é um importante agente inibidor da agregação plaquetária. Em contrapartida, o tromboxano é a molécula pró-trombótica. O organismo saudável está em constante equilíbrio para que não sobressaia nenhuma destas funções. (COOK et al., 2015).

\subsubsection{FLUNIXIN MEGLUMINE}

O Flunixin Meglumine é um fármaco anti-inflamatório não esteroidal cujo mecanismo de ação cursa como não sendo um fármaco seletivo COX-2, ou seja, os efeitos em trato gastrointestinal aparecem devido ao seu uso sem associação com gastroprotetores e/ou tempo prolongado de tratamento.

Agentes corriqueiramente utilizados nos equinos como a fenilbutazona e o flunixin meglumine são mais seletivos para a COX-1 enquanto que o meloxicam é mais seletivo para a COX-2 (BERETTA et al., 2005). Burket et al (2016) encontraram grande inibição do tromboxano tanto em 1 hora, como 5 dias após a 
administração de flunixin na dose de $1,1 \mathrm{mg} / \mathrm{Kg}$ em equinos saudáveis. Neste mesmo estudo, não foram encontradas alterações plaquetárias induzidas pelo flunixin.

O flunixin meglumine é um fármaco amplamente utilizado em equinos, aplicado para o tratamento da dor de origem visceral, sendo parte do protocolo de tratamento na síndrome cólica (SELLON et al., 2004; TORFS et al., 2009; COLE, 2015). Também é um fármaco utilizado para o tratamento de distúrbios musculoesqueléticos, como no estudo de Foreman e colaboradores (2010), onde demonstraram que uma única dose de flunixin também pode mascarar um quadro inicial de laminite, assim como uma única dose de fenilbutazona, sendo então de grande importância o estudo deste fármaco principalmente em equinos competidores, devido à importância dos fármacos que fazem são considerados dopping.

Alguns medicamentos são considerados dopping para equinos de esporte, como por exemplo a fenilbutazona. Porém, outros anti-inflamatórios são permitidos determinados níveis de concentração plasmática, como é o caso do fluninine meglumine tanto para a Association of Racing Commissioners International (ARCl) (KNYCH et al., 2015) como para a Federação Equestre Internacional (FEI, 2015).

Cook et. al (2009) compararam o uso de firocoxibe na dose de $0,09 \mathrm{mg} / \mathrm{Kg}$ a cada 24 horas, flunixin meglumine $1,1 \mathrm{mg} / \mathrm{Kg}$ a cada 12 horas e solução salina a cada 24 horas no pós operatório de lesão isquêmica induzida em jejuno de cavalos, concluindo que, após 18 horas da isquemia, o grupo tratado com flunixin teve grande aumento na permeabilidade à lipossacarídeos. Além de que ao poupar COX-1, o grupo que recebeu firocoxibe obteve menos complicações intestinais. Naylor et al. (2014) realizaram um estudo clínico não cego em cavalos com lesões estrangulativas em intestino delgado e não identificaram diferença significativa na permeabilidade intestinal entre os efeitos do flunixin meglumine $(1,1 \mathrm{mg} / \mathrm{Kg}$, pela via intravenosa [IV], a cada 12 horas) com o meloxicam $(0,6 \mathrm{mg} / \mathrm{Kg}$, IV, a cada 12 horas).

Duz et al. (2015) compararam a atividade de inibição do tromboxano $B_{2}$ $\left(\mathrm{TXB}_{2}\right)$, prostaglandina $\mathrm{E}_{2}\left(\mathrm{PGE}_{2}\right)$ e os metabólitos da $\mathrm{PGE}$ entre flunixin meglumine e firocoxibe em cavalos que passaram por algum procedimento cirúrgico eletivo. Encontraram que no grupo firocoxibe não houve inibição 
significativa da atividade de COX-1. Não houve redução da atividade de COX-2 em ambos grupos, além de que no grupo flunixin, houve redução na atividade de coagulação induzida pelo $\mathrm{TXB}_{2}$ nos momentos 2 e 24 horas.

Naylor et al. (2014) realizaram um estudo clínico não cego em cavalos com lesões estrangulativas em intestino delgado e não identificaram diferença significativa na permeabilidade intestinal entre os efeitos do flunixin meglumine $(1,1 \mathrm{mg} / \mathrm{Kg}$, pela via intravenosa [IV], a cada 12 horas) com o meloxicam $(0,6 \mathrm{mg} / \mathrm{Kg}$, IV, a cada 12 horas).

Em equinos, um risco maior de trombogênese pode ser induzido devido ao desenvolvimento de lesões vasculares relacionadas ao uso do cateter. A avaliação de 102 cavalos com acesso venoso em jugular demonstrou que tanto fenilbutazona como flunixin meglumine exercem função protetora contra alterações vasculares subclínicas (GERAGHTY et al., 2009).

\subsection{DIPIRONA}

A dipirona (N - [(2,3-dimetil-5-oxo-1-fenil-3-pirazolin-4-il) -N-metilamino] metanossulfonato) é um antipirético e analgésico que foi introduzido na prática clínica no ano de 1922 (HINZ et al., 2007; GIORGl et al., 2016). Quando empregada no homem é um analgésico considerado seguro no que diz respeito a sua pequena propensão de promover efeitos adversos renais ou gastrointestinais. Entretanto, é indicada apenas para dor de grau leve, podendo ser empregada juntamente com agentes opioides mais fracos para aumentar-se o grau analgésico (FANTONI \& MASTROCINQUE, 2002). Embora seja classificada como antiinflamatório não esteroidal em literatura (BATU \& EROL, 2007; DOMíNGUEZRAMÍREZ et al., 2010), não apresenta seu mecanismo de ação completamente elucidado até o presente momento.

Vem sendo utilizada por mais de 80 anos e, em solução aquosa, é hidrolisada em 4-metil-amino-antipirina (MAA), que posteriormente sofre metabolização para 4-amino-antipirina ( $A A)$, 4-formol-amino-antipirina (FAA) ou 4acetil-amino-antipirina (AAA). Destes quatro metabólitos citados, o MAA demonstra 
ter potencial ativo, enquanto AA tem ação fraca e FAA e AAA são inativos (PIERRE, S.C. et al., 2007). Giorgi et al. (2015) encontraram farmacocinética do MAA semelhante comparando a administração de dipirona pela via intravenosa com a via intramuscular em ovelhas. Giorgi et al. (2016) demonstraram que a administração intravenosa (IV) de dipirona produz concentrações semelhantes do metabólito MAA quando comparada com a administração intramuscular (IM), porém, o dobro da concentração do metabólito AA foi formado após administração IV.

Desde 1977 a dipirona teve seu uso abolido nos Estados Unidos devido a casos fatais de agranulocitose. Este é o efeito secundário mais comum associado ao uso contínuo deste agente em humanos. Também pode causar insuficiência renal aguda, necrose tubular, e raramente trombocitopenia (REDONDO-PACHON et al., 2014). Ibañez et al. (2005), em um estudo retrospectivo com dados laboratoriais de hospitais na área metropolitana de Barcelona, demonstrou um baixo risco de agranulocitose em pacientes que utilizam dipirona por curtos períodos nas doses recomendadas. Já Huber et al. (2015) fez um levantamento de casos de agranulocitose induzida pelo metamizole em Berlim, o qual concluiu que a doença persiste atualmente como um distúrbio grave, e que a crescente utilização de metamizole deve ser avaliada quanto à indicação e especialmente à duração do tratamento. Há alguma evidência sugerindo que a administração prolongada pode causar algum dano ao sistema sanguíneo, sendo relatadas a ocorrência de leucopenia, agranulocitose e anemia aplástica (GARCÍA-MARTíNEZ et al., 2003; BASAK et al., 2010). Estudo in vitro realizado por García-Martínez et al. (2003) compararam a mielotoxicidade da dipirona com o diclofenaco e o ácido acetilsalicílico (fármacos que não são associados à agranulocitose) e não encontraram maior mielotoxicidade pela dipirona. A administração de doses terapêuticas de dipirona não demonstrou interferência no processo de granulocitose nem no processo de apoptose de granulócitos. A dipirona é contraindicada em pacientes com histórico ou presença de discrasia sanguínea (GARCÍA-MARTÍNEZ et al., 2003; BASAK et al., 2010).

As investigações supracitadas demonstram que a agranulocitose atribuível à dipirona é rara, porém, de acordo com estudo realizado em animais, faz-se necessário realizar projeto de investigação prospectiva multicêntrico em países onde a dipirona é prescrita rotineiramente, para que se chegue a consenso acerca 
da prescrição de dipirona. A literatura acessível carece de quaisquer dados sobre a incidência da agranulocitose ou outros efeitos hematológicos atribuídos à administração de dipirona em animais (JASIECKA, MAŚLANKA, JAROSZEWSKI, 2014). Zanuzzo e colaboradores (2015) encontraram em seu estudo inibição da agregação plaquetária por 3 horas após administração intravenosa de dipirona em cadelas e por 5 horas quando esta foi associada ao meloxicam, efeito não observado com o uso do meloxicam sozinho.

Em comparação com outros analgésicos não opiáceos, a dipirona parece ser um fármaco relativamente seguro (IMAGAWA et al., 2011). Os efeitos adversos mais comuns são distúrbios gastrointestinais como: náuseas, vômitos, dor abdominal e diarreia (EDWARDS et al., 2010). Existem evidências epidemiológicas para uma boa tolerabilidade gastrointestinal da dipirona, como por exemplo, o estudo endoscópico de Bianchi Porro et al. (1996) que demonstrou que um tratamento de 2 semanas de voluntários saudáveis com dipirona não produziu nenhuma diferença estatisticamente significativa na incidência de lesões nas mucosas gástricas e duodenais quando a dipirona foi comparada com placebo (3g/dia e $1,5 \mathrm{~g} / \mathrm{dia})$, ou mesmo quando a dose dipirona inferior à recomendada $(1,5 \mathrm{~g} / \mathrm{dia})$ foi comparada com doses clínicas de acetoaminofeno. Porém, três dos doze voluntários tratados com a dose elevada de dipirona desenvolveram lesões importantes, o que pode sugerir um efeito danoso à mucosa, de forma dosedependente, em alguns indivíduos provavelmente devido à inibição ligeiramente mais elevada e sustentada da COX-1. Além disso, mecanismos como a redução do metabolismo da glutationa (SANCHEZ et al., 2002a) e a inibição da atividade de óxido nítrico/guanosina monofosfato cíclico e óxido nítrico sintetase vem sendo sugeridos como conducentes para a lesão da mucosa provocada pela dipirona em doses elevadas em ratos (SANCHEZ et al., 2002b). No trabalho de Yildrim et al. (2013), os autores encontraram que a dipirona em todas as doses estudadas inibiu significativamente a prevalência de úlcera gástrica induzida pelo Diethyldithiocarbamate (DDC) e estresse pelo frio, em ratos. Esta atividade foi ótima na dose de $25 \mathrm{mg} / \mathrm{kg}$, no entanto, reduziu significativamente a secreção de muco nesta dose, quando comparada com doses altas de $50 \mathrm{mg} / \mathrm{Kg}$ e $100 \mathrm{mg} / \mathrm{Kg}$. Os efeitos da dipirona em inibir úlceras induzidas pelo DDC foram independentes da dose, porém a secreção de muco variou conforme as dosagens utilizadas e pela opinião do autor, parece que outros mecanismos que não só a produção de muco 
estão relacionados com a formação de úlceras gástricas induzidas. Foi provado experimentalmente por Batu \& Erol (2007) que o fármaco pode ter um efeito protetor contra alguns tipos de úlceras gástricas não induzidas por estresse, sugerindo que a dipirona pode aumentar a síntese e/ou a liberação de muco gástrico e, paradoxalmente, pode ser capaz de aumentar o teor de $\mathrm{PGE}_{2}$ gástrica. Assim, em relação à influência sobre o aparelho digestório, a dipirona parece ser muito mais segura do que os AINES, sendo utilizada em animais com contraindicações aos anti-inflamatórios (IMAGAWA et al, 2011).

Ao contrário dos AINES tradicionais, a dipirona possui potente efeito analgésico com pouco efeito anti-inflamatório. Foi demonstrado efeito espasmolítico em cobaia (GULMEZ et al., 2007). Seu mecanismo de ação tem sido amplamente discutido na literatura, sendo cogitado o efeito de inibição de prostaglandina no tecido cerebral, e recentemente descrito como inibidor da enzima COX-3 (uma possível variante da COX-1), motivo pelo qual, se explicaria a ação analgésica da dipirona e a pouca ação anti-inflamatória. Este provável mecanismo de ação também seria o responsável pela menor incidência de efeitos adversos gástricos e da coagulação no homem (CHANDRASEKHARAN et al., 2002; MUÑOZ et al., 2010). Redondo-Pachon et al. (2014) não a classificam como AINE. Zanuzzo e seus colaboradores (2015) demonstraram que a analgesia promovida pela dipirona foi melhor do que a analgesia promovida pelo meloxicam em cadelas após cirurgia de ovariosalpingohisterectomia ( $\mathrm{OSH})$, e que a associação de ambos os fármacos promove sinergismo e melhor analgesia.

Entretanto, apesar desta nova COX ser inicialmente denominada COX-3, devido ao seu gene de formação ser o mesmo formador da COX-1, a mesma poderia ser designada de COX-1-B. O que difere uma da outra é a inserção de 3034 aminoácidos, dependendo da espécie de mamífero. Sua presença foi relatada no córtex cerebral de cães, e em humanos seria mais abundante no cérebro e coração. Rogosch et al. (2012) encontraram MAA e AA no cérebro e na medula espinal de ratos. Além disso, sabe-se que os derivados da dipirona podem facilmente penetrar na barreira hematoencefálica e suas concentrações no fluido cerebrospinal, embora menores do que no plasma, são suficientemente elevadas para induzir um efeito terapêutico (COHEN et al., 1998).

Aparentemente a COX-3 seria inibida por agentes analgésicos e antipiréticos, como acetoaminofeno, fenacetina, antipirina e dipirona, bem como 
alguns AINES. Assim sendo, apesar de existirem apenas dois genes para enzimas COX (COX- 1 e COX-2), podem existir múltiplas isoformas de COX subjacentes a produção de prostanóides através de uma variedade de tecidos (WARNER \& MITCHELL, 2004). O mecanismo envolvido no seu efeito analgésico é complexo. Muito provavelmente, este efeito é obtido por meio tanto da ação em COX-3, uma variante da COX-1, que ocorre principalmente no sistema nervoso central (CHANDRASEKHARAN et al., 2002), quanto do impacto sobre os sistemas opioidérgico e canabinóide. O sistema canabinóide, que desempenha um papel importante na regulação da sensação de dor, está provavelmente envolvido (JASIECKA, MAŚLANKA, JAROSZEWSK, 2014). Rogosch et al. (2012) relataram que MAA e AA são agonistas de receptores canabinóides tipo 1 (CB1), que são receptores também incluídos no sistema antinociceptivo descendente. A contribuição do sistema canabinóide para o mecanismo analgésico da dipirona também foi citado por Escobar et al. (2012), que provaram que o efeito antinociceptivo deste agente foi reduzido após a administração de um antagonista de CB1.

Outro mecanismo provável de estar envolvido na analgesia promovida pela dipirona é a ativação do sistema opioidérgico endógeno. Tortorici \& Vanegas (2000) administraram dipirona na massa cinzenta periaquedutal (principal local de analgesia opioidérgica) em ratos acordados, induzindo efeito antinociceptivo e, ao repetirem diversas vezes, induziu tolerância à dipirona, assim como tolerância cruzada à morfina. Demonstraram também que uma microinjeção de naloxona (antagonista opioide) no mesmo local reduziu os efeitos antinociceptivos da dipirona. Vazquez e colaboradores (2005) também encontraram efeito semelhante da dipirona, concluindo que seu efeito é mediado pelo sistema opioidérgico.

Alguns estudos relataram que o efeito antipirético da dipirona ocorre devido à inibição da síntese de PGE $_{2}$ (KANASHIRO et al., 2009), outros estudos sugerem que não. Demonstrou-se que há o bloqueio de ambas as vias, dependentes e independentes de PG, da febre induzida por lipopolissacarídeo bacteriano (LPS), o que sugere que este fármaco tem um perfil de ação antipirética distinto do de outros inibidores de COX, o que pode ser vantajoso no tratamento da febre (MALVAR et al., 2011). Pierre et al. (2007) não encontraram bloqueio da síntese de prostaglandina induzida pelos metabólitos da dipirona em humanos, porém, houve um redirecionamento da produção de $\mathrm{PGE}_{2}, \mathrm{PGD}_{2}$ e $P \mathrm{PF}_{2} \alpha$ para outras 
prostaglandinas não identificadas e como conclusão de seu trabalho, acreditam que tanto o MAA quanto o AA reagem com doadores de elétrons, como por exemplo, o íon ferro, prevenindo o início do ciclo catalítico da COX, e alternativamente reduzem sua ativação.

Hinz et al. (2007) encontraram, em um trabalho realizado no homem, uma inibição fraca de COX-3 pela dipirona em 5 voluntários. Nesses casos utilizou-se as doses de $500 \mathrm{mg}$ e $1000 \mathrm{mg}$, e as avaliações prosseguiram por 12 horas. Os autores acreditam que a teoria da farmacologia de analgésicos não ácidos (como dipirona e paracetamol) inibindo COX-3 não é válida. Porém, foi observado que o principal metabólito da dipirona, MAA, provoca uma inibição acentuada de ambas COX-1 e COX-2, com inibição ligeiramente maior em COX-1, in vitro e ex vivo com pacientes tratados com doses clinicamente recomendadas.

\subsection{TRAMADOL}

Opioides são compostos purificados do extrato de papoula, mais especificamente da espécie Papaverum somniferum e são fármacos essenciais para o tratamento da dor em Medicina Veterinária. São substâncias variáveis indicadas desde o tratamento da dor aguda pós-operatória até como parte do protocolo de tratamento da dor crônica (LAMONT \& MATHEWS, 2013).

O tramadol é um opioide sintético agonista $\mu$, porém seu mecanismo de ação também envolve a inibição de recaptação de serotonina e noradrenalina (LAMONT \& MATHEWS, 2013). Sua molécula é metabolizada pelo fígado em: Odesmetiltramadol (M1) e N-desmetiltramadol (M2), sendo ativo apenas o metabólito M1 (SCOTT \& PERRY, 2000).

Sua utilização em equinos é demonstrada por diversos trabalhos em literatura, que contatam sua eficácia analgésica para diversos tipos de dor, com doses variando de $2-10 \mathrm{mg} / \mathrm{Kg}$, podendo ser administrado por diversas vias, inclusive a oral. (KNYCH et al., 2012; GUEDES et al., 2013; KNYCH et al., 2013; GUEDES et al., 2016; KNYCH et al, 2016). 


\section{MATERIAIS E MÉTODOS}

O estudo foi previamente submetido e aprovado pelo Comitê de Ética no Uso de Animais da FMVZ/USP, sob o número de registro ํㅜ 8862020715.

$\mathrm{O}$ estudo foi dividido em duas fases. Na fase 01 verificou-se a ação da dipirona sobre o tromboxano $B_{2}$ e prostaglandina $E_{2}$ em cavalos hígidos não submetidos a qualquer intervenção, ao passo que na fase dois avaliou-se a ação analgésica da dipirona em cavalos submetidos a castração eletiva.

\subsection{FASE 01}

\subsubsection{ANIMAIS E CRITÉRIOS DE INCLUSÃO}

Foram utilizados 12 animais, da raça Puro Sangue Árabe, machos e fêmeas de idades variadas.

Foram incluídos no estudo apenas animais comprovadamente saudáveis. Para tanto foram realizados, exame físico completo com avaliação da frequência cardíaca (FC), frequência respiratória (FR), temperatura retal, auscultação pulmonar e traqueal, tempo de preenchimento capilar (TPC), avaliação da coloração de mucosas, hidratação, auscultação dos quadrantes intestinais e palpação dos linfonodos foi realizado em todos os animais. Assim como coleta de sangue para realização de hemograma completo, bioquímica renal (ureia e creatinina), e hepática (GGT, AST, bilirrubina total e direta e albumina), proteína total, fibrinogênio foram realizados previamente ao experimento

\subsubsection{CRITÉRIOS DE EXCLUSÃO}

Animais com alterações cardiológicas, hematológicas, indicadores de insuficiência renal e/ou hepática, além daqueles apresentando alterações gastrointestinais, como diarreia foram excluídos. Ainda, presença de dor de qualquer intensidade e origem, quaisquer sinais de inflamação, doenças ou uso de 
fármacos analgésicos e/ou anti-inflamatórios anteriormente ao estudo com intervalo menor do que 1 mês foram considerados fatores de exclusão.

\subsubsection{PREPARO DOS ANIMAIS}

Todos os animais obtiveram os pelos sobre a jugular direita tricotomizados, com posterior antissepsia com clorexidine e clorexidine alcoólico para passagem de cateter ${ }^{1}$ 14GX2", com adaptador $\mathrm{PRN}^{2}$ para vedar sua entrada. O cateter e adaptador eram fixados com supercola ${ }^{3}$ e fio de sutura Nylon ${ }^{4}$ 2-0 (um ponto simples) e permaneciam durante as primeiras 12 horas. A coleta de sangue das 24 horas foi realizada diretamente por punção direta da veia jugular com seringa ${ }^{5}$ de $5 \mathrm{~mL}$ e agulha ${ }^{6} 30 \times 8 \mathrm{~mm}$.

Os animais já residiam no Hospital Veterinário da FMVZ-USP, portanto não foram submetidos a período de adaptação no local.

\subsubsection{DELINEAMENTO EXPERIMENTAL}

\subsubsection{GRUPOS EXPERIMENTAIS}

Os 12 cavalos foram distribuídos aleatoriamente em 2 grupos de seis animais cada. Um grupo recebeu dipirona ${ }^{7}$ (GD) pela via intravenosa, na dose de $15 \mathrm{mg} / \mathrm{Kg}$, sendo repetida a cada doze horas, durante 24 horas. Outro grupo recebeu flunixin meglumine ${ }^{8}$ (GF) pela via intravenosa, na dose de $1,1 \mathrm{mg} / \mathrm{Kg}$, em apenas uma única dose. Foi realizada uma distribuição aleatória a um dos dois

\footnotetext{
${ }^{1}$ Safelet ${ }^{\circledR}$, Nipro Medical Corporation, New Jersey, EUA.

${ }^{2} \mathrm{PRN}^{\circledR}, \mathrm{BD}, \mathrm{PR}$.

${ }^{3}$ Super Bonder ${ }^{\circledR}$, Loctite, Henkel Ltda., SP.

${ }^{4}$ MicroNylon ${ }^{\circledR}$, Microsuture, SP.

${ }^{5}$ Seringa hipodérmica, INJEX Indústrias Cirúrgicas Ltda., SP.

${ }^{6}$ Agulha hipodérmica, $B D, P R$.

${ }^{7} \mathrm{D} 500^{\circledR}$, Zoetis Indústria de Produtos Veterinários Ltda., SP.

${ }^{8}$ Meflosyl $^{\circledR}$, Zoetis Indústria de Produtos Veterinários Ltda., SP.
} 
tratamentos ( $\mathrm{n}=06$ cavalos por grupo) por um gerador de sequência aleatória (http://www.randomization.com).

Foram coletadas amostras de sangue, em tempos pré-estabelecidos para mensuração ex vivo da concentração de tromboxano $B_{2}\left(T_{X} B_{2}\right)$ e prostaglandina $E_{2}$ $\left(\mathrm{PGE}_{2}\right)$.

\subsubsection{DETERMINAÇÃO EX VIVO DA CONCENTRAÇÃO DE TXB E PGE $_{2}$}

As medições das taxas de $\mathrm{TXB}_{2}$ e $\mathrm{PGE}_{2}$ foram realizadas em amostras de sangue coletadas em seis animais de cada grupo (GD e GF) no tempo basal (previamente à primeira administração de dipirona ou flunixin meglumine) e decorridos 2 (T2), 8 (T8), 12 (T12) e 24 (T24) horas após a primeira administração da medicação (Figura 02).

No GD, no tempo 12 a coleta foi realizada imediatamente antes da segunda dose de dipirona. Todas as amostras foram armazenadas em duplicata em diferentes freezers à $-80^{\circ} \mathrm{C}$ até o momento da realização do teste de ELISA. Para realização da curva utilizou-se adaptação da metodologia descrita por Duz et al. (2015) e as amostras foram avaliadas por meio dos kits Prostaglandin $E_{2}$ kitmonoclonal e Thromboxan $B_{2}$ ELISA kit, ambos da marca Cayman ${ }^{\circledR}$ Chemical (Michigan, EUA). Todas as análises foram realizadas no laboratório do Departamento de Patologia da Faculdade de Medicina Veterinária e Zootecnia da Universidade de São Paulo.

Figura 2 - Delineamento experimental das coletas de sangue para mensuração da concentração de $\mathrm{PGE}_{2}$ e $\mathrm{TXB}_{2}$ de 12 cavalos distribuídos aleatoriamente nos 2 grupos do estudo - FMVZ - São Paulo - 2017

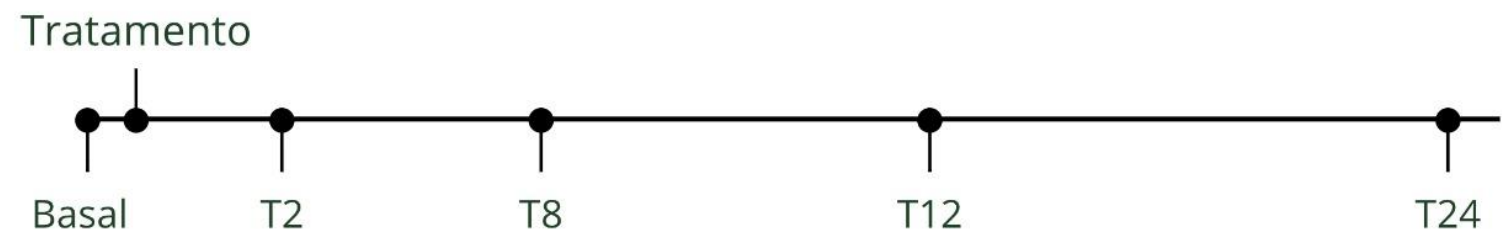

Fonte: (SANTOS, R. S. T. dos, 2017). 
Legenda: Basal: momento imediatamente anterior à administração da medicação referente ao grupo de tratamento; T2, T8, T12 e T24: 2, 8, 12 e 24 horas após a administração da medicação, respectivamente.

\subsection{AVALIAÇÃO DA CONCENTRAÇÃO DE TROMBOXANO B ${ }_{2}$}

1) coleta de $1 \mathrm{~mL}$ de sangue com agulha $30 \times 8 \mathrm{~mm}$ e seringa de $3 \mathrm{ml}$ e transferência para um tubo de vidro o qual foi mantido em estufa a $37^{\circ} \mathrm{C}$ por uma hora ;

2) Passagem de todo conteúdo do tubo de vidro (coágulo e plasma) para um microtubo ${ }^{9}$ de $1,5 \mathrm{~mL}$ limpo;

3) As amostras então eram centrifugadas à $2000 \mathrm{G}$ por 5 minutos à $18^{\circ} \mathrm{C}$;

4) Após, com o auxílio de uma pipeta, $100 \mu \mathrm{L}$ do plasma foi aliquotado a um novo microtubo, contendo $400 \mu \mathrm{L}$ de metanol sendo este procedimento realizado em duplicata;

5) Centrifugou-se novamente as amostras, agora com o metanol, à 6000G por 10 min à $18^{\circ} \mathrm{C}$;

6) Os tubos foram então congelados em dois freezers à $-80^{\circ} \mathrm{C}$ (laboratório de hemoterapia e laboratório do Departamento de Patologia da Faculdade de Medicina Veterinária e Zootecnia da Universidade de São Paulo) até o momento da dosagem pelo kit de $\mathrm{TXB}_{2}$;

7) Descongelamento das amostras no laboratório no dia do ensaio de dosagem de $\mathrm{TXB}_{2}$;

8) Para realização da curva de $T X B_{2}$, foi necessário diluir as amostras 4 vezes;

9) Deu-se sequência a análise pelo método de ELISA conforme metodologia proposta pelo fabricante. $O$ ensaio foi realizado no laboratório do Departamento de Patologia da Faculdade de Medicina Veterinária e Zootecnia da Universidade de São Paulo.

\footnotetext{
${ }^{9} \mathrm{CWR}^{\circledR}$, importado por Biosystems, Brasil.
} 


\subsection{AVALIAÇÃO DA CONCENTRAÇÃO DE PROSTAGLANDINA E ${ }_{2}$}

1) Coleta de $1 \mathrm{~mL}$ de sangue e transferência de $500 \mu \mathrm{L}$ em dois microtubos. Foi realizada uma adição de $25 \mu \mathrm{L}$ da solução de LPS (Escherichia coli 0111:B4) a uma concentração final de $100 \mu \mathrm{g} / \mathrm{ml}$ no primeiro microtubo (amostra estimulada - $\mathrm{PGE}_{2}$-E) para ocorrer um aumento sustentado e consistente da produção de $\mathrm{PGE}_{2}$ no sangue dos cavalos. No segundo microtubo, $10 \mu \mathrm{L}$ de PBS foram adicionados para se obter amostras de controle negativo (amostra não estimulada - $\mathrm{PGE}_{2}-\mathrm{NE}$ );

2) Incubação das amostras com a tampa fechada em uma estufa a $37^{\circ} \mathrm{C}$ por 24 horas;

3) Ao término da incubação, centrifugação dos microtubos a 2000G por 5 minutos a $18^{\circ} \mathrm{C}$;

4) Com auxílio de uma pipeta, adição de $100 \mu \mathrm{L}$ do plasma em quatro novos microtubos (2-E e 2-NE) com $400 \mu \mathrm{L}$ de Metanol (duplicata);

5) Centrifugação das amostras com o metanol a 6000G por 10 minutos a $18^{\mathrm{a}} \mathrm{C}$;

6) Coleta do sobrenadante e divisão em quatro novos tubos (2-E e 2-NE), $150 \mu \mathrm{L}$ em cada, e congelamento a $-80^{\circ} \mathrm{C}$ até o momento da dosagem pelo kit de prostaglandina E2 $\left(\mathrm{PGE}_{2}\right)$;

7) Descongelamento das amostras no laboratório no dia do ensaio de dosagem de $\mathrm{PGE}_{2}$;

8) Para realização da curva de $\mathrm{PGE}_{2}$, foi necessário diluir as amostras 10 vezes;

9) Deu-se sequência a análise pelo método de ELISA conforme metodologia proposta pelo fabricante. O ensaio foi realizado no laboratório do Departamento de Patologia da Faculdade de Medicina Veterinária e Zootecnia da Universidade de São Paulo.

\subsection{FASE 02}




\subsubsection{ANIMAIS E CRITÉRIOS DE INCLUSÃO}

A segunda fase do estudo foi desenvolvida com a utilização de animais saudáveis e com a indicação de orquiectomia eletiva. Foram utilizados 15 animais, de raças variadas, machos, acima de 1 ano de idade, pertencentes à tutores que procuraram o serviço de cirurgia de grandes animais da FMVZ-USP para realização de orquiectomia eletiva.

Apenas animais que não apresentassem alterações clínicas que descaracterizassem o procedimento eletivo foram incluídos neste estudo. Procediase então a realização de exame físico, com avaliação da frequência cardíaca (FC), frequência respiratória (FR), temperatura retal, auscultação pulmonar e traqueal, tempo de preenchimento capilar (TPC), avaliação da coloração de mucosas, hidratação, auscultação dos quadrantes intestinais e palpação dos linfonodos. Foram também avaliados apetite, ingestão de água, assim como parâmetros comportamentais de locomoção na baia, interação, e interesse pelo ambiente. Era realizada palpação dos testículos para certificação que ambos estavam na bolsa escrotal.

\subsubsection{PREPARO DOS ANIMAIS}

Todos os animais obtiveram os pelos sobre a jugular tricotomizados, com posterior antissepsia com clorexidine e clorexidine alcoólico para passagem de cateter ${ }^{3}$ 14GX2", com adaptador $\mathrm{PRN}^{4}$ para vedar sua entrada. O cateter e adaptador eram fixados com supercola ${ }^{5}$ e permaneciam durante as 24 horas, ou até a constatação que não havia mais acesso ao vaso sanguíneo. A administração do protocolo de anestesia e analgesia era realizada por meio deste cateter.

Oito animais eram habituados às instalações nas quais permaneceram para a avaliação de dor, ao passo que os demais foram traduzidos ao HOVET no dia anterior. No entanto, o número de animais de cada grupo ficou igualmente distribuído.

\subsubsection{DELINEAMENTO EXPERIMENTAL}




\subsubsection{GRUPOS EXPERIMENTAIS}

Os animais foram divididos aleatoriamente em dois grupos: Grupo Dipirona (GD) e Grupo Flunixin (GF). No GD, administrou-se dipirona na dose de $15 \mathrm{mg} / \mathrm{Kg}$ pela via intravenosa, sendo repetida a cada doze horas, durante 24 horas. Já no GF, administrou-se flunixin meglumine na dose de $1,1 \mathrm{mg} / \mathrm{Kg}$ pela via intravenosa, a cada 24 horas.

\subsubsection{TÉCNICA ANESTÉSICA}

Todos os animais receberam a administração de sedação com alfa-2 agonista Detomidina ${ }^{10}$ em doses que variaram de $8-20 \mu \mathrm{g} / \mathrm{kg}$ de acordo com a índole do animal, até se obter um grau de sedação eficaz e seguro para procederse a indução anestésica (abaixamento de cabeça, ptose labial e palpebral). Como indutores utilizou-se cetamina ${ }^{11}$ na dose de $2,5 \mathrm{mg} / \mathrm{Kg}$ e diazepam ${ }^{12}$ na dose de $0,05 \mathrm{mg} / \mathrm{Kg}$, ambos associados na mesma seringa, p-ela via intravenosa. Para manutenção anestésica utilizou-se infusão contínua de éter gliceril guaiacol ${ }^{13}$ (EGG) à $5 \%$. Todos os animais receberam anestesia local com lidocaína ${ }^{14}$ sem vasoconstrictor $2 \%$, sendo administrados $20 \mathrm{~mL}$ em cada testículo assim que se instituía o plano anestésico e após antissepsia do local. Imediatamente antes do início da cirurgia, todos os animais receberam outra dose de cetamina ${ }^{13}(1,2$ $\mathrm{mg} / \mathrm{Kg}$ ) pela via intravenosa.

Os procedimentos cirúrgicos foram realizados conforme técnica padrão da FMVZ-USP e realizados por cirurgião experiente. A antibioticoterapia foi realizada com enrofloxacina ${ }^{15} 10 \%$ (5mg/Kg a cada 24 horas por 3 dias) ou pentabiótico ${ }^{16}$ (40000Ui/Kg baseado na Penicilina Benzatina em dose única), além de soro antitetânico ${ }^{17}$ (1 frasco por animal) em dose única.

\footnotetext{
${ }^{10}$ Dormium $^{\circledR}$, Agener União, SP.

${ }^{11}$ Cetamin $^{\circledR}$, Syntec, SP.

${ }^{12}$ Diazepam $^{\circledR}$, Genérico Hipolabor, MG.

${ }^{13} \mathrm{EGG}^{\circledR}$,Henrifarma, SP.

${ }^{14}$ Lidocaína $^{\circledR}$, Genérico Hipolabor, MG.

${ }^{15}$ Chemitril $^{\circledR}$, Chemitec, SP.

${ }^{16}$ Pentabiótico ${ }^{\circledR}$, Zoetis, Indústria de Produtos Veterinários Ltda., SP.

${ }^{17}$ Vencosat $^{\circledR}$, Vencofarma, Londrina, PR.
} 
Como orientações pós-operatórias, foram recomendados para todos os animais seguimento de administração de fenilbutazona ${ }^{18}$ (1g para cada $250 \mathrm{Kg}$ ) pela via oral, a cada 24 horas, por três dias; 20 minutos de ducha fria de cada lado da bolsa escrotal três vezes ao dia; curativo com repelente ${ }^{19}$ e que o animal ficasse solto em um piquete pequeno para caminhadas leves até a total cicatrização da ferida cirúrgica.

\subsubsection{AVALIAÇÕES DE DOR}

Para avaliação da dor foram utilizadas as seguintes escalas: Escala Multidimensional da UNESP- Botucatu (TAFFAREL et al., 2015), Escala Facial (DALLA COSTA et al., 2014) e Escala Visual Analógica (EAV), conforme anexos A, $B$ e C. A pontuação da escala EAV varia de 0 (nenhuma dor) à $10 \mathrm{~cm}$ (pior dor possível), e a graduação referente ao resgate analgésico é a partir de $4 \mathrm{~cm}$. Assim sendo, no presente estudo foi utilizada a pontuação da EAV para a instituição, se necessário do resgate analgésico.

Para avaliação da sedação e ataxia, empregou-se escala de sedação/ataxia (TAYLOR et al., 2013 adaptada), cuja pontuação varia de 0 (sem sedação aparente) à 3 (sedação intensa) (Anexo D).

As avaliações de dor foram realizadas nos momentos Basal (previamente à cirurgia), e decorridas 1 (T1), 2 (T2), 4 (T4), 8 (T8), 12 (T12) e 24 (T24) horas após a aplicação do fármaco pós-operatório (Figura 3). Todas as avaliações de dor foram comparadas com as avaliações no momento basal para quantificação do aumento ou não na pontuação das escalas para, se necessário, proceder-se o resgate analgésico. A avaliações foram realizadas sempre pelo mesmo indivíduo (RT) que desconhecia o protocolo de analgesia utilizado e era familiarizado com a espécie equina e as escalas de dor.

Como resgate analgésico preconizou-se tramadol ${ }^{20}$ na dose de $2 \mathrm{mg} / \mathrm{Kg}$ pela via intravenosa. Se o animal necessitasse, receberia o opioide e seria

\footnotetext{
${ }^{18}$ Equipalazone ${ }^{\circledR}$ pó, Marcolab, Duque de Caxias, RJ.

${ }^{19}$ Tanidil $^{\circledR}$, Bayer, Brasil ou Alantol ${ }^{\circledR}$, Vetnil, SP.

${ }^{20}$ Tramadol $^{\circledR}$, Cristália, SP.
} 
acompanhado até normalização das escalas de dor, além do que seria imediatamente retirado do estudo.

Figura 3 - Delineamento experimental dos momentos de avaliação dos escores de dor, sedação e ataxia de 15 cavalos distribuídos aleatoriamente nos 2 grupos do estudo da fase 02 - FMVZ - São Paulo - 2017

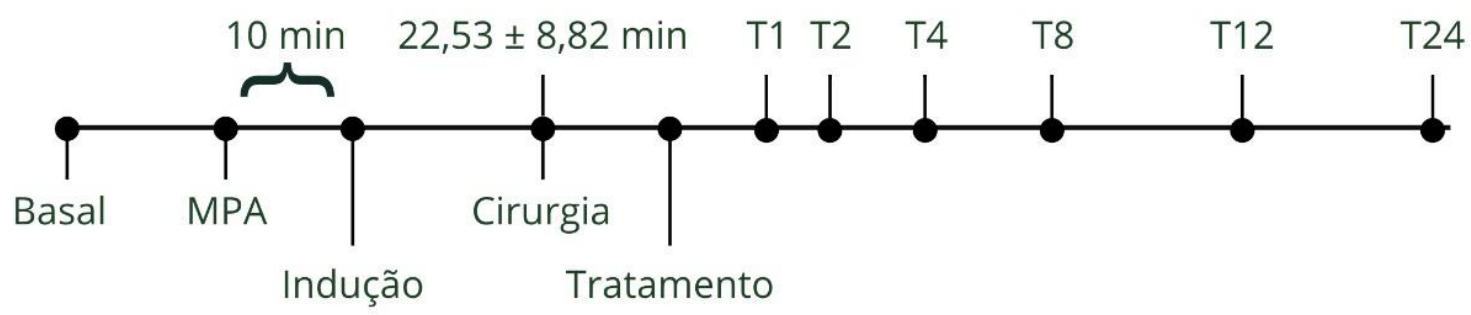

Fonte: (SANTOS, R. S. T. dos, 2017).

Legenda: Basal: momento imediatamente anterior à administração da medicação referente ao grupo de tratamento; MPA: Medicação pré anestésica; indução: indução anestésica com cetamina e diazepam; média (22,53 min) e desvio padrão (8,82 min) do tempo cirúrgico; T1, T2, T4, T8, T12 e T24: 1, 2, 4, 8, 12 e 24 horas após a administração da medicação pós-operatória, respectivamente.

\subsubsection{AVALIAÇÕES PARAMÉTRICAS}

Os parâmetros vitais avaliados foram frequência cardíaca ( $F C)$, frequência respiratória e temperatura retal e foram realizadas nos momentos Basal (previamente à cirurgia), e decorridas 1 (T1), 2 (T2), 4 (T4), 8 (T8), 12 (T12) e 24 (T24) horas após a aplicação do fármaco pós-operatório.

\subsubsection{AVALIAÇÕES DOS EFEITOS DELETÉRIOS}

Efeitos adversos relacionados ao uso de AINES foram avaliados, tais como/; sinais de desconforto abdominal (deitar, rolar, dor), sinais de gastrite (redução de apetite, ficar 'brincando' com a água do cocho, bruxismo) e sinais de desregulação 
do trânsito intestinal (hipomotilidade, hipermotilidade, diarreia) foram avaliados durante todo o período de 24 horas nas quais os animais participaram do estudo. 


\section{AVALIAÇÃO ESTATÍSTICA}

As análises estatísticas foram realizadas com o software GraphPad Prism versão $7.03^{21}$. Para análise de peso, idade e tempo cirúrgico, utilizou-se Teste $t$ independente, sem pós-teste. Para análise de FC, FR e temperatura utilizou-se análise de variância Two-away ANOVA com pós-teste de Sidak (entre os grupos) e análises de variância de medidas repetidas (RM-ANOVA) de duas vias com pósteste de Dunnett (entre momentos).

Os escores de dor e sedação foram comparados entre os grupos pelo teste não paramétrico de Kruskal-Wallis, seguido de pós-teste de Dunn. E entre diferentes momentos de um mesmo grupo pelo teste de Friedman, seguido de pósteste de Dunn.

Para as concentrações de $T X B_{2}$ e de $P G E_{2}$ foram realizadas análises de variância (Two-away ANOVA) de duas vias com pós-teste de Sidak para comparação entre grupos e análises de variância de medidas repetidas Two away ANOVA RM de duas vias com pós-teste de Tukey para comparação entre os momentos em um mesmo grupo.

\section{RESULTADOS}

\subsection{FASE 01}

Foram utilizados inicialmente 14 animais nesta fase do estudo, porém, os dados de dois animais do GD foram excluídos.

\footnotetext{
${ }^{21}$ GraphPad Software Inc., La Jolla, EUA.
} 


\subsubsection{DADOS DEMOGRÁFICOS}

Utilizou-se 10 machos (83\%) e 2 fêmeas (17\%), com idades variando de 2 à 8 anos. Os pesos variaram entre $262-390 \mathrm{Kg}$. Todos os animais eram da raça Árabe (Apêndice E).

\subsubsection{AVALIAÇÃO DA CONCENTRAÇÃO DE TXB 2}

As concentrações iniciais de $\mathrm{TXB}_{2}$ (Basal) não diferiram entre os grupos do estudo. Ao longo dos tempos de avaliação, não houve diferença entre os grupos de tratamento. Entretanto, dentro dos grupos (comparação entre tempos), houve diferença estatística nos seguintes tempos (Gráfico 01, Tabela 01 e Apêndices A e B):

- GD: verificou-se diferença significativa entre os tempos basal e T2, basal e T8, basal e T12 e T2 e T24, sendo o valor de $\mathrm{P}<0,0001$; Apenas a partir de T24 a concentração de $\mathrm{TXB}_{2}$ atingiu valores superiores a $50 \%$ da concentração basal, sendo $P=0,0023$; Os valores de T2 e T12 também diferiram significativamente $(P=0,0275)$ bem como de T8 e T24 $(P=0,0246)$.

- GF: os valores de $\mathrm{TXB}_{2}$ diferiram significativamente entre os tempos de avaliação com $P<0,0001$ nos tempos basal e T2, basal e T8, basal e T12 e basal e T24. Já entre T2 e T24 o valor de $P$ foi de 0,0061 e T8 e T24 P= 0,0191 . 
Gráfico 01. Gráfico Boxplot da porcentagem de mudança na concentração de Tromboxano $\mathrm{B}_{2}\left(\mathrm{TX}_{2}\right)$, representando a atividade da ciclooxigenase 1 (COX-1), em comparação com o valor imediatamente anterior à administração da medicação referente ao grupo (Basal: valor considerado como 100\% [linha pontilhada horizontal]) de 12 cavalos distribuídos aleatoriamente nos 2 grupos do estudo durante os momentos avaliados na fase 01- FMVZUSP - São Paulo - 2017.

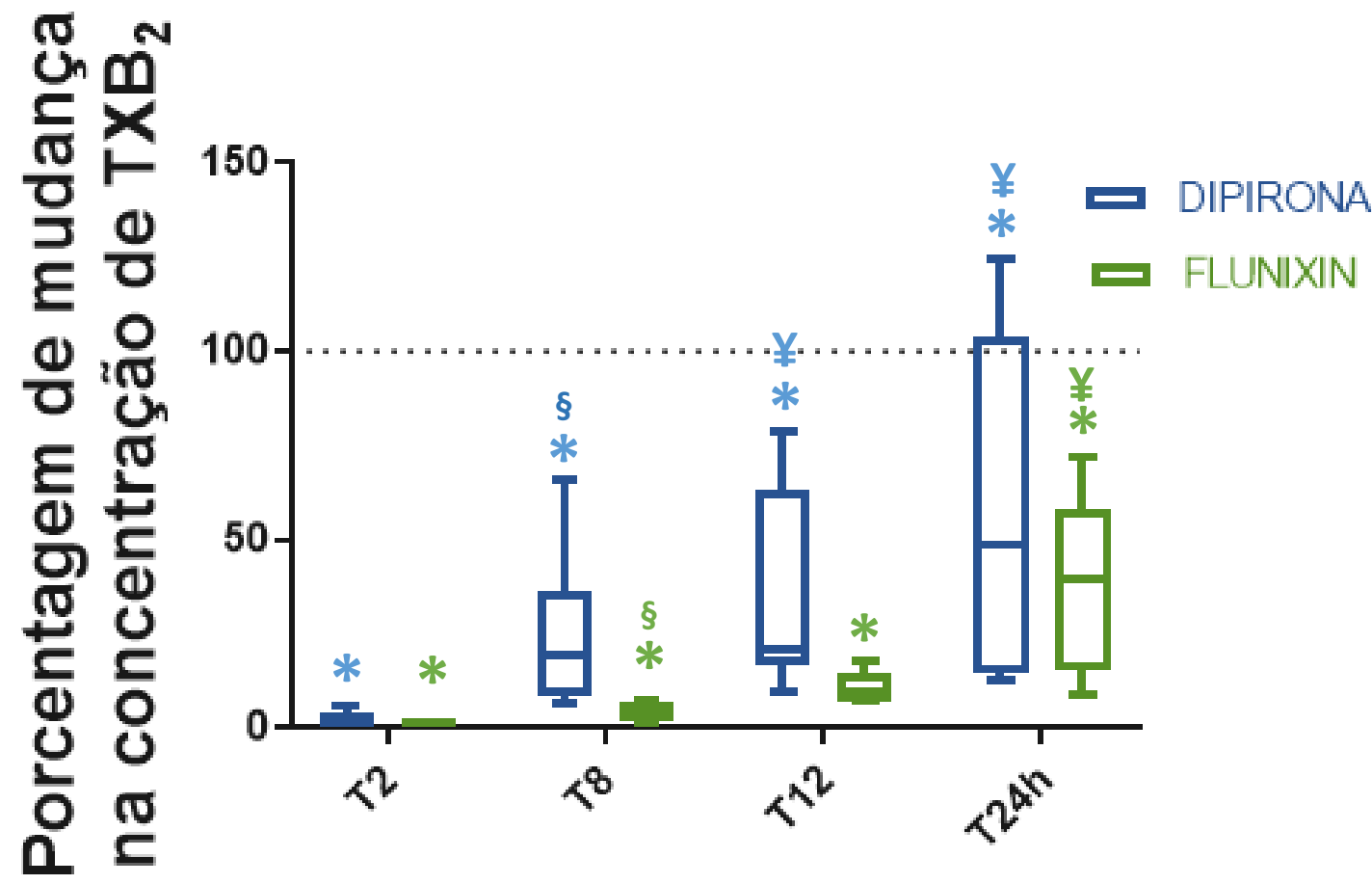

Fonte: (SANTOS, R. S. T. dos, 2017).

Legenda: T2, T8, T12 e T24: 2, 8, 12 e 24 horas após a administração da medicação (Dipirona ou Flunixin), respectivamente; *: valor significativamente diferente de Basal; ¥: valor significativamente diferente de T2; $\S=$ valor significativamente diferente de T24; 0 grau de significância estabelecido para os testes estatísticos foi de $5 \%(P<0,05)$.

Tabela 1 - Média e desvio padrão da porcentagem de mudança das concentrações de Tromboxano $\mathrm{B}_{2}\left(\mathrm{TXB}_{2}\right)$, representando a atividade da cicloxigenase 1 (COX-1) em comparação com o valor imediatamente anterior à administração da medicação (Basal: valor considerado como 100\%), dos 12 cavalos distribuídos aleatoriamente nos 2 grupos do estudo durante os momentos avaliados na fase 01- FMVZ - São Paulo - 2017.

\begin{tabular}{l|c|ccccc}
\hline \multicolumn{6}{c}{ Momentos de avaliação } \\
\hline \multirow{7}{*}{ Dipirona } & & Basal & T2 & T8 & T12 & T24 \\
\cline { 3 - 7 } & Média & 100 & $2,15^{*}$ & $24,69 * \S$ & $34,77^{*} ¥$ & $57,77^{*} ¥$ \\
& DP & 0 & 2,33 & 21,42 & 27,14 & 44,75 \\
& & & & & & \\
\hline \multirow{3}{*}{ Flunixin } & Média & 100 & $0,02^{*}$ & $4,49 * \S$ & $10,94^{*}$ & $33,61^{*} ¥$ \\
& DP & 0 & 0,02 & 2,6 & 4,02 & 25,03 \\
\hline
\end{tabular}


Fonte: (SANTOS, R. S. T. dos, 2017).

Legenda: DP: desvio Padrão; Basal: momento imediatamente anterior à administração da medicação; T2, T8, T12 e T24: 2, 8, 12 e 24 horas após a administração da medicação; *: valor significativamente diferente de Basal; ¥: valor significativamente diferente de T2h; $\S=$ valor significativamente diferente de T24; O grau de significância estabelecido para os testes estatísticos foi de $5 \%(P<0,05)$.

\subsubsection{AVALIAÇÃO DA CONCENTRAÇÃO DE PGE 2}

Para as análises estatísticas foram considerados apenas os dados das amostras estimuladas pelo LPS $\left(\mathrm{PGE}_{2}-\mathrm{E}\right)$. Não houve diferença estatística entre quaisquer momentos avaliados do GF. Já no grupo dipirona, houve aumento significativo em T12 quando comparado ao basal $(P=0,061)$. Já na comparação entre os grupos, houve diferença no momento $T 2(P=0,0311)$ e no momento $T 12$ $(P=0,0018)$, sendo ambas concentrações maiores no grupo dipirona (Gráfico 02, Tabela 02, Apêndices C e D).

Tabela 2 - Média e desvio padrão da porcentagem de mudança das concentrações de Prostaglandina $\mathrm{E}_{2}\left(\mathrm{PGE}_{2}\right)$, representando a atividade da ciclooxigenase 2 (COX-2) em comparação com o valor imediatamente anterior à administração da medicação referente ao grupo (Basal: valor considerado como 100\%), dos 12 cavalos distribuídos aleatoriamente nos 2 grupos do estudo durante os momentos avaliados na fase 01 - FMVZ - São Paulo - 2017.

\begin{tabular}{l|c|cccc}
\hline \multicolumn{2}{c}{} & \multicolumn{5}{c}{ Momentos Avaliados } \\
\hline \multirow{3}{*}{ Dipirona } & & Basal & T2 & T12 & T24 \\
\cline { 3 - 6 } & Média & 100 & $129,66 f$ & $187,73 ¥ f$ & 148,39 \\
& DP & 0 & 71,77 & 83,51 & 64,51 \\
\hline \multirow{2}{*}{ Flunixin } & Média & 100 & $68,27 f$ & $86,4 f$ & 101,9 \\
& DP & 0 & 16,64 & 21,98 & 2,99 \\
\hline
\end{tabular}

Fonte: (SANTOS, R. S. T. dos, 2017).

Legenda: DP: desvio Padrão; Basal: momento imediatamente anterior à administração da medicação; T2, T12 e T24: 2, 12 e 24 horas após a administração da medicação; ¥: valor significativamente diferente de basal; $f$ : diferença significativa entre os grupos. O grau de significância estabelecido para os testes estatísticos foi de 5\% $(P<0,05)$. 
Gráfico 02. Gráfico Boxplot da porcentagem de mudança na concentração de Prostaglandina $E_{2}$ $\left(\mathrm{PGE}_{2}\right)$, representando a atividade da cicloxigenase 2 (COX-2), em comparação com o valor imediatamente anterior à administração da medicação referente ao grupo (Basal: valor considerado como 100\% [linha pontilhada horizontal]) de 12 cavalos distribuídos aleatoriamente nos 2 grupos do estudo durante os momentos avaliados na fase 01- FMVZ-USP - São Paulo - 2017.

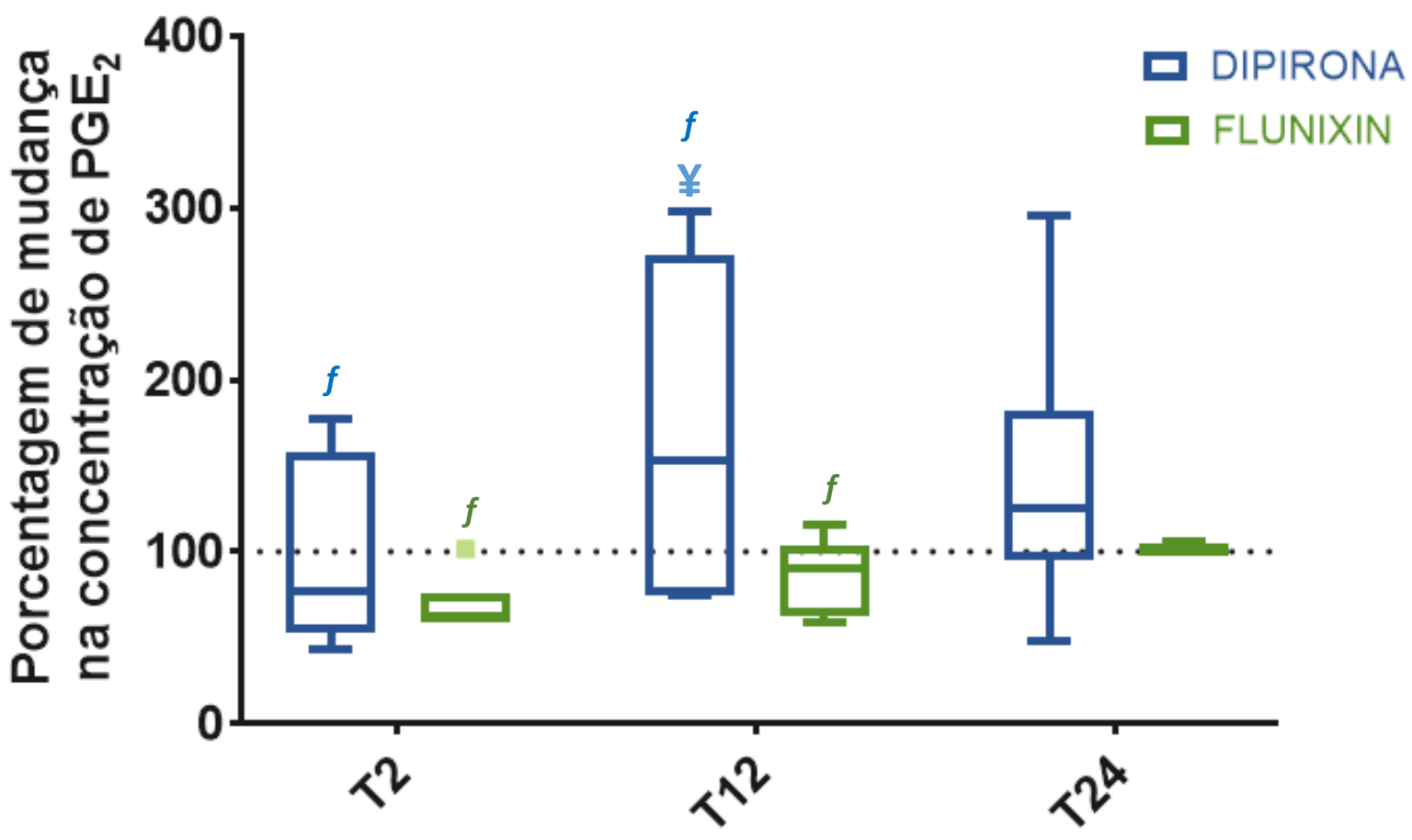

Fonte: (SANTOS, R. S. T. dos, 2017).

Legenda: T2, T12 e T24: 2, 12 e 24 horas após a administração da medicação (Dipirona ou Flunixin), respectivamente; ¥: valor significativamente diferente de Basal; $f$ : diferença significativa entre os grupos; a: outliers do grupo flunixin . O grau de significância estabelecido para os testes estatísticos foi de $5 \%(P<0,05)$. 


\subsection{FASE 02}

Dezessete animais foram inicialmente incluídos nesta fase do estudo, porém devido a sangramento pós-operatório, dois animais foram descartados do estudo devido à necessidade de nova manipulação cirúrgica.

\subsubsection{DADOS DEMOGRÁFICOS}

Os animais apresentaram média de peso de $385,81 \mathrm{Kg}$ no GD e de $392,71 \mathrm{Kg}$ em GF. Os animais do GD eram das raças SRD (75\%), Bretão (12,5\%) e Luzitano (12,5\%); já os animais do GF eram SRD (57,1\%), Mangalarga Paulista (14,3\%), Mangalarga Marchador (14,3\%) e Luzitano (14,3\%). A idade média no GD foi de 5,4 anos (+- 1,77) e no GF 5,14 anos (+- 1,35). Não houveram diferenças estatísticas significativas entre os grupos em relação ao peso e a idade. (Gráfico 3 e Apêndice E).

Gráfico 03. Gráfico Boxplot da variação da idade em anos e do peso em quilogramas dos 15 cavalos distribuídos aleatoriamente nos 2 grupos do estudo durante os momentos avaliados na fase 02- FMVZ-USP - São Paulo - 2017.
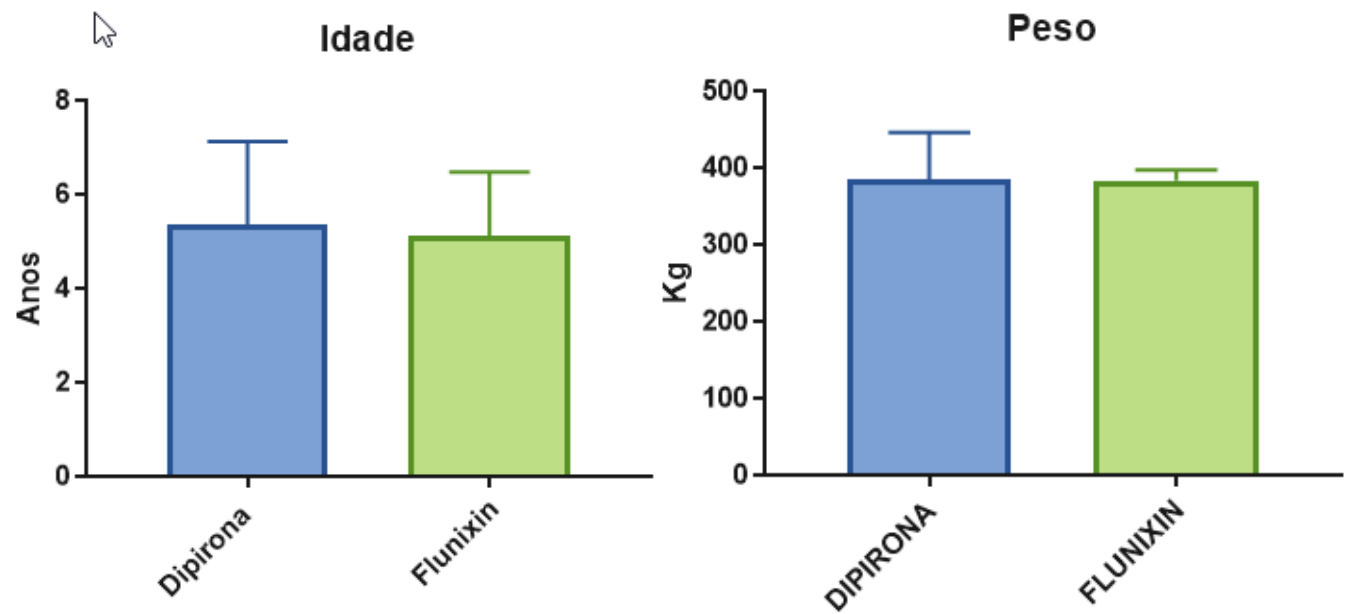

Fonte: (SANTOS, R. S. T. dos, 2017).

Legenda: Kg: quilogramas. O grau de significância estabelecido para os testes estatísticos foi de $5 \%$ $(P<0,05)$. 


\subsubsection{TEMPO CIRÚRGICO}

Os procedimentos cirúrgicos duraram entre 15-40 minutos, e não tiveram horário padronizado para início. Não houve diferença estatística entre os grupos. (Tabela 03, Gráfico 04 e Apêndice N).

Tabela 3 - Média e desvio padrão do tempo cirúrgico dos 15 cavalos distribuídos aleatoriamente nos 2 grupos do estudo durante os momentos avaliados na fase 02 - FMVZ - São Paulo - 2017.

\begin{tabular}{l|c|r}
\hline \multicolumn{3}{c}{ Tempo Cirúrgico } \\
\hline \multirow{2}{*}{ Dipirona } & Média & 22,13 \\
& DP & 9,05 \\
\hline \multirow{2}{*}{ Flunixin } & Média & 23 \\
\hline
\end{tabular}

Fonte: (SANTOS, R. S. T. dos, 2017) Legenda: DP: desvio Padrão.

Gráfico 04. Gráfico Boxplot da variação do tempo cirúrgico dos 15 cavalos distribuídos aleatoriamente nos 2 grupos do estudo durante os momentos avaliados na fase 02- FMVZ-USP São Paulo - 2017.

Tempo Cirúrgico

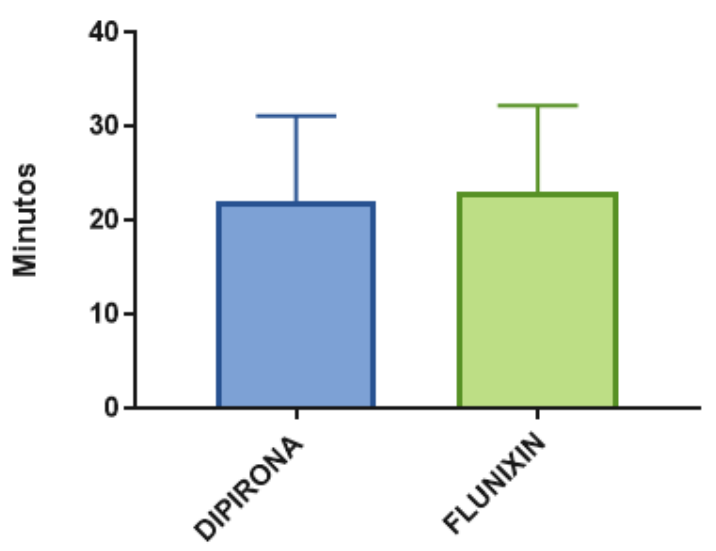

Fonte: (SANTOS, R. S. T. dos, 2017). 


\subsubsection{PARÂMETROS FISIOLÓGICOS}

\subsubsection{FREQUÊNCIA CARDÍACA (FC)}

Não houve diferença significativa entre os grupos e tampouco entre os momentos (dentro do grupo) avaliados. A média foi de 50bpm no GD e 46bpm no GF. (Gráfico 05 e Apêndice F).

Gráfico 05 - Gráfico Boxplot das médias \pm desvio padrão da frequência cardíaca ( $F C)$, em batimentos por minuto, de 15 cavalos distribuídos aleatoriamente nos 2 grupos do estudo durante os momentos avaliados na fase 02-FMVZ-USP - São Paulo - 2017.

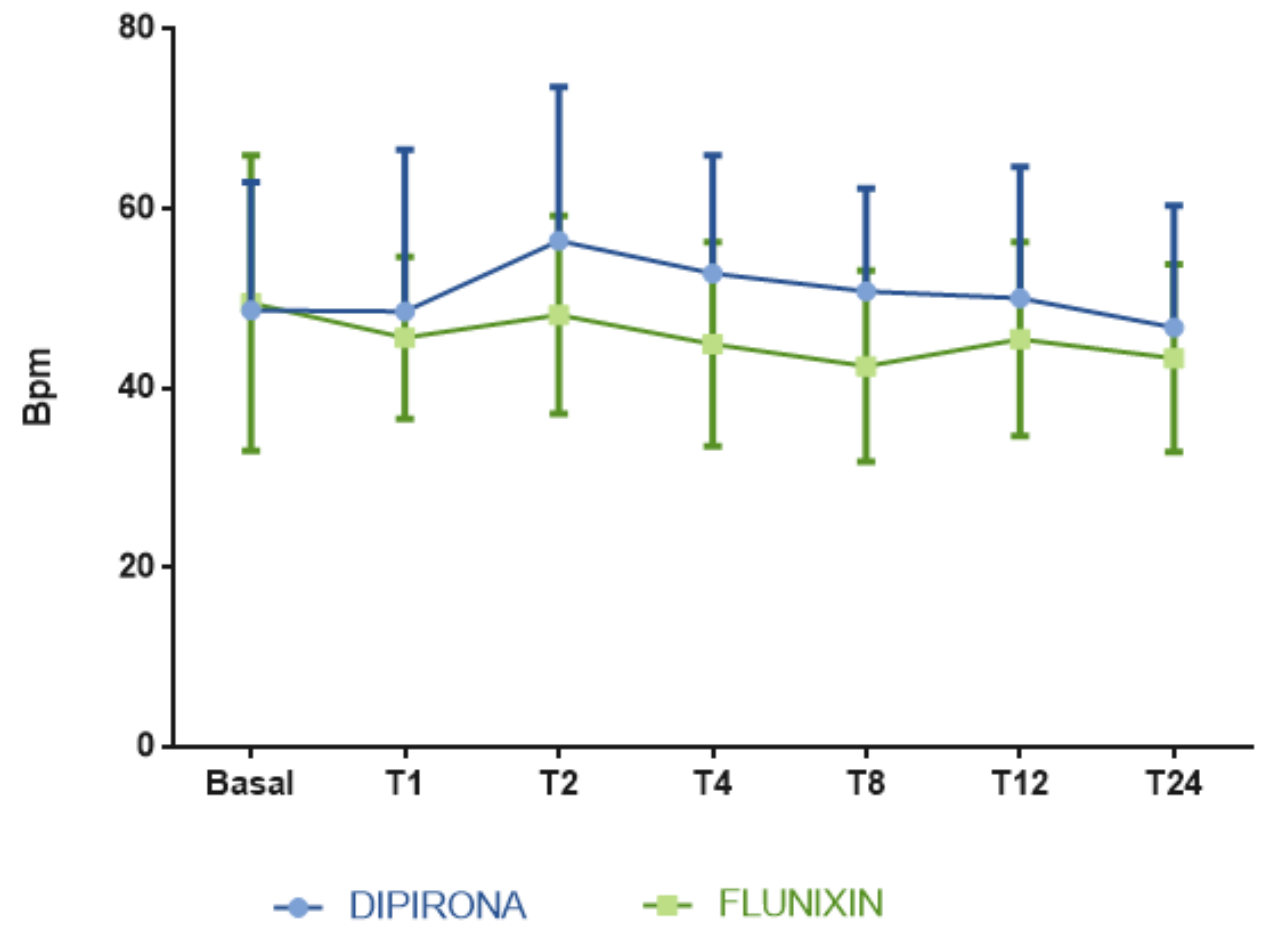

Fonte: (SANTOS, R. S. T. dos, 2017).

Legenda: Bpm: batimentos por minuto; basal: avaliação antes do procedimento anestésico/cirúrgico; T1, T2, T4, T8, T12 e T24: 1, 2, 4, 8, 12 e 24 horas após a administração do protocolo pósoperatório. O grau de significância estabelecido para os testes estatísticos foi de $5 \%(P<0,05)$. 


\subsubsection{FREQUÊNCIA RESPIRATÓRIA (FR)}

A frequência respiratória foi em média $26 \pm 2,29$ movimentos respiratórios por minuto (mpm) no GD e de $24 \pm 1,13 \mathrm{mpm}$ no GF. Não houve diferenças estatísticas tanto na avaliação entre os grupos, como na avaliação entre os momentos. (Gráfico 06, Apêndice G).

Gráfico 06 - Gráfico Boxplot das médias \pm desvio padrão da frequência respiratória (FR), em movimentos por minuto, de 15 cavalos distribuídos aleatoriamente nos 2 grupos do estudo durante os momentos avaliados na fase 02- FMVZ-USP - São Paulo - 2017.

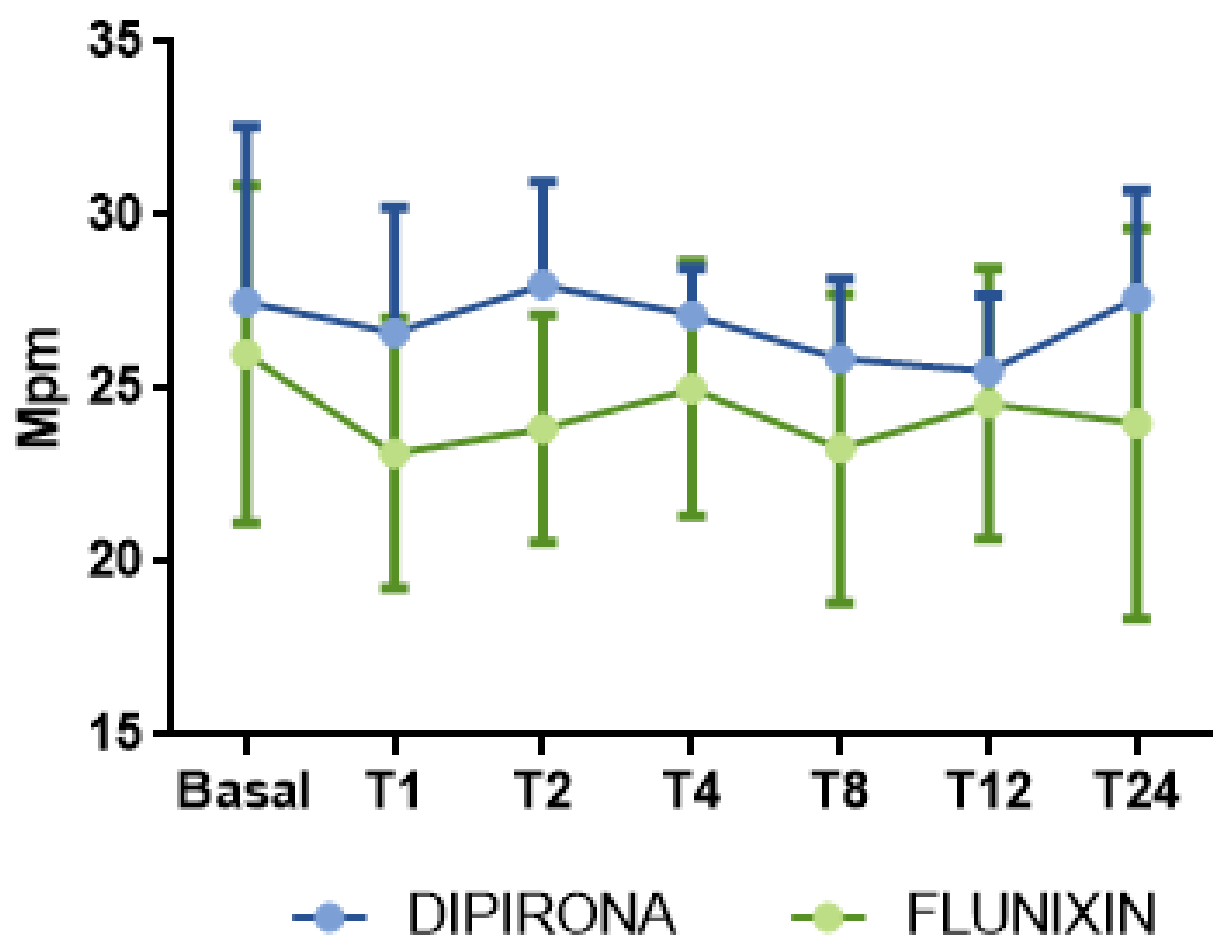

Fonte: (SANTOS, R. S. T. dos, 2017).

Legenda: Mpm: movimentos por minuto; basal: avaliação antes do procedimento anestésico/cirúrgico; T1, T2, T4, T8, T12 e T24: 1, 2, 4, 8, 12 e 24 horas após a administração do protocolo pós-operatório. O grau de significância estabelecido para os testes estatísticos foi de $5 \%$ $(P<0,05)$. 


\subsubsection{TEMPERATURA RETAL $\left(\mathrm{T}^{\circ} \mathrm{C}\right)$}

A temperatura retal ficou em média $38,1^{\circ} \mathrm{C} \pm 0,08$ no $\mathrm{GD}$ e $38,2^{\circ} \mathrm{C} \pm 0,15$ no GF. Houve redução significativa em $T 1$ quando comparada com o basal no GD $(P=$ $0,0150)$ e no $G F(P=0,0028)$. Não houve diferença estatística entre os grupos. Gráfico 07, Apêndice H).

Gráfico 07 - Gráfico Boxplot das médias \pm desvio padrão da temperatura retal, em graus Celsius $\left({ }^{\circ} \mathrm{C}\right)$ nos momentos avaliados de 15 cavalos distribuídos aleatoriamente nos 2 grupos do estudo durante os momentos avaliados na fase 02- FMVZ-USP - São Paulo - 2017.

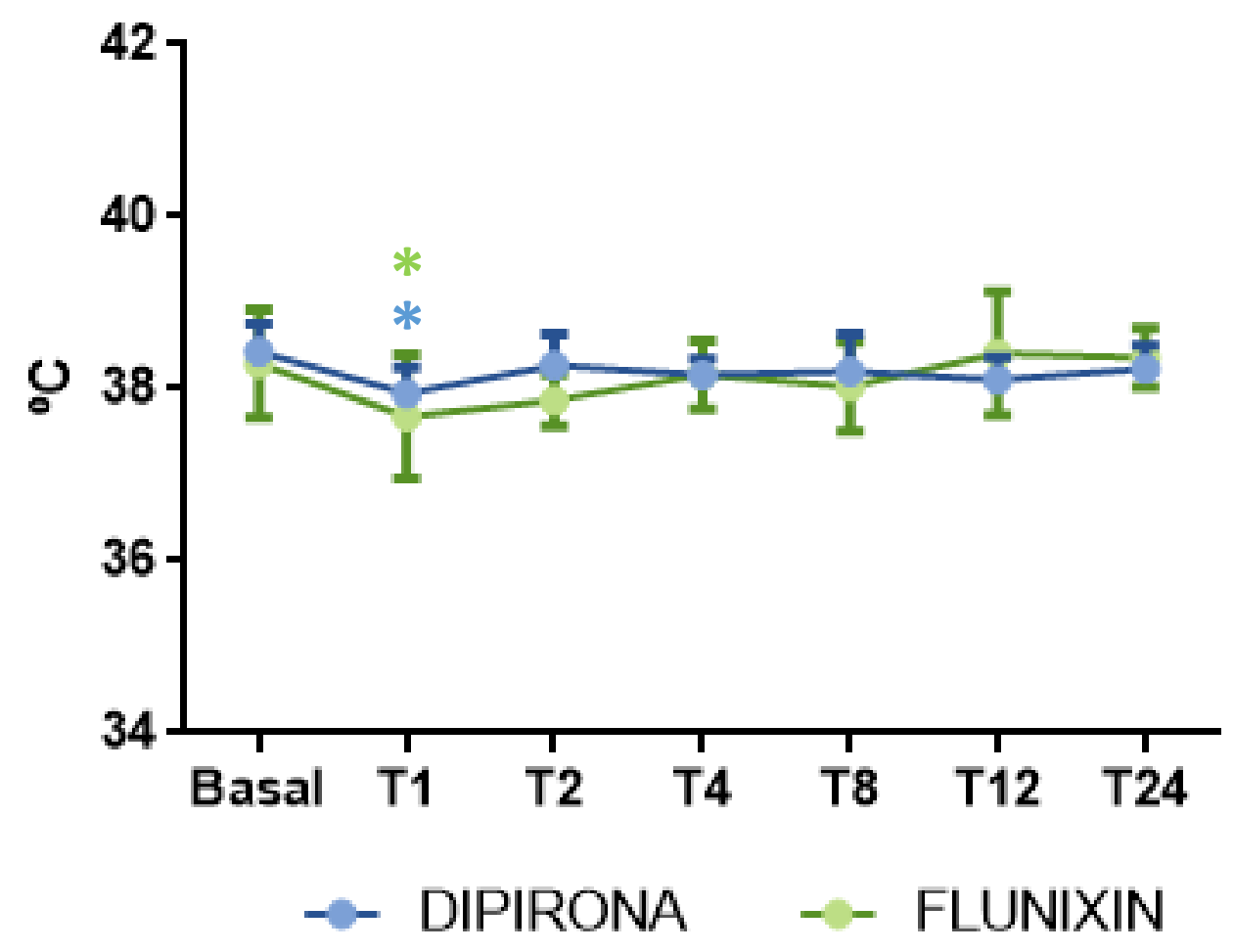

Fonte: (SANTOS, R. S. T. dos, 2017).

Legenda: ${ }^{\circ} \mathrm{C}$ : graus Celsius; *: valor significativamente diferente de basal; basal: avaliação antes do procedimento anestésico/cirúrgico; T1, T2, T4, T8, T12 e T24: 1, 2, 4, 8, 12 e 24 horas após a administração do protocolo pós-operatório. O grau de significância estabelecido para os testes estatísticos foi de $5 \%(P<0,05)$. 


\subsubsection{EAV}

Não houve diferença estatística entre os grupos. Dentro dos grupos (entre momentos) houve aumento significativo entre Basal e T12 no GD ( $P=0,0466)$, no entanto nenhum animal atingiu o valor de resgate (Gráfico 08 e Apêndice I).

Gráfico 08 - Gráfico Boxplot de médias \pm desvio padrão dos escores de dor, em centímetros, obtidos pela Escala Analógica Visual (EAV) de 15 cavalos distribuídos aleatoriamente nos 2 grupos do estudo durante os momentos avaliados na fase 02- FMVZ-USP - São Paulo - 2017.

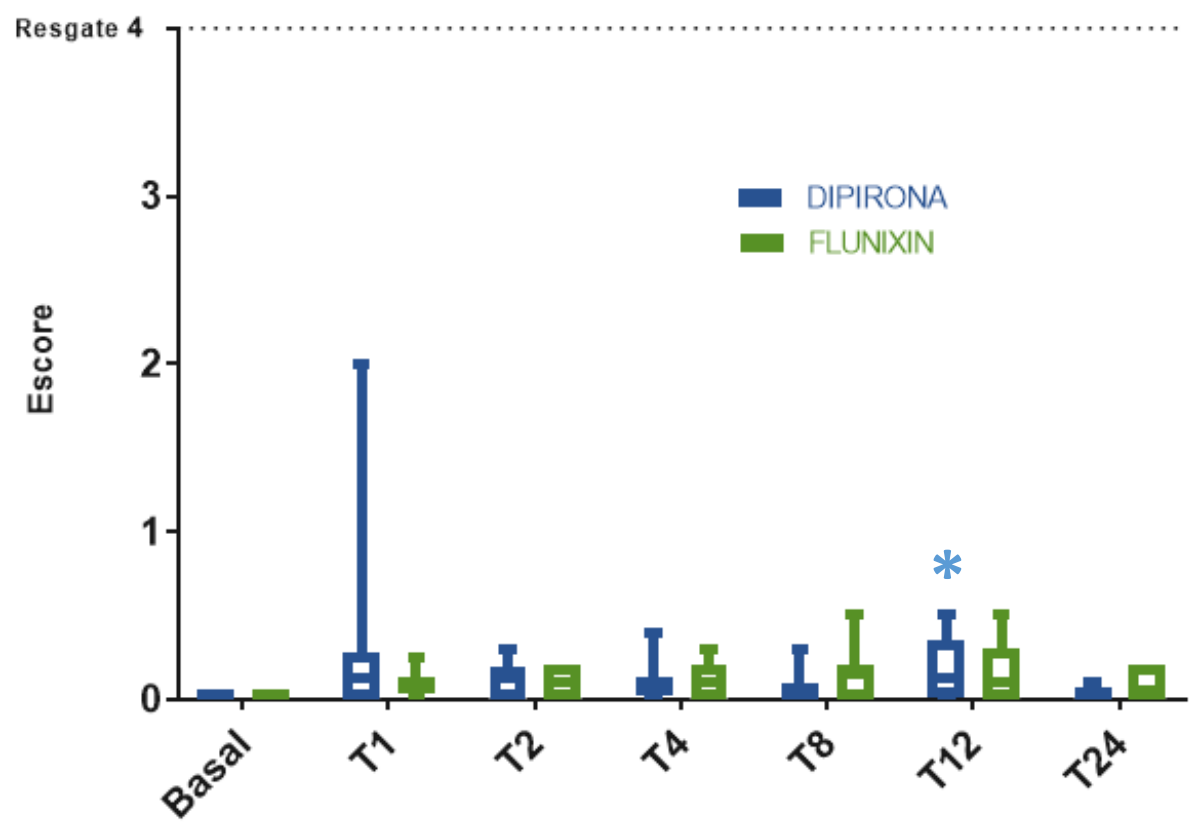

Fonte: (SANTOS, R. S. T. dos, 2017).

Legenda: *: valor significativamente diferente de basal; basal: avaliação antes do procedimento anestésico/cirúrgico; T1, T2, T4, T8, T12 e T24: 1, 2, 4, 8, 12 e 24 horas após a administração do protocolo pós-operatório. O grau de significância estabelecido para os testes estatísticos foi de $5 \%(P<0,05)$. 


\subsubsection{ESCALA MULTIDIMENSIONAL DA UNESP-BOTUCATU}

Não houve diferença estatística entre os grupos ou entre os momentos avaliados. A pontuação máxima desta escala é de 17 pontos, para este trabalho considerou-se a pontuação de no mínimo 6 na escala como indicativa de resgate analgésico. Um animal do GF apresentou pontuação 6 no basal, porém foi atribuído à agitação e não a sintomas dolorosos, pois o basal era aferido antes do procedimento cirúrgico. Nenhum animal necessitou de resgate durante o período avaliado. (Gráfico 9, Apêndice J e Anexo A).

Gráfico 09 - Gráfico Boxplot de médias \pm desvio padrão dos escores de dor obtidos pela Escala Multidimensional da UNESP-Botucatu de 15 cavalos distribuídos aleatoriamente nos 2 grupos do estudo durante os momentos avaliados na fase 02- FMVZ-USP - São Paulo - 2017.

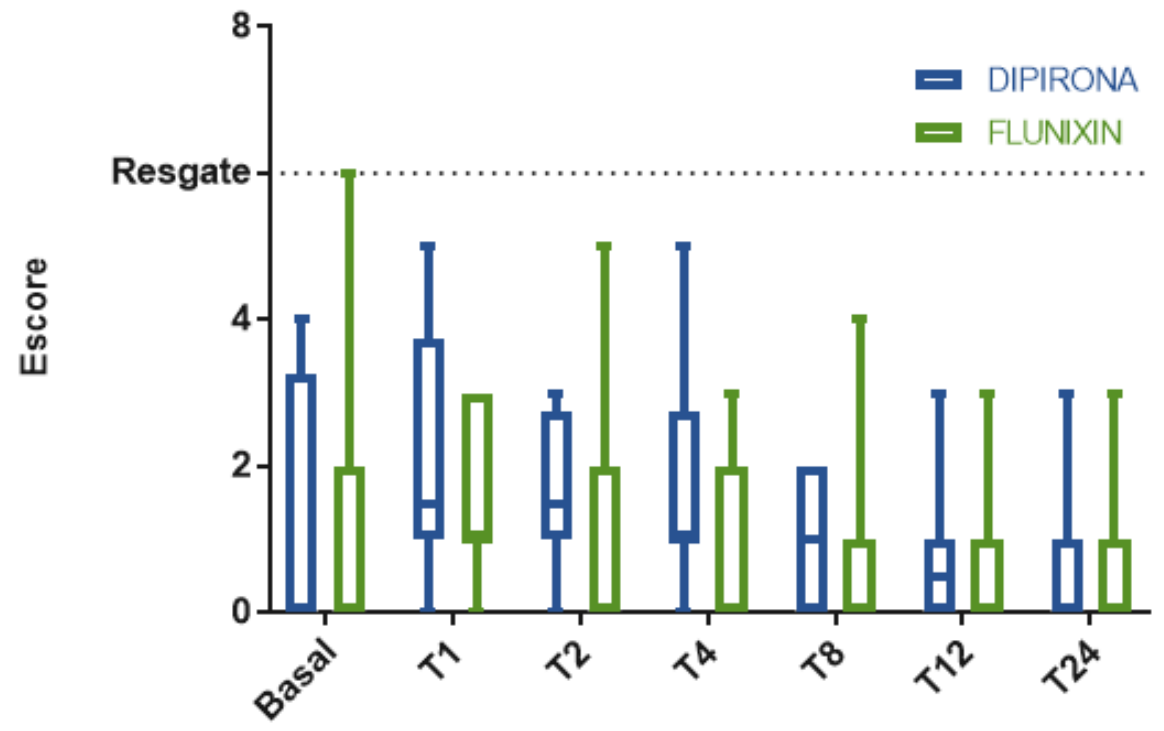

Fonte: (SANTOS, R. S. T. dos, 2017).

Legenda: Basal: avaliação antes do procedimento anestésico/cirúrgico; T1, T2, T4, T8, T12 e T24: $1,2,4,8,12$ e 24 horas após a administração do protocolo pós-operatório. O grau de significância estabelecido para os testes estatísticos foi de $5 \%(P<0,05)$. 


\subsubsection{ESCALA MULTIDIMENSIONAL DE EXPRESSÕES FACIAIS PARA AVALIAÇÃO DE DOR EM CAVALOS (FACIAL)}

Não houve diferença estatística entre os grupos ou entre os momentos avaliados. A pontuação máxima desta escala é de 12 pontos, para este trabalho considerou-se a pontuação de no mínimo 4 na escala como indicativa de resgate analgésico. Nenhum animal necessitou de resgate durante o período avaliado. (Gráfico 10, Apêndice K e Anexo B).

Gráfico 10 - Gráfico Boxplot médias \pm desvio padrão dos escores de dor obtidos pela Escala Facial de 15 cavalos distribuídos aleatoriamente nos 2 grupos do estudo durante os momentos avaliados na fase 02- FMVZ-USP - São Paulo - 2017.

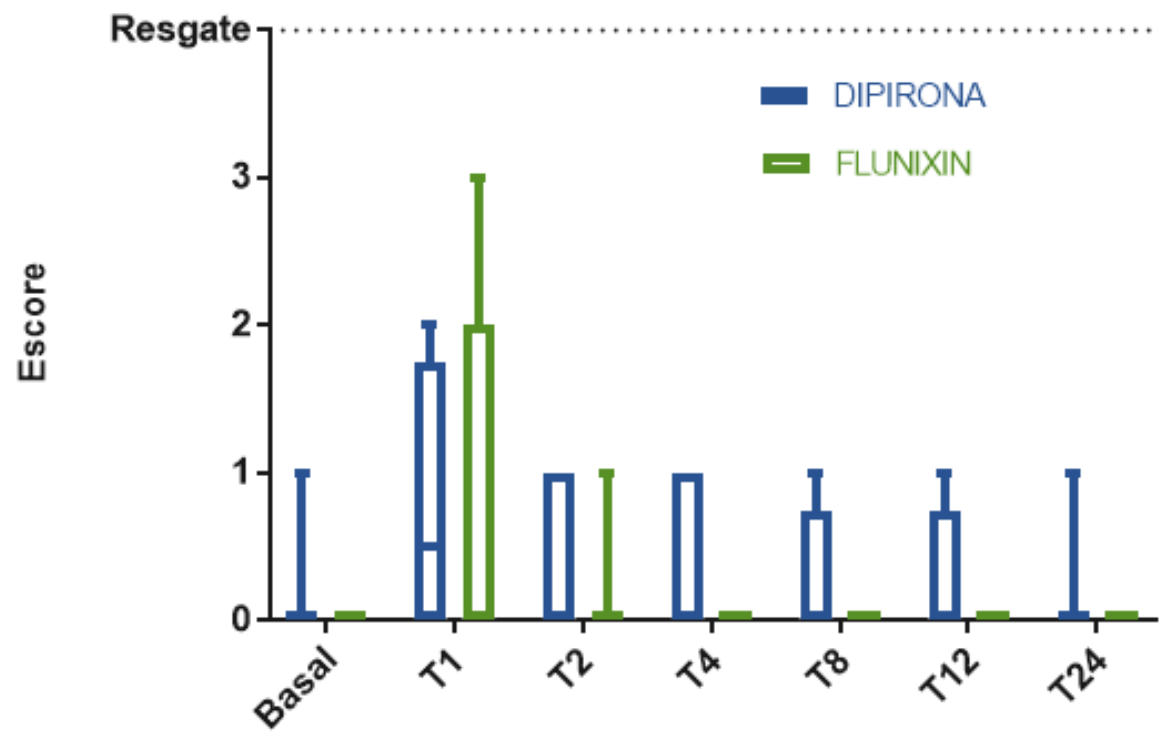

Fonte: (SANTOS, R. S. T. dos, 2017).

Legenda: Basal: avaliação antes do procedimento anestésico/cirúrgico; T1, T2, T4, T8, T12 e T24: $1,2,4,8,12$ e 24 horas após a administração do protocolo pós-operatório. O grau de significância estabelecido para os testes estatísticos foi de $5 \%(P<0,05)$. 


\subsubsection{SEDAÇÃO}

Não houve diferença estatística significativa entre os grupos ou entre os momentos avaliados. O momento de maiores escores de sedação foi em T1, como esperado, pois era o momento bem próximo da recuperação anestésica. (Gráfico 11, Apêndice L e Anexo D).

Gráfico 11 - Gráfico Boxplot médias \pm desvio padrão dos escores de sedação obtidos pela Escala de Sedação de 15 cavalos distribuídos aleatoriamente nos 2 grupos do estudo durante os momentos avaliados na fase 02- FMVZ-USP - São Paulo - 2017.

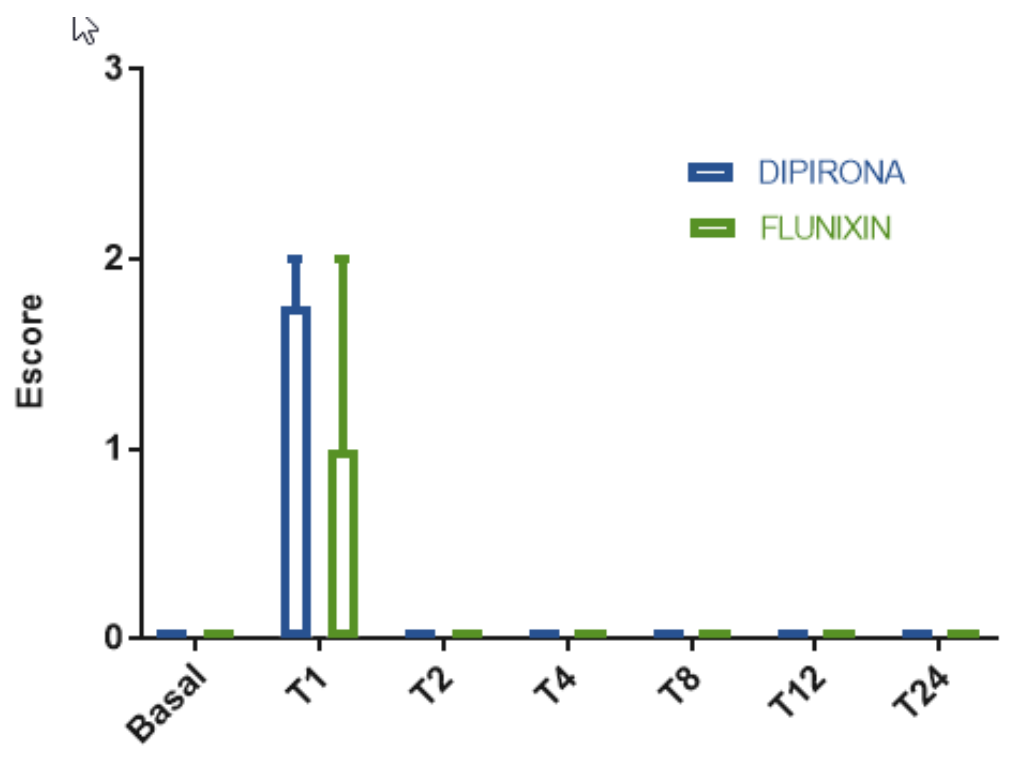

Fonte: (SANTOS, R. S. T. dos, 2017).

Legenda: Basal: avaliação antes do procedimento anestésico/cirúrgico; T1, T2, T4, T8, T12 e T24: $1,2,4,8,12$ e 24 horas após a administração do protocolo pós-operatório. O grau de significância estabelecido para os testes estatísticos foi de $5 \%(P<0,05)$. 


\subsubsection{ATAXIA}

Não houve diferença significativa entre os grupos ou entre os momentos avaliados. Também houve aumento não significativo nos escores em T1, como esperado devido à proximidade do período de recuperação pós-anestésica. (Gráfico 12, Apêndice M e Anexo D).

Gráfico 12 - Gráfico Boxplot médias \pm desvio padrão dos escores de sedação obtidos pela Escala de Sedação de 15 cavalos distribuídos aleatoriamente nos 2 grupos do estudo durante os momentos avaliados na fase 02- FMVZ-USP - São Paulo - 2017.

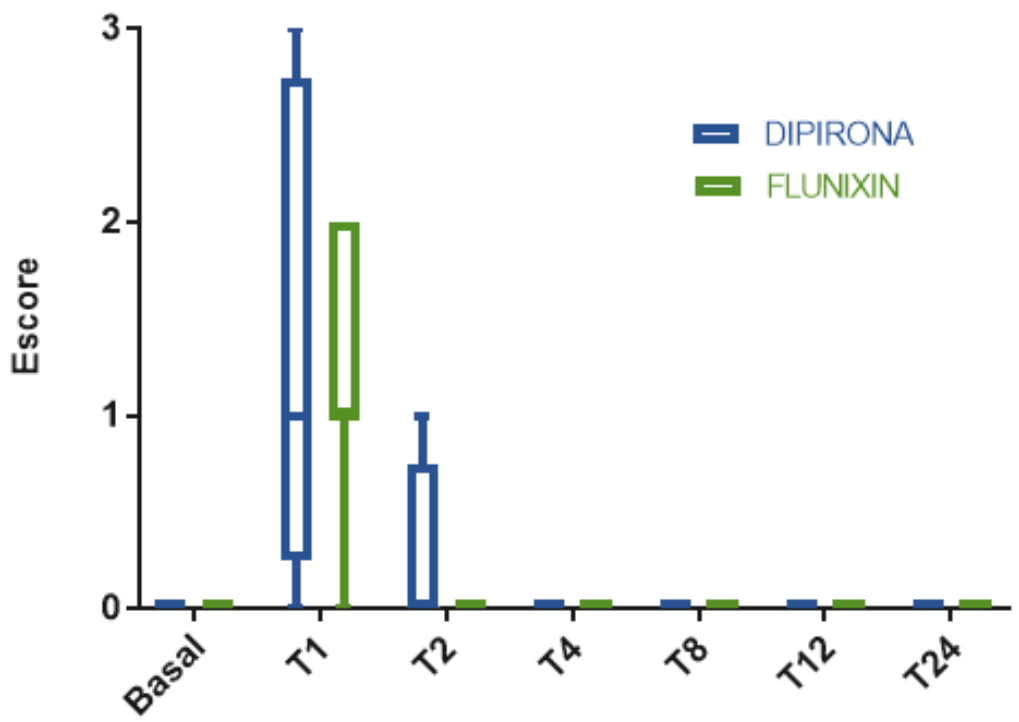

Fonte: (SANTOS, R. S. T. dos, 2017).

Legenda: Basal: avaliação antes do procedimento anestésico/cirúrgico; T1, T2, T4, T8, T12 e T24: 1, 2, 4, 8, 12 e 24 horas após a administração do protocolo pós-operatório. O grau de significância estabelecido para os testes estatísticos foi de $5 \%(P<0,05)$. 


\subsubsection{RESGATE ANALGÉSICO}

Nenhum animal necessitou de resgate analgésico durante o tempo de avaliação do estudo.

\subsubsection{EFEITOS ADVERSOS}

Não foram verificados quaisquer efeitos adversos em decorrência do emprego da dipirona ou do flunixin meglumine nos animais do estudo. 


\section{DISCUSSÃO}

No presente trabalho, como indicado por vários estudos em que AINES e/ou dipirona são suficientes para o tratamento de dor leve à moderada, a dipirona mostrou-se tão eficaz para analgesia pós orquiectomia eletiva em cavalos quanto o AINE tradicionalmente utilizado nesta espécie, o flunixin meglumine. Porém, foi demonstrada de maneira inesperada que a dipirona tem, assim como o flunixin, o poder de redução na concentração de $\mathrm{TXB}_{2}$, ou seja, demonstrando sua ação em inibir COX-1. Não foi revelada, porém, inibição de $\mathrm{PGE}_{2}$ tanto pela dipirona como pelo flunixin. Apesar disso, os animais que participaram do presente trabalho não apresentaram clinicamente quaisquer efeitos deletérios associados ao bloqueio COX-1.

A dor, segundo a IASP (Associação Internacional para o Estudo da Dor), é uma experiência sensorial e emocional desagradável, relacionada à lesão tecidual real ou potencial. A dor surge por meio da ativação de diversos mecanismos específicos de receptores e vias neurais por estímulos nocivos que por sua vez prejudicam o tecido ou pelo menos têm o potencial de prejudicá-lo. A percepção da dor é evidenciada por alterações comportamentais e/ou biológicas, e trata-se de uma experiência subjetiva que vem acompanhada de sentimentos de medo, ansiedade e pânico (LOESER \& TREEDE, 2008; HELLYER et al., 2013).

Apesar de ser um mecanismo de defesa, se não tratada ou tratada insuficientemente, a dor aguda induz o aparecimento de dor crônica. A Organização Mundial de Saúde (OMS) protocola o tratamento da dor conforme uma escada, na qual quanto mais intensa a dor se torna, mais adições farmacológicas e não farmacológicas este tratamento ganha (SPAIN, 1987). Atualmente existem diversos fármacos utilizados para o tratamento da dor em animais, sendo os opioides e os AINES os mais utilizados (SCHATZMANN, 2002). No presente trabalho, um dos objetivos foi o de comparar a analgesia de dois fármacos utilizados corriqueiramente, quais sejam a dipirona e o flunixin, fármaco muito difundido para tratamento antiálgico em equinos (SELLON et al., 2004; COOK et. al, 2009; TORFS et al., 2009; FOREMAN et al.; 2010; DALLA COSTA et al., 2014; NAYLOR et al., 2014; TAFFAREL et al., 2015).

$\mathrm{Na}$ fase 02 , foram incluídos no estudo cavalos jovens, com escores corporais ideais e saudáveis (sem nenhuma alteração na avaliação clínica e 
exames laboratoriais) para mimetizar o ambiente no qual os procedimentos de esterilização eletiva são comumente realizados nesta espécie. Para sedação foi utilizada detomidina e para a indução anestésica cetamina e diazepam, portanto o mesmo protocolo foi utilizado em todos os animais para limitar os efeitos de variáveis não cirúrgicas no período transoperatório e nas avaliações de dor no pósoperatório. Por se tratarem de procedimentos realizados na sua maioria a campo, foi utilizada lidocaína sem vasoconstrictor como analgesia trans-cirúrgica. Não foi realizada analgesia transoperatória com fármacos injetáveis, pois os mesmos possuem efeito residual, o que atrapalharia a avaliação de dor pós-operatória. Levando-se em consideração o período hábil anestésico da lidocaína de 60-90 minutos (BECKER \& REED, 2006) e que a anestesia local foi realizada com a técnica intratesticular, acredita-se que a analgesia promovida pela lidocaína não influenciou nas avaliações de dor. A sedação proveniente da detomidina também não influenciou nas avaliações de dor devido ao seu tempo hábil anestésico ser em média 40 minutos, o que pôde ser evidenciado pelas tabelas de sedação e ataxia, que não demonstraram diferenças estatisticamente pertinentes quanto ao basal.

Apesar do tramadol ser um opioide considerado de fraca ligação ao receptor $\mu$, este foi escolhido como medicação de resgate devido à diversas comprovações em literatura em que há boa analgesia na espécie equina para diversos tipos de dor (KNYCH et al., 2012; GUEDES et al., 2013; KNYCH et al., 2013; GUEDES et al., 2016; KNYCH et al, 2016).

O diagnóstico da dor é algo extremamente subjetivo. Para minimizar a subjetividade, criaram-se escalas espécie-específicas e direcionadas para o tipo de dor na qual o animal está acometido (BUSIÈRES et al., 2008; VAN LOON et al., 2010; SUTTON et al., 2013; DALLA COSTA et al., 2014; TAFFAREL et al., 2015; VAN LOON \& VAN DIERENDONCK, 2015; GRAUW \& VAN LOON, 2016). Porém, o uso isolado de uma escala de dor pode ser insuficiente para avaliarmos a dor de um cavalo, pois algumas escalas podem pontuar parâmetros e comportamentos não específicos apenas para demonstração de dor já que mudanças nas variáveis fisiológicas e neuroendócrinas (adrenalina, noradrenalina, cortisol e $\beta$-endorfinas) que também são consideradas indicativos de dor (OLIVEIRA et al., 2011), podem ser influenciadas por outros fatores, como estresse (SMITH et al., 1996).

Portanto, no presente trabalho utilizou-se duas escalas multidimensionais (DALLA COSTA et al., 2014 e TAFFAREL et al., 2015) e uma escala 
unidimensional (EAV) para avaliação da dor nos animais da fase 02 . Correlacionou-se também os escores de dor com a escala de sedação e ataxia que foi adaptada da literatura para melhor se adequar ao presente estudo (TAYLOR et al., 2013) para assim reduzir ao máximo a influência do avaliador no julgamento do grau de analgesia apresentada pelos animais. Nenhum animal necessitou de resgate analgésico, sugerindo que a analgesia promovida pela dipirona seja suficiente para o procedimento de orquiectomia eletiva em cavalos saudáveis, corroborando com a literatura, na qual encontramos pesquisas que descrevem a ação analgésica como sendo satisfatória para 0 procedimento de ovariosalpingohisterectomia (OSH) em gatas (PEREIRA, 2017), OSH em cadelas (Zanuzzo et al., 2015), e inclusive, quando associada ao tramadol, demonstrou melhora na qualidade de vida em cães com dor crônica severa devido ao câncer (FLÔR et al., 2013). Seu mecanismo de ação analgésico tem indícios de ação em receptores canabinóides (ESCOBAR et al., 2012; ROGOSCH et al., 2012; JASIECKA, MAŚLANKA, JAROSZEWSK, 2014), opioidérgicos (TORTORICI \& VANEGAS, 2000; VAZQUEZ et al., 2005), assim como alguns indicativos de ação na via das ciclooxigenases (BIANCHI PORRO et al., 1996; CHANDRASEKHARAN et al., 2002; HINZ et al., 2007; PIERRE et al., 2007; KANASHIRO et al., 2009; MUÑOZ et al., 2010).

Dalla Costa et al. (2014) demonstraram em seu estudo que escala de expressões faciais é específica e sensível o suficiente para diagnosticar dor pós orquiectomia em equinos saudáveis, assim como estudos anteriores de escalas faciais em outras espécies, como a escala facial para neonatos humanos (GRUNAU \& CRAIG, 1987), crianças (KOHUT et al., 2012), ovelhas (GUESGEN et al., 2016), ratos (LANGFORD et al., 2010; SOTOCINAL et al., 2011), dentre outras. Em seu trabalho, Dalla Costa e seus colaboradores (2014) iniciaram a avaliação da dor apenas 8 horas após a recuperação anestésica, para minimizarem-se os efeitos dos anestésicos, como por exemplo, a sedação. No presente trabalho, as avaliações da dor iniciaram com apenas uma hora após a administração do protocolo analgésico, muitas vezes sendo muito próximo ao momento em que o animal ficava em estação. Porém, para reduzir o viés, utilizamos uma adaptação da escala de sedação e ataxia descrita por Taylor e seus colaboradores (2013) para avaliar se o comportamento apresentado era devido à sedação e ataxia ou à analgesia promovida pelo fármaco em questão. Também, utilizar a escala de dor 
apenas oito horas após o procedimento cirúrgico pode ser questionável já que são nas primeiras horas de pós-operatório que a inflamação e a dor estão mais exacerbadas. Por questões éticas, nenhum animal deixou de receber analgesia pós-operatória.

Ao utilizar a FC como uma das pontuações para a avaliação da dor em equinos, a escala de Taffarel e colaboradores (2015) utiliza a variação frente ao basal, e não simplesmente o valor numérico, levando em consideração que cada animal tem o seu basal de parâmetros fisiológicos, dentro do esperado para a espécie, assim como a interferência de diversas variáveis nesta (SMITH et al., 1996). Juntamente com a FC, esta escala correlaciona também alterações comportamentais e resposta frente à palpação da ferida, tendo-se em vista que de acordo com Bley e seus colaboradores (2004) a palpação da ferida cirúrgica também pode ocasionar, ou melhor, evidenciar a resposta de dor.

Sabe-se que os AINES bloqueiam as enzimas COX, sendo que alguns agentes bloqueiam especificamente a COX-2. A dipirona, em contrapartida, não tem seu mecanismo de ação completamente esclarecido, principalmente na espécie equina. Acredita-se que a dipirona possa ser bloqueadora de uma nova enzima, denominada COX-3, cuja presença já foi relatada no córtex cerebral de cães, e em cérebro e coração de humanos. Aparentemente a COX-3 seria inibida por agentes analgésicos e antipiréticos, como por exemplo a dipirona e alguns AINES (WARNER \& MITCHELL, 2004). Hinz e seus colaboradores (2007) também relataram ação em COX-3 da dipirona em estudo ex vivo no homem, assim como o estudo de Chandrasekharan e colaboradores (2002), que também encontraram genes de expressão para COX-3 no córtex cerebral e coração de humanos e ainda no tecido cerebral de cães, e devido a este efeito, foram relatadas alterações adversas gástricas em camundongos (MUÑOZ et al., 2010). Estudos em ratos também demonstraram efeitos gástricos deletérios com o uso da dipirona (SANCHEZ et al., 2002a; SANCHEZ et al., 2002b), ao contrário de outros indícios em literatura que comprovaram a segurança gastrointestinal deste fármaco (BIANCHI PORRO et al.,1996; BATU \& EROL, 2007; IMAGAWA et al, 2011; YILDRIM et al., 2013).

Assim como nos trabalhos de Brideau et al. (2001), Beretta et al. (2005), Duz et al. (2015) e Burkett et al. (2016) que avaliaram o bloqueio de COX promovido pelo flunixin e outros fármacos, aventou-se a possibilidade da avaliação se a 
dipirona teria o potencial de inibir COX-1 e COX-2 em cavalos, assim como demonstrado em humanos (HINZ et al., 2007) e ratos (PIERRE et al., 2007).

A avaliação do bloqueio da COX-1 COX-2 pode ser indiretamente avaliado mensurando-se as concentrações de $\mathrm{TXB}_{2}$ e $\mathrm{PGE}_{2}$. Seguindo a metodologia de Duz et al. (2015) foi possível constatar que a concentração de $\mathrm{TXB}_{2}$ variou nitidamente em todos os tempos avaliados em relação ao basal, principalmente em T2 (tempo em que houve bloqueio mais acentuado), demonstrando provavelmente grande inibição da COX-1 tanto pela dipirona, como pelo flunixin. O estudo de Bianchi Porro e colaboradores (1996) em voluntários humanos também evidenciou inibição COX-1 pela dipirona. A inibição COX-1 pelo flunixin em cavalos já foi demonstrada por diversos estudos (BRIDEAU et al., 2001; BERETTA et al., 2005; DUZ et al., 2015; BURKETT et al., 2016).

Hinz et al. (2007) obtiveram inibição máxima de 94\% de COX-1 e 87\% de COX2 na dose de 500mg e inibição de 97\% de COX-1 e 94\% de COX-2 para dose de $1000 \mathrm{mg}$ de dipirona ex vivo em humanos utilizando avaliação semelhante de $\mathrm{TXB}_{2}$ e $\mathrm{PGE}_{2}$. A porcentagem de inibição do presente trabalho foi calculada de maneira análoga à descrita por Hiz et al. (2007), sempre levando em consideração o valor basal para comparar a inibição nos tempos posteriores. Os valores aqui obtidos foram da mesma magnitude de inibição COX-1, sobretudo em T2, onde a média de inibição de $\mathrm{TXB}_{2}$ da dipirona foi de $97,76 \% \pm 2,02$, enquanto a inibição do grupo flunixin foi em média 99,98\% $\pm 0,02$. Como evidenciado por Knych et al. (2015), o flunixin meglumine tem maior inibição COX-1 após 2 horas de administração do fármaco. Por outro lado, não houve inibição de $\mathrm{PGE}_{2}$ pela dipirona, contradizendo os resultados de Hinz et al. (2007), porém ratificando o estudo de Pierre e colaboradores (2007), que concluem que o efeito dos metabólitos da dipirona MAA e AA seriam de redução do ciclo catalítico da COX por meio de doação de elétrons, e não simplesmente a competição com o ácido araquidônico. Todavia, no estudo de Kanashiro et al. (2009) houve ação inibitória da produção de $\mathrm{PGE}_{2}$ pela dipirona em ratos. A razão de tal diferença necessita ser elucidada.

Já no trabalho de Duz et al. (2015), realizado em cavalos submetidos a cirurgia eletiva, o flunixin demonstrou grande inibição de COX-1, porém não houve diferença entre os grupos flunixin e firocoxibe quanto à inibição de COX-2: apesar de não terem comprovado ação em COX-2, ambos demonstraram efeitos semelhantes na concentração de $\mathrm{PGE}_{2}$ plasmática nas primeiras 24 horas após a 
cirurgia, porém não significativo para concluir como inibição, concluindo então que, devido à ação semelhante, acreditam que ambos os fármacos impediram o aumento da inflamação, porém, como não realizaram grupo controle apenas com procedimento cirúrgico, não pode-se afirmar com absoluta certeza. Na presente pesquisa, a dipirona foi menos efetiva no controle da inflamação do que o flunixin meglumine, apesar de não serem evidenciadas diferenças estatísticas de inibição de COX-2. Semelhante ao trabalho de Duz et al. (2015), pode-se inferir que o flunixin impediu o grande aumento de COX-2. Porém, é necessário a realização de um grupo controle sem a utilização de quaisquer fármacos, para assim, quantificarmos a faixa normal de aumento COX-2 devido ao estímulo realizado pelo LPS.

A não inibição da COX-2 pelo flunixin encontrada no presente estudo contraria os resultados da literatura mundial em que o flunixin meglumine é um AINE não seletivo COX-2, porém com ação em ambas isoformas COX (BRIDEAU et al., 2001; BERETTA et al., 2005; KNYCH et al., 2015; BURKETT et al., 2016).

Beretta et. al (2005) compararam o efeito de inibição de COX-1 e COX-2 in vitro dos quatro principais AINES utilizados em cavalos: fenilbutazona, flunixin meglumine, carprofeno e meloxicam. O flunixin demonstrou a maior atividade em inibir COX-1, porém teve atividade inibitória satisfatória em COX-2. Já a fenilbutazona apareceu como o fármaco que exerce menor efeito anti-COX-2, deixando claro sua não seletividade e grande potencial de indução de efeitos deletérios associados aos AINES. Neste estudo ainda, o meloxicam obteve maior inibição de COX-2, seguido do carprofeno, e como conclusão os autores acreditam que o meloxicam e o carprofeno sejam os mais seletivos e recomendados deste grupo de AINES para COX-2 em cavalos. Contrariando o estudo de Brideau e seus colaboradores (2001) que em um estudo também in vitro, avaliaram a inibição de COX por meio de diversos anti-inflamatórios, e concluíram que o carprofeno não exerce inibição em COX-2 nos equinos, constatando ainda que a fenilbutazona e o flunixin meglumine seriam os mais potentes inibidores COX-1 e COX-2 em cães e equinos.

A dipirona além de promover grande inibição de COX-1, mostrou-se no presente trabalho uma opção de fármaco para tratamento de dor pós-operatória leve à moderada suficiente para equinos. Devido à maior probabilidade de gastrite ou ulcerações gastrointestinais apresentada pela espécie equina com o uso de 
AINES tradicionais, a dipirona pode ser uma opção tão válida quanto AINES seletivos COX-2 para o tratamento destes animais, com menores impactos negativos no trato gastrointestinal, com a vantagem de ter o custo do tratamento inferior e de mais fácil acesso. Entretanto, como limitações ao presente estudo, e para que esta indicação seja de fato verdadeira, confrontou-se com a dificuldade em realização de avaliação gastroscópica frente ao uso prolongado da dipirona por impossibilidade de utilização do videoendoscópio que poderia comprovar que a ação COX-1 ex vivo aqui comprovada, estaria associada a efeitos adversos gástricos. Portanto, faz-se complementar à esta pesquisa, a avaliação da mucosa gástrica, assim como avaliações hematológicas com o uso prolongado da dipirona, antes que este fármaco possa ser indicado como terapia pós-operatória para procedimentos que cursam com dor leva à no máximo moderada. No entanto, acreditamos que a dipirona não está indicada para situações que envolvam grandes inflamações. 


\section{CONCLUSÕES}

A dipirona mostrou analgesia adequada para o cavalo tendo-se em vista que controlou de forma tão efetiva quanto o flunixin meglumine a dor pós-operatória promovida pela castração.

Foi possível concluir ainda que tanto a dipirona quanto o flunixin meglumine inibem de maneira marcante a ação da COX-1, fato evidenciado pela redução da concentração de tromboxano $\mathrm{B}_{2}$. Por outro lado estes fármacos não demonstraram ação significativa em COX-2. 


\section{REFERÊNCIAS BIBLIOGRÁFICAS}

BASAK, G. W.; DROZD-SOKOŁOWSKA, J.; WIKTOR-JEDRZEJCZAK, W. Update on the incidence of metamizole sodium-induced blood dyscrasias in Poland. The Journal of International Medical Research, v. 38, n. 4, p. 1374-1380, Jul.-Aug. 2010.

BATU, O. S.\& EROL, K. The effects of some nonsteroidal anti-inflammatory drugs on experimental induced gastric ulcers in rats. Inflammopharmacology, v. 15, n.6, p. 260-265, Dec. 2007.

BECKER, D. E. \& REED, K. L.. Essentials of Local Anesthetic Pharmacology.

BERETTA, C.; GARAVAGLIA, G.; CAVALLI, M. COX-1 and COX-2 inhibition in horse blood by phenylbutazone, flunix, carprofen and meloxicam: $\mathrm{Na}$ in vitro analysis. Pharmacological research. N. 52, p. 302-306. 2005.

BIANCHI PORRO, G.; ARDIZZONE, S.; PETRILLO, M.; CARUSO, I.; MONTRONE, F. Endoscopic assessment of the effects of dipyrone (metamizol) in comparison to paracetamol and placebo on the gastric and duodenal mucosa of healthy adult volunteers. Digestion. N.57, p.186-190. 1996.

BLEY, C. R.; NEIGER, G.; BUSATO, A.; SCHATZMANN, U. Comparison of perioperative racemic methadone, levo-methadone and dextromoramide in cats using indicators of post-operative pain. Veterinary Anaesthesia and Analgesia. v. 31, n. 3, p. 175-182, Julho 2004.

BRASIL. Instituto Brasileiro de Geografia e Estatística. Séries estatísticas \& Séries históricas. Efetivo dos rebanhos por tipo de rebanho 1974-2014. Rio de Janeiro, RJ, 2017. 
BURKETT, B. N.; THOMASON, J. M.; HURDLE, H. M.; WILLS, R. W.; FONTENOT, R. L. Effects of Firocoxib, Flunixin Meglumine, and Phenylbutazone on Platelet Function and ThromboxaneSynthesis in Healthy Horses. Veterinary Surgery. Vol. 45, p. 1087-1094. 2016.

BUSSIÈRES, G.; JACQUES, C.; LAINAY, O.; BEAUCHAMP, G.; LEBLOND, A.; CADORÉ, J. L.; DESMAIZIÈRES, L. M.; CUVELLIEZ, S. G.; TRONCY, E. Development of a composite orthopaedic pain scale in horses. Research in Veterinary Science. Vol. 85, p. 294-306. 2008.

CARDOZO, L. B. Avaliação da eficácia analgésica e resposta inflamatória em cães tratados com metadona ou tramadol e submetidos a osteotomias corretivas. 2013. 72 f. Tese (Doutorado - Programa de Clínica Cirúrgica Veterinária) - Faculdade de Medicina Veterinária e Zootecnia, Universidade de São Paulo, São Paulo, 2013.

CHANDRASEKHARAN, N. V.; DAI, H.; ROOS, K. L.; EVANSON, N. K.; TOMSIK, J.; ELTON, T. S.; SIMMONS, D. L. COX-3, a cyclooxygenase-1 variant inhibited by acetaminophen and other analgesic/antipyretic drugs: cloning, structure, and expression. Proceeding of the National Academy of Sciences of USA, v. 99, n. 21, p. 13926-13931, Out. 2002.

ChATTERJEe, A., CHATtERJEE, S., DAS, S., SAHA, A., CHATTOPADHYAY, S., BANDYOPADHYAY, S. K. Ellagic acid facilitates indomethacin-induced gastric ulcer healing via COX-2 up-regulation. Acta Biochimica et Biophysica Sinica. 2012. n. 44, p. 565-576.

COHEN, O.; ZYLBER-KATZ, E.; CARACO, Y.; GRANIT, L.; LEVY, M. Cerebrospinal fluid and plasma concentrations of dipyrone metabolites after a single 
oral dose of dipyrone. European Journal of Clinical Pharmacology, v. 54, n. 7, p. 549-553, Sep. 1998.

COLE, CYNTHIA. Pharmacology of nonsteroidal anti-inflammatory drugs. In: COLE, C.; BENTZ, B.; MAXELL, L. Equine Pharmacology. 1a edição. Ed. John Wiley \& sons, inc. 2015.

COOK, V. L. AND BLIKSLAGER, A. T. The use of nonsteroidal anti-inflammatory drugs in critically ill horses. Journal of Veternary Emergency and Critical Care. V. 25, n. 01, pp. 76-88. 2015.

COOK, V. L.; MEYER, C. T.; CAMPBELL, N. B; BLIKSLAGER, A. T. Effect of firocoxib or flunixin meglumine on recovery of ichemic-injured equine jejunum. American Journal Veterinary Research. Vol. 70. N 08, pp. 992-1000. 2009.

DALLA COSTA, E.; MINERO, M.; LEBELT, D.; STUCKE, D.; CANALI, E.; LEACH, M. C. Development of the Horse Grimace Scale (HSG) as a pain assessment tool in horses undergoing routine castration. Plos One. Vol. 9, n. 3. 2014.

DIONNE, R. M.; VRINS, A.; DOUCET, M. Y.; PARE, J.. Gastric Ulcers in Standardbred Racehorses: Prevalence, Lesion Description, and Risk Factors. Journal of Veterinary Internal Medicine. N. 17, pp. 218-222. 2003.

DOMíNGUEZ-RAMÍREZ, A. M.; CORTS-ARROYO, A. R.; Y de la PEÃN, M. H.; LÓPEZ, J. R.; LÓPEZ-MUÑOZ, F. J. Effect of metamizol on morphine pharmacokinetics and pharmacodynamics after acute and subchronic administration in arthritic rats. European Journal of Pharmacology, v. 645, n. 1-3, p. 94-101, Out. 2010. 
DUJARDIN, C.L. \& VAN LOON, J.P. Pain recognition and treatment in the horse: A survey of equine veterinarians in The Netherlands and Belgium. Diergeneeskunde Journal. Vol. 136, p. 715-724. 2011.

DUZ, M.; PARKIN, T. D.; CULLANDER, R. M.; MARSHALL, J. F. Effect of flunixin meglumine and firocoxib on ex vivo cyclooxygenase activity in horses undergoing elective surgery. American Journal of Veterinary Research. Vol. 76, n. 03. P. 208-215. Março, 2015.

EDWARDS, J. E.; MESEGUER, F.; FAURA, C. C.; MOORE, R. A.; MCQUAY, H. J.; Single-dose dipyrone for acute postoperative pain. Cochrane Database of Systematic Reviews, n. 9, Set. 2010.

EPSTEIN, M.; RODAN, I.; GRIFFENHAGEN, G.; KADRLIK, J.; PETTY, M.; ROBERTSON, S.; SIMPSON, W. 2015 AAHA/AAFP Pain Management Guidelines for Dogs and Cats. Journal of the American Animal Hospital Association, v. 51, n. 2, p. 67-84, 2015.

ESCOBAR, W.; RAMIREZ, K.; AVILA, C.; LIMONGI, R.; VANEGAS, H.; VAZQUEZ, E. Metamizol, a non-opioid analgesic, acts via endocannabinoids in the PAG-RVM axis during inflammation in rats. European Journal of Pain, v. 16, n. 5, p. 676-689, May. 2012.

FANTONI, D. T.; MASTROCINQUE, S. Fisiopatologia e controle da dor. In: FANTONI, D. T.; CORTOPASSI, S. R. G. Anestesia em cães e gatos. 1a edição. São Paulo, Brasil: Editora Roca Ltda.. Cap. 31, p. 323-336. 2002.

FEI. Equine Prohibited Substances List CONTROLLED MEDICATION. 2016. Disponível em: http://inside.fei.org/sites/default/files/2017\%20Controlled\%20Medication\%20List 0. pdf. Acessado em 10 de Julho de 2016 
FLÔR, P. B.; YAZBEK, K. V. B.; IDA, K. K.; FANTONI, D. T. Tramadol plus metamizole combine dor not with anti-inflamatory drugs is clinically effective for moderate to severe chronic pain treatment in câncer patients. Veterinary Anaesthesia and Analgesia. Vol. 40, p. 316-327. 2013.

FOREMAN, J. H.; GRUBB, T. L.; INOUE, O. J.; BANNER, S. E.; BALL K. T. Efficacy of single-dose intravenous phenylbutazone and flunixin meglumine before, during and after exercise in an experimental reversible model of foot lameness in horses. Equine Veterinary Journal Supplement. Vol. 38, p.601-605, Nov. 2010. García-MARtíneZ, J. M.; VARA, J. A. F.; LAStRes, P.; BeRnABÉU, C.; BETÉS, P. O.; MARTíN-PÉREZ, J. Effect of metamizol on promyelocytic and terminally differentiated granulocytic cells. Comparative analysis with acetylsalicylic acid and diclofenac. Biochemical Pharmacology, v. 65, n. 2, p. 209-217, Jan. 2003.

GERAGHTY, T. E.; LOVE, S.; TAYLOR, D. J.; HELLER, J.; MELLOR, D. J.; HUGHES, K. J. Assessment of subclinical venous catheter-related diseases in horses and associated risk factors. Veterinary Record. V. 164, n. 8, pp. 227-231. 2009.

GIORGI, M.; AUPANUN, S.; LEE, H. -K.; POAPOLATHEP, A.; RYCHSHANOVA, R.; VULLO, C.; FAILLACE, V.; LAUS, F. Pharmacokinetic profiles of the active metamizole metabolites in healthy horses. Journal of Veterinary Pharmacology and Therapeutics. N. 40, p. 165-171.2016.

GIORGI, M.; DE VITO, V.; KI LEE, H.; LAUS, F.; KOWALSKI, C.; FAILLACE, V.; BURMANCZUK, A.; VULLO, C. Pharmacokinetic investigations of the marker active metabolite-4-methylamino-antipyrin after intravenous and 
intramuscular injection of metamizole in healthy sheep. Small ruminant Research. N.132, pp. 143-146. 2015.

GRAUW, J. C. \& VAN LOON, J. P. A. M. Systematic pain assessment in horses. The Veterinary Journal. N. 209, p. 14-22. 2016.

GRUNAU, R. V.; CRAIG, K. D. Pain expression in neonates: facial action and cry. Pain. Vol. 28, n.3, p.395-410. Março 1987.

GUEDES, A. G. P.; KNYCH, H. K.; HOOD, D. Plasma concentrations, analgesic and physiological assessments in horses with chronic laminitis treated with two doses of oral tramadol Equine Veterinary Journal. Vol. 48, p. 528-531. 2016.

GUEDES, A. G. P.; KNYCH, H. K.; SOARES, J. H. N.; BROSNAN, R. J. Pharmacokinetics and physiological effects of repeated oral administrations of tramadol in horses. Journal of Veterinary Pharmacology Therapy. Vol. 37, p. 269-278. 2013.

GUESGEN, M. J.; BEASOLEIL, N. J.; LEACH, M.; MINOT, E. O.; STEWART, M.; STAFFORD, K. J. Coding and quantification of a facial expression. For pain in lambs. Behavioural Processes. N 132, p.49-56. 2016.

GULMEZ, S. E.; CELIK, G.; MISIRLIGIL, Z.; TULUNAY, F. C. Dipyrone improves small airway function in asthmatic patients with moderate obstruction. Journal of Investigational of Allergology \& Clinical Immunology, v. 17, n. 4, p. 242-248, 2007.

HELLYER, P. W.; ROBERTSON, S. A.; FAILS, A. D. Dor: conceitos e manejo. In: TRANQUILLI, W. J.; THURMON, J. C.; GRIMM, K. A. LUMB \& JONES Anestesiologia e Analgesia Veterinária. $4^{a}$ edição. São Paulo, Brasil: Editora Roca Ltda., 2013. Cap.03, p. 38-66. 
HINZ, B.; CHEREMINA, O.; BACHMAKOV, J.; RENNER, B.; ZOLK, O.; FROMM, M. F.; BRUNE, K.. Dipyrone elicits substantial inhibition of peripheral cyclooxygenases in humans: new insights into the pharmacology of an old analgesic. The FASEB Journal. Vol 21, pp.2343- 2351. 2007.

HUBER, M.; ANDERSOHN, F.; SARGANAS, G.; BRONDER, E.; KLIMPEL, A.; THOMAE, M.; KONZEN, C.; KREUTZ, R.; GARBE, E. Metamizole-induced agranulocytosis revisited: results from the prospective Berlin Case-Control Surveillance Study. European Journal of Clinical Pharmacology. N. 71, pp. 219227. 2015.

IASP Pain Terminology. International Association for the Study of Pain Committee on Taxonomy. Washington DC, IASP, 2014. Disponível em: <http:// www.iasppain.org/Taxonomy\#Pain >. Acesso em 08/11/2017.

IBAÑEZ, L.; $\quad$ VIDAL, $\quad$ X.; $\quad$ BALLARÍN, $\quad$ E.; $\quad$ LAPORTE, $\quad$ J.R. Agranulocytosis associated with dipyrone (metamizol). European Journal of Clinical Pharmacology. N. 60, pp.821-829. 2005.

IMAGAWA, V. H.; FANTONI, D. T.; TATARUNAS, A. C.; MASTROCINQUE, S.; ALMEIDA, T. F.; FERREIRA, F.; POSSO, I. P. The use of different doses of metamizol for post-operative analgesia in dogs. Veterinary Anaesthesia and Analgesia, v. 38, n. 4, p. 385-393, 2011.

INGWERSEN, W.; FOX, R.; CUNNINGHAM, G.; WINHALL, M. Efficacy and safety of 3 versus 5 days of meloxicam as an analgesic for feline onychectomy and sterilization. Canadian Veterinary Journal, v. 53, n. 3, p. 257-264, 2012.

JASIECKA, A.; MAŚLANKA, T.; JAROSZEWSKI, J. J. Pharmacological characteristics of metamizole. Polish Journal of Veterinary Sciences, v. 17, n. 1, p. 207-14, 2014. 
JR, J. V. P.; RAFFA, R. B.; JR, R. T. Review Article Treating Acute Pain in Light of the Chronification of Pain. Pain Management Nursing, v. 15, n. 1, p. 380-390, Mar. 2014. Disponível em: <http://dx.doi.org/10.1016/j.pmn.2012.07.004>. Acesso em: 20 de Agosto de 2017.

KANASHIRO, A.; PESSINI, A. C.; MACHADO, R. R.; MALVAR, D. C.; AGUIAR, F. A.; SOARES, D. M.; Do VALE, M. L.; De SOUZA, G. E. Characterization and pharmacological evaluation of febrile response on zymosan-induced arthritis in rats. American Journal of Physiology. Regulatory, Integrative and Comparative Physiology, v. 296 ,n. 5, p. R1631-R1640, May, 2009.

KAYE, A. D., CORNETT, E. M., HELANDER, E., MENARD, B., HSU, E., HART, B., BRUNK, A. Na update on nonopioids intravenous or oral analgesic for perioperative pain management. Anesthesiology Clinics. N.35, e. 55-71. 2017.

KNYCH, H. K.; STEFFEY, E. P.; WHITE, A. M.; MCKEMIE, D. S. Effects of age on the pharmacokinetics of tramadol and its active metabolite, O-desmethyltramadol following intravenous administration to foals. Equine Veterinary Journal. Vol. 48, p. $65-71.2016$.

KNYCH, H. K.; ARTHUR, R. M.; MCKEMIE, D. S.; CHAPMAN, N. Pharmacokinetics and effects on thromboxane B2 production following intravenous administration of flunixin meglumine to exercised thoroughbred horses. Journal of Veterinary Pharmacology Therapy. Vol. 38, p. 313-320. 2015.

KNYCH, H. K.; CORADO, C. R.; MCKEMIE, D. S.; SCHOLTZ, E.; SAMS, R. Pharmacokinetics and pharmacodynamics of tramadol in horses following oral administration. Journal of Veterinary Pharmacology Therapy. Vol. 36, p.389-398. 2012 
KNYCH, H. K.; CORADO, C. R.; McKEMIE, D. S.; STEFFEY, E. P. Pharmacokinetics and selected pharmacodynamic effects of tramadol following intravenous administration to the horse. Equine Veterinary Journal. Vol. 45, p.490-496. 2013.

KOHUT, S. A.; RIDDELL, R. P.; FLORA, D. B.; OSTER, H. A longitudinal analysis of the development of infant facial expressions in response to acute pain: Immediate and regulatory expressions. Pain. Vol. 153, n. 12, p.2458-2465. Dezembro 2012.

LAMONT, L. A. \& MATHEWS, K. A. Opioides, Anti-inflamatórios não esteroidais e analgésicos adjuvantes. In: TRANQUILLI, W. J.; THURMON, J. C.; GRIMM, K. A. LUMB \& JONES Anestesiologia e Analgesia Veterinária. 4aa edição. São Paulo, Brasil: Editora Roca, 2013. Cap. 10, p. 270-304.

LANGFORD, D. J.; BAILEY, A. L.; CHANDA, M. L.; CLARKE, S. E.; DRUMMOND, T. E.; ECHOLS, S.; GLICK, S.; INGRAO, J.; KLASSEN-ROSS, T.; LACROIXFRALISH, M. L.; MATSUMIYA, L.; SORGE, R. E.; SOTOCINAL, S. G.; TABAKA, J. M.; WONG, D.; VAN DEN MAAGDENBERG, A. M. J. M.; FERRARI, M. D.; CRAIG, K. D.; MOGIL, J. S. Coding of facial expressions of pain in the laboratory mouse. Nature Methods. Vol 7, n. 6, p.447-452. Junho 2010.

LOESER, J. D. \& TREEDE, R. D. The Kyoto protocol of IASP basic pain terminology. Pain. Vol.137, p.473-477. 2008

MACALLISTER, C. G.; ANDREWS, F. M.; DEEGAN, E.; RUOFF, W.; OLOVSON, S. G. A scoring system for gastric ulcers in the horse. Equine Veterinary Journal. V. 29, n. 06, pp. 430-433. 1997.

MALVAR, D. D. C.; SOARES, D. M.; FABRÍCIO, A. S. C.; KANASHIRO, A.; MACHADO, R. R.; FIGUEIREDO, M. J.; RAE, G. a.; DE SOUZA, G. E. P. The 
antipyretic effect of dipyrone is unrelated to inhibition of PGE2 synthesis in the hypothalamus. British Journal of Pharmacology, v. 162, n. 6, p. 1401-1409, 2011.

MEISSNER, W.; COLUZZI, F.; FLETCHER, D.; HUYGEN, F.; MORLION, B.; NEUGEBAUER, E.; PÉREZ, A. M.; PERGOLIZZI, J. Improving the management of post-operative acute pain: priorities for change. Current Medical Ressearch \& Opinion. Vol. 31, n. 11, p. 2131-2143. 2015.

MUÑOZ, J.; NAVARRO, C.; NORIEGA, V.; PINARDI, G.; SIERRALTA, F.; PRIETO, J. C.; MIRANDA, H. F. Synergism between COX-3 inhibitors in two animal models of pain. Inflammopharmacology, v. 18, n. 2, p. 65-71, Apr. 2010.

MURRAY, M.J. Diseases of the stomach. In: MAIR, T., DIVERS, T., DUCHARME, N. Manual of Equine Gastroenterology. $1^{\text {st }}$ edition. 2002. Editora: Elsevier, cap. 12, p. $241-248$.

NAYLOR, R. J.; TAYLOR, A. H.; KNOWLES, E. J.; WILFORD, S.; LINNENKOHL, W.; MAIR, T. S.; JOHNS. I. C. Comparison of flunixin meglumine and meloxicam for post-operative management of horses with strangulating small intestinal lesions. Equine Veterinary Journal. Vol. 46, p. 427-434. 2014

OLIVEIRA, C. M. B. de; SAKATA, R. K.; ISSY, A. M.; GEROLA, L. R.; SALOM, O. R. Citocinas e Dor. Revista Brasileira de Anestesiologia, v. 61, n. 2, p. 255-265, 2011. Disponível em: <http://dx.doi.org/10.1016/S0034-7094(11)70029-0>. Acessado em: 20 de Agosto de 2017.

PAPICH, M. G. An Update on Nonsteroidal Anti-Inflammatory Drugs (NSAIDs) in Small Animals. Veterinary Clinics of North America - Small Animal Practice, v. 38, n. 6, p. 1243-1266, 2008. 
PEREIRA, M. A. A. Avaliação da eficácia analgésica e da inibição ex vivo da atividade das cicloxigenases 1 e 2 após o emprego da dipirona ou do meloxicam em gatas submetidas à ovariosalpingohisterectomia eletiva. 2017 . 130 f. Dissertação (Mestrado - Programa de Clínica Cirúrgica Veterinária) Faculdade de Medicina Veterinária e Zootecnia, Universidade de São Paulo, São Paulo, 2017.

PIERRE, S.C., SCHMIDT, R., BRENNEIS, C., MICHAELIS, M., GEISSLINGER, G., SCHOLICH, K. Inhibition of cyclooxygenases by dipyrone. British Journal of Pharmacology. 2007. n. 151, p. 494-503.

PRICE, J.; CATRIONA, S.; WELSH, E.M.; WARAN, N.K. Preliminary evaluation of a behaviour-based system for assessment of post-operative pain in horses following arthroscopic surgery. Veterinary Anaesthesia and Analgesia. Vol.30, p. 124-137. 2003.

REDONDO-PACHON, M.D.; ENRÍQUEZ, R.; SIRVENT, A. E.; MILLAN, I.; ROMERO, A.; AMORÓS, F. Acute Renal Failure and Severe Thrombocytopenia Associated with Metamizole- Case Report. Saudi Journal of Kidney Diseases and Transplantation. Vol. 25, n. 1, p. 11-125. 2014.

ROBERTSON, S. A. Managing Pain in Feline Patients. Veterinary Clinics of North America - Small Animal Practice, v. 38, n. 6, p. 1267-1290, 2008.

ROBERTSON, S. A.; LASCELLES, B. D. X. Long-Term pain in cats. How much do we know about this important welfare issue? Journal of Feline Medicine and Surgery, v. 12, n. 3, p. 188-199, 2010.

ROGOSCH, T.; SINNING, C.; PODLEWSKI, A.; WATZER, B.; SCHLOSBURG, J.; LICHTMAN, A. H.; CASCIO, M. G.; BISOGNO, T.; Di MARZO, V.; NÜSIN, R.; 
IMMING, P. Novel bioactive metabolites of dipyrone (metamizol). Bioorganic \& Medicinal Chemistry, v. 20, n. 1, p. 101-107, Jan. 2012.

SAKATA, R. Tratamento da dor. In: YAMASHITA, A.; TAKAOKA, F.; AULER, J. J.; IWATA, N. (Eds.) Anestesiologia - SAESP. 5. ed. São Paulo: Atheneu, 2001. p. $1165-1182$

SANCHEZ, L. C. \& ROBERTSON, S. A. Pain control in horses: What do we really know? Equine Veterinary Journal. Vol. 46, p. 517-523. 2014.

SANCHEZ, S.; MARTIN, M. J.; ORTIZ, P.; MOTILVA, V.; ALARCON DE LA LASTRA, C. Effects of dipyrone on inflammatory infiltration and oxidative metabolismo in gastric mucosa: comparison with acetaminophen and diclofenac. Digestive Diseases and Sciences. V.47, n. 06, pp.1389-1398. 2002a.

SANCHEZ, S.; MARTIN, M. J.; ORTIZ, P.; MOTILVA, V.; HERRERIAS, J. M.; ALARCON DE LA LASTRA, C. Role of prostaglandins and nitric oxide in gastric damage induced by metamizol in rats. Inflammation Research. V. 51, n.8, pp.385-392. 2002b.

SCHATZMANN, U. Tratamento Analgésico Prático em Cavalos. In: HELLEBREKERS, L. J. Dor em Animais. 1aㅡ edição. Barueri, São Paulo: Editora Manole Ltda, cap. 10, p. 151-165. 2002.

SCOTT, L. J. \& PERRY, C. M. Tramadol: a review of its use in perioperative pain. Drugs. Vol. 60, n. 1, p.139-176. Jul, 2000. 
SELLON, D. C.; ROBERTS, M. C.; BLIKSLAGER, A. T.; ULIBARRI, C.; PAPICH, M. G. Effects of Continuous Rate Intravenous Infusion of Butorphanol on Physiologic and Outcome Variables in Horses after Celiotomy. Journal of Veterinary Internal Medicine. Vol. 18, p. 555-563.2004.

SMITH, J.; ALLEN, S.; QUANDT, J.; TACKETT, R. L. Indicators of postoperative pain in cats and correlation with clinical criteria. American Journal of Veterinary Research , v. 57, n. 11, p. 1674-1678, 1996

SOTOCINAL, S. G.; SORGE, R. E.; ZALOUM, A.; TUTTLE, A. H.; MARTIN, L. J.; WIESKOPF, J. S.; MAPPLEBECK, J. C. S.; WEI, P.; ZHAN, S.; ZHANG, S.; MCDOUGALL, J. J.; KING, O. D.; MOGIL, J. S. The Rat Grimace Scale: A partially automated method for quantifying pain in the laboratory rat via facial expressions. Molecular Pain. Vol. 7, n. 55. 2011.

SPAIN. Organización Mundial de la Salud. Alivio del dolor en el cáncer. Ginebra, 1987.

SUTTON, G. A.; DAHAN, R.; TURNER, D.; PALTIEL, O. A behaviour-based pain scale for horses with acute colic: Scale construction. The Veterinary Journal. N. 196, p. 394-401. 2013.

TAFFAREL, M. O.; LUNA, S. P. L.; OLIVEIRA, F. A. de; CARDOSO, G. S.; ALONSO, J. M.; PANTOJA, J. C.; BRONDANI, J. T.; LOVE, E.; TAYLOR, P.; WHITE, K.; MURRELL, J. C. Refinement and partial validation of the UNESPBotucatu multidimensional composite pain scale for assessing postoperative pain in horses. BMC Veterinary Ressearch. Vol. 11, n. 83. 2015.

TAYLOR, P.; COUMBE, K.; HENSON, F.; SCOTT, D.; TAYLOR, A. Evaluation of sedation for standing clinical procedures in horses using detomidine combined with 
buprenorphine. Veterinary Anaesthesia and Analgesia. Vol. 41, n. 1, p. 14-24, Jun. 2013.

TORFS, S.; DELESALLE, C.; DEWULF, J.; DEVISSCHER, L.; DEPREZ, P. Risk Factors for Equine Postoperative lleus and Effectiveness of Prophylactic Lidocaine. Journal of Veterinary Internal Medicine. Vol. 23, p. 606-611. 2009.

TORTORICI, V.\& VANEGAS, H. Opioid tolerance induced by metamizol (dipyrone) microinjections into the periaqueductal grey of rats. European Journal of Neuroscience, v. 12, n. 11, p. 4074-4080, Nov. 2000.

VAN LOON, J. P. A. M. \& VAN DIERENDONCK, M. C. Monitoring acute equine visceral pain with the equine ultrecht University scale do composite pain assessment (EQUUS-COMPASS) and the equine Utrecht university scale for facial assessment of pain (EQUUS-FAP): A scale- constuction study. The Veterinary Journal. Vol. 206, p. 356-364. 2015.

VAN LOON, J. P. A. M.; BACK, W.; HELLEBREKERS, L. J.; VAN WEEREN, P. R. Application of a composite pain scale to objectively monitor horses with somatic and visceral pain under hospital conditions. Journal of Equine Veterinary Science. Vol. 30, n. 11. 2010.

VAZQUEZ, E.; HERNANDEZ, N.; ESCOBAR, W.; VANEGAS, H. Antinociception induced by intravenous dipyrone (metamizol) upon dorsal horn neurons: involvement of endogenous opioids at the periaqueductal gray matter, the nucleus raphe magnus, and the spinal cord in rats. Brain Research, v. 1048, n. 1, p. 211217, Jun. 2005.

WARNER, T. D. and MITCHELL, J. A.. Cyclooxygenases: new forms, new inhibitors, and lessons from the clinic. The FASEB Journal. Vol. 18, pp.790- 804. May, 2004. 
XU, J.; BRENNAN, T. J. The pathophysiology of acute pain: animal models. Current Opinion in Anaesthesioly, v. 24, n. 5, p. 508-514, Oct. 2011.

YILDIRIM, E., SAGROGLU, O., KILIÇ, F. S., EROL, K. Effects of Nabumetone and Dipyrone on experimentally induced gastric ulcers in rats. Inflammation. Abril 2013. Vol. 36, n. 2, p. 476-481.

YILDIRIM, E., SAGROGLU, O., KILIÇ, F. S., EROL, K. Effects of Nabumetone and Dipyrone on experimentally induced gastric ulcers in rats. Inflammation. Vol. 36, n. 2, p. 476-481. Abril 2013.

ZANUZZO, F. S.; TEIXEIRA-NETO, F. J.; TEIXEIRA, L. R.; DINIZ, M. S.; SOUZA, V. L.; THOMAZINI, C. M.; STEAGALL, P. V. M. Analgesic and antihyperalgesic effects of dipyrone, meloxicam or a dipyrone-meloxicam combination in bitches undergoing ovariohysterectomy. The Veterinary Journal, v. 205, n. 1, p. 33-37, jul. 2015.

ZIEGLER, A.; FOGLE, C.; BLIKSLAGER, A. Update on the use of ciclooxygenase2-selective nonsteroidal anti-inflammatory drugs in horses. Journal of the American Veterinary Medical Association. N.11. Junho, 2017. 


\section{APÊNDICES}


APÊNDICE A - Concentrações de tromboxano $B_{2}\left(\mathrm{TXB}_{2}\right)$ em picogramas por mililitro $(\mathrm{pg} / \mathrm{mL})$, representando a atividade da ciclooxigenase 1 (COX-1), dos 12 cavalos distribuídas aleatoriamente nos 2 grupos do estudo durante os momentos avaliados na fase 01 - FMVZ - São Paulo - 2017.

\begin{tabular}{|c|c|c|c|c|c|c|}
\hline & & \multicolumn{5}{|c|}{ Momentos de Avaliação } \\
\hline & & Basal & $\mathrm{T} 2$ & T8 & T12 & T24 \\
\hline & Cavalo 1 & 4200 & 7,36 & 410,976 & 870,036 & 662,016 \\
\hline & Cavalo 2 & 4200 & 140,94 & 883,868 & 912,388 & 2075,756 \\
\hline & Cavalo 3 & 1689,936 & 0 & 1111,268 & 327,552 & 209,792 \\
\hline \multirow[t]{8}{*}{ Dipirona } & Cavalo 4 & 2795,7 & 51,264 & 183,972 & 279,732 & 1323,192 \\
\hline & Cavalo 5 & 652,38 & 8,64 & 119,64 & 511,82 & 633,62 \\
\hline & Cavalo 6 & 1563,572 & 96,868 & 416,568 & 912,388 & 1947,956 \\
\hline & Média & 2516,931 & 50,84533 & 521,0487 & 635,6527 & 1142,055 \\
\hline & DP & 1470,55 & 57,43 & 394,41 & 298,34 & 763,17 \\
\hline & Cavalo 1 & 2031,864 & 1,108 & 59,54 & 144,796 & 179,184 \\
\hline & Cavalo 2 & 1758,5 & 0 & 36,36 & 235,996 & 606,692 \\
\hline & Cavalo 3 & 2167,692 & 0,04 & 126,412 & 235,996 & 379,128 \\
\hline \multirow[t]{5}{*}{ Flunixin } & Cavalo 4 & 2121,012 & 0,46 & 140,94 & 374,088 & 1534,04 \\
\hline & Cavalo 5 & 1593,9 & 0,352 & 124,688 & 142,856 & 856,48 \\
\hline & Cavalo 6 & 1689,936 & 0 & 27,928 & 128,152 & 757,136 \\
\hline & Média & 1893,82 & 0,33 & 85,98 & 210,31 & 718,78 \\
\hline & DP & 243,11 & 0,43 & 50,37 & 93,53 & 469,93 \\
\hline
\end{tabular}

Fonte: (SANTOS, R. S. T. dos, 2017).

Legenda: Basal: momento imediatamente anterior à administração da medicação; T2, T8, T12 e T24: 2, 8, 12 e 24 horas após a administração da medicação pós-operatória; DP: desvio padrão. 
APÊNDICE B - Porcentagem de mudança das concentrações de tromboxano $B_{2}$ $\left(\mathrm{TXB}_{2}\right)$, representando a atividade da ciclooxigenase 1 (COX-1), em comparação com o valor imediatamente anterior à administração da medicação pós-operatória (T0h; valor considerado como 100\%), dos 12 cavalos distribuídos aleatoriamente nos 2 grupos do estudo durante os momentos avaliados da fase 01 - FMVZ - São Paulo - 2017.

\begin{tabular}{|c|c|c|c|c|c|c|}
\hline & \multicolumn{6}{|c|}{ Momentos de Avaliação } \\
\hline & & Basal & T2 & T8 & T12 & T24 \\
\hline & Cavalo 1 & 100 & 0,18 & 9,79 & 20,72 & 15,76 \\
\hline & Cavalo 2 & 100 & 3,36 & 21,04 & 21,72 & 49,42 \\
\hline & Cavalo 3 & 100 & 0,00 & 65,76 & 19,38 & 12,41 \\
\hline \multirow[t]{8}{*}{ Dipirona } & Cavalo 4 & 100 & 1,83 & 6,56 & 10,01 & 47,33 \\
\hline & Cavalo 5 & 100 & 1,32 & 18,34 & 78,45 & 97,12 \\
\hline & Cavalo 6 & 100 & 6,2 & 26,64 & 58,35 & 124,58 \\
\hline & Média & 100 & 2,15 & 24,69 & 34,77 & 57,77 \\
\hline & DP & 0 & 2,33 & 21,42 & 27,14 & 44,75 \\
\hline & Cavalo 1 & 100 & 0,05 & 2,93 & 7,13 & 8,82 \\
\hline & Cavalo 2 & 100 & 0,00 & 2,07 & 13,42 & 34,5 \\
\hline & Cavalo 3 & 100 & 0,00 & 5,83 & 10,89 & 17,49 \\
\hline \multirow[t]{5}{*}{ Flunixin } & Cavalo 4 & 100 & 0,02 & 6,64 & 17,64 & 72,33 \\
\hline & Cavalo 5 & 100 & 0,02 & 7,82 & 8,96 & 53,73 \\
\hline & Cavalo 6 & 100 & 0 & 1,65 & 7,58 & 14,8 \\
\hline & Média & 100 & 0,02 & 4,49 & 10,94 & 33,61 \\
\hline & DP & 0,00 & 0,02 & 2,60 & 4,02 & 25,03 \\
\hline
\end{tabular}

Fonte: (SANTOS, R. S. T. dos, 2017).

Legenda: Basal: momento imediatamente anterior à administração da medicação; T2, T8, T12 e T24: 2, 8, 12 e 24 horas após a administração da medicação pós-operatória; DP: desvio padrão. 
APÊNDICE C - Concentrações de prostaglandina $E_{2}$ estimulada pelo LPS (PGE $2^{-}$ E), em picogramas por mililitro $(\mathrm{pg} / \mathrm{mL})$, representando a atividade da ciclooxigenase 2 (COX-2), dos 12 cavalos distribuídos aleatoriamente nos 2 grupos do estudo durante os momentos avaliados na fase 01 - FMVZ - São Paulo - 2017.

\begin{tabular}{|c|c|c|c|c|c|}
\hline & & \multicolumn{4}{|c|}{ Momentos Avaliados } \\
\hline & & Basal & T2 & T12 & T24 \\
\hline & Cavalo 1 & 807,42 & 1277,28 & 1138,4 & 2010,69 \\
\hline & Cavalo 2 & 508,3 & 1219 & 1179,5 & 1011,11 \\
\hline & Cavalo 3 & 1666,1 & 709,84 & 1245,5 & 1942,91 \\
\hline \multirow[t]{8}{*}{ Dipirona } & Cavalo 4 & 539,3 & 818,29 & 563,7 & 779,74 \\
\hline & Cavalo 5 & 846 & 1498,47 & 2515,7 & 1131,35 \\
\hline & Cavalo 6 & 761,41 & 619,65 & 2010,69 & 2244,91 \\
\hline & Média & 854,76 & 1104,58 & 1328,56 & 1375,16 \\
\hline & DP & 468,61 & 330,09 & 717,56 & 564,08 \\
\hline & Cavalo 1 & 8809,13 & 5884,57 & 10183,9 & 9241,41 \\
\hline & Cavalo 2 & 9857,46 & 10019,07 & 6255,91 & 10500 \\
\hline & Cavalo 3 & 10500 & 6160,84 & 10019,07 & 10500 \\
\hline \multirow[t]{5}{*}{ Flunixin } & Cavalo 4 & 10500 & 6352,53 & 10500 & 10500 \\
\hline & Cavalo 5 & 10500 & 6160,84 & 8950,53 & 10500 \\
\hline & Cavalo 6 & 10500 & 6651,99 & 6160,84 & 10500 \\
\hline & Média & 10111,10 & 6871,64 & 8678,38 & 10290,24 \\
\hline & DP & 687,67 & 1562,61 & 1983,07 & 513,82 \\
\hline
\end{tabular}

Fonte: (SANTOS, R. S. T. dos, 2017).

Legenda: Basal: momento imediatamente anterior à administração da medicação; T2, T8, T12 e T24: 2, 8, 12 e 24 horas após a administração da medicação pós-operatória; DP: desvio padrão. 
APÊNDICE D - Porcentagem de mudança das concentrações de prostaglandina $E_{2}$ estimulada pelo LPS $\left(\mathrm{PGE}_{2}-\mathrm{E}\right)$, representando a atividade da ciclooxigenase 2 (COX-2), em comparação com o valor imediatamente anterior à administração da medicação pós-operatória (Basal: valor considerado como 100\%), dos 12 cavalos distribuídos aleatoriamente nos 2 grupos do estudo durante os momentos avaliados na fase 01 - FMVZ - São Paulo - 2017.

\begin{tabular}{cccccc}
\hline & & \multicolumn{4}{c}{ Momentos Avaliados } \\
\hline \multirow{7}{*}{ Dipirona } & Basal & T2 & T12 & T24 \\
& Cavalo 1 & 100 & 158,19 & 140,99 & 249,03 \\
& Cavalo 2 & 100 & 239,82 & 232,05 & 198,92 \\
& Cavalo 3 & 100 & 42,60 & 74,76 & 116,61 \\
& Cavalo 4 & 100 & 151,73 & 104,52 & 144,58 \\
& Cavalo 5 & 100 & 177,12 & 297,36 & 133,73 \\
& Cavalo 6 & 100 & 81,38 & 264,07 & 294,84 \\
\hline \multirow{6}{*}{ Média } & 100 & 141,81 & 185,63 & 189,62 \\
& DP & 0 & 70,30 & 91,28 & 70,95 \\
& Cavalo 1 & 100 & 66,80 & 115,61 & 104,91 \\
& Cavalo 2 & 100 & 101,64 & 63,46 & 106,52 \\
& Cavalo 3 & 100 & 58,67 & 95,42 & 100,00 \\
& Cavalo 4 & 100 & 60,50 & 100,00 & 100,00 \\
& Cavalo 5 & 100 & 58,67 & 85,24 & 100,00 \\
& Cavalo 6 & 100 & 63,35 & 58,67 & 100,00 \\
\hline \multirow{6}{*}{ Flunixin } & Média & 100 & 68,27 & 86,40 & 101,90 \\
& DP & 0 & 16,64 & 21,98 & 2,99 \\
\hline
\end{tabular}

Fonte: (SANTOS, R. S. T. dos, 2017).

Legenda: Basal: momento imediatamente anterior à administração da medicação; T2, T8, T12 e T24: 2, 8, 12 e 24 horas após a administração da medicação pós-operatória; DP: desvio padrão. 
APÊNDICE E - Dados demográficos dos 15 cavalos da fase 02 distribuídos aleatoriamente nos 2 grupos do estudo da fase 02 - FMVZ - São Paulo - 2017.

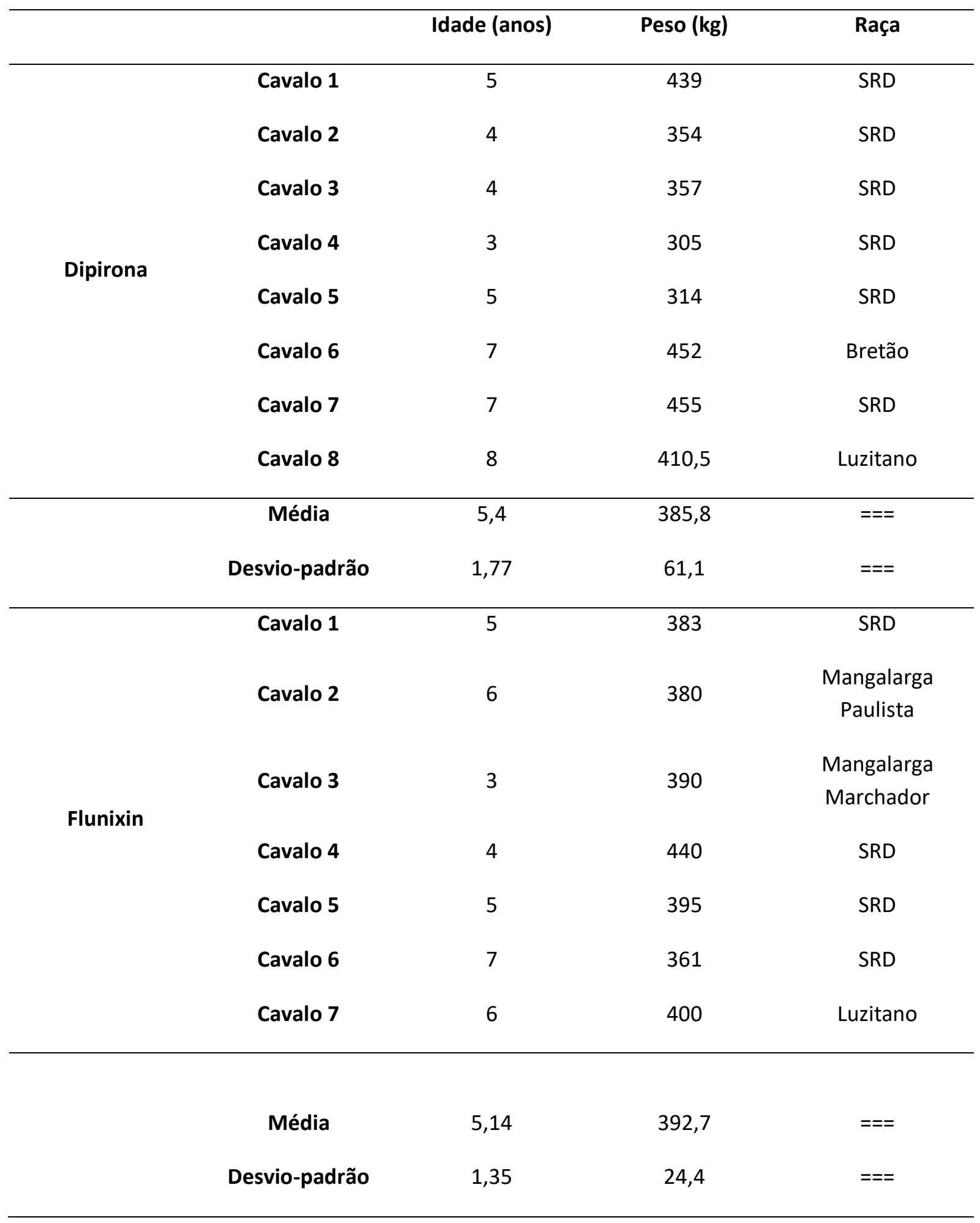

Fonte: (SANTOS, R. S. T. dos, 2017).

Legenda: kg: quilogramas. 
APÊNDICE F - Frequência cardíaca em batimentos por minuto dos 15 cavalos distribuídos aleatoriamente nos 2 grupos do estudo durante os momentos avaliados na Fase 02 - FMVZ - São Paulo - 2017.

\section{Tempos de Avaliação}

\begin{tabular}{|c|c|c|c|c|c|c|c|c|}
\hline & & Basal & T1 & T2 & T4 & T8 & T12 & T24 \\
\hline & Cavalo 1 & 60 & 76 & 77 & 57 & 49 & 52 & 51 \\
\hline & Cavalo 2 & 66 & 54 & 67 & 55 & 62 & 70 & 52 \\
\hline & Cavalo 3 & 65 & 62 & 75 & 66 & 55 & 63 & 68 \\
\hline & Cavalo 4 & 44 & 24 & 36 & 32 & 40 & 38 & 38 \\
\hline \multirow[t]{9}{*}{ Dipirona } & Cavalo 5 & 46 & 60 & 60 & 60 & 56 & 56 & 52 \\
\hline & Cavalo 6 & 32 & 28 & 50 & 60 & 56 & 43 & 34 \\
\hline & Cavalo 7 & 48 & 48 & 56 & 60 & 60 & 54 & 54 \\
\hline & Cavalo 8 & 28 & 36 & 30 & 32 & 28 & 24 & 25 \\
\hline & Média & 48,63 & 48,50 & 56,38 & 52,75 & 50,75 & 50,00 & 46,75 \\
\hline & DP & 14,29 & 18,04 & 17,11 & 13,19 & 11,47 & 14,61 & 13,57 \\
\hline & Cavalo 1 & 55 & 50 & 52 & 51 & 53 & 54 & 57 \\
\hline & Cavalo 2 & 34 & 37 & 33 & 33 & 34 & 27 & 30 \\
\hline & Cavalo 3 & 41 & 44 & 52 & 32 & 28 & 42 & 46 \\
\hline \multirow[t]{6}{*}{ Flunixin } & Cavalo 4 & 56 & 60 & 64 & 60 & 52 & 60 & 52 \\
\hline & Cavalo 5 & 80 & 42 & 50 & 46 & 50 & 40 & 40 \\
\hline & Cavalo 6 & 48 & 52 & 52 & 56 & 48 & 51 & 48 \\
\hline & Cavalo 7 & 32 & 34 & 34 & 36 & 32 & 44 & 30 \\
\hline & Média & 49,43 & 45,57 & 48,14 & 44,86 & 42,43 & 45,43 & 43,29 \\
\hline & DP & 16,45 & 9,05 & 11,02 & 11,38 & 10,64 & 10,80 & 10,47 \\
\hline
\end{tabular}

Fonte: (SANTOS, R. S. T. dos, 2017).

Legenda: Basal: avaliação antes do procedimento anestésico/cirúrgico; T1, T2, T4, T8, T12 e T24:

1, 2, 4, 8, 12 e 24 horas após a administração da medicação pós-operatória; DP: desvio padrão. 
APÊNDICE G - Frequência respiratória em movimentos por minuto dos 15 cavalos distribuídos aleatoriamente nos 2 grupos do estudo durante os momentos avaliados na Fase 02 - FMVZ - São Paulo - 2017.

\begin{tabular}{ccccccccc}
\hline & & \multicolumn{7}{c}{ Tempos Avaliados } \\
\hline Cavalo 1 & 34 & 33 & 35 & 28 & 27 & 27 & 30 \\
Cavalo 2 & 33 & 27 & 28 & 27 & 30 & 30 & 32 \\
Cavalo 3 & 32 & 30 & 28 & 24 & 27 & 2 & 34 \\
Cavalo 4 & 22 & 10 & 20 & 20 & 27 & 24 & 30 \\
Dipironal & Cavalo 5 & 20 & 28 & 27 & 28 & 25 & 23 & 23 \\
Cavalo 6 & 23 & 25 & 25 & 28 & 23 & 25 & 24 \\
Cavalo 7 & 28 & 24 & 27 & 27 & 24 & 26 & 26 \\
Cavalo 8 & 25 & 24 & 27 & 27 & 27 & 25 & 28 \\
\hline Média & 27 & 25 & 27 & 26 & 26 & 23 & 28 \\
DP & 5,41 & 6,85 & 4,12 & 2,80 & 2,19 & 8,65 & 3,85 \\
\hline Cavalo 1 & 32 & 29 & 28 & 30 & 29 & 30 & 33 \\
Cavalo 2 & 30 & 25 & 28 & 30 & 29 & 29 & 30 \\
Cavalo 3 & 28 & 25 & 24 & 16 & 14 & 20 & 22 \\
Cavalo 4 & 18 & 22 & 22 & 24 & 22 & 20 & 25 \\
Cavalo 5 & 18 & 22 & 22 & 23 & 17 & 27 & 18 \\
Cavalo 6 & 24 & 20 & 24 & 24 & 22 & 24 & 20 \\
Cavalo 7 & 22 & 17 & 22 & 24 & 24 & 25 & 20 \\
\hline Média & 25 & 23 & 24 & 24 & 22 & 25 & 24 \\
DP & 5,62 & 3,89 & 2,69 & 4,76 & 5,62 & 4,00 & 5,63 \\
& & & & & & & \\
\hline
\end{tabular}

Fonte: (SANTOS, R. S. T. dos, 2017).

Legenda: Basal: avaliação antes do procedimento anestésico/cirúrgico; T1, T2, T4, T8, T12 e T24: 1, 2, 4, 8, 12 e 24 horas após a administração da medicação pós-operatória; DP: desvio padrão. 
APÊNDICE H - Temperatura retal, em graus Celsius, dos 15 cavalos distribuídos aleatoriamente nos 2 grupos do estudo durante os momentos avaliados na Fase 02 - FMVZ - São Paulo - 2017.

\begin{tabular}{|c|c|c|c|c|c|c|c|c|}
\hline & & \multicolumn{7}{|c|}{ Momentos Avaliados } \\
\hline & & Basal & $\mathrm{T1}$ & T2 & T4 & T8 & T12 & T24 \\
\hline & Cavalo 1 & 38,5 & 38 & 37,3 & 38 & 38 & 37,3 & 38,3 \\
\hline & Cavalo 2 & 38,5 & 38,3 & 38,7 & 38,3 & 38,3 & 37,9 & 37,8 \\
\hline & Cavalo 3 & 38,7 & 37,5 & 38,4 & 38,5 & 39 & 38,5 & 38,5 \\
\hline & Cavalo 4 & 39 & 37,7 & 37,8 & 38,2 & 38,5 & 38,5 & 38,5 \\
\hline \multirow[t]{9}{*}{ Dipirona } & Cavalo 5 & 38 & 37,5 & 38 & 38 & 38 & 37,5 & 38,5 \\
\hline & Cavalo 6 & 38,1 & 37 & 37,8 & 38 & 37,3 & 37,6 & 38 \\
\hline & Cavalo 7 & 38,5 & 37,7 & 37,9 & 38,7 & 37,7 & 38,2 & 38,3 \\
\hline & Cavalo 8 & 38,2 & 37,4 & 37,9 & 37,8 & 37,8 & 37,8 & 37,8 \\
\hline & Média & 38,4 & 37,6 & 38,0 & 38,2 & 38,1 & 37,9 & 38,2 \\
\hline & DP & 0,33 & 0,39 & 0,42 & 0,30 & 0,52 & 0,45 & 0,30 \\
\hline & Cavalo 1 & 39 & 38,7 & 38,2 & 38 & 37,9 & 37,9 & 38 \\
\hline & Cavalo 2 & 39,2 & 38,6 & 38,1 & 38,9 & 39 & 39,3 & 39 \\
\hline & Cavalo 3 & 37,7 & 38,3 & 38 & 38 & 37,9 & 38,6 & 38,5 \\
\hline \multirow[t]{6}{*}{ Flunixin } & Cavalo 4 & 37,8 & 37,2 & 37,3 & 37,6 & 37,8 & 38,3 & 38,3 \\
\hline & Cavalo 5 & 37,7 & 39,1 & 37,7 & 38,2 & 37,8 & 37,2 & 38 \\
\hline & Cavalo 6 & 38,1 & 38 & 38 & 38,2 & 37,4 & 39,1 & 38,3 \\
\hline & Cavalo 7 & 38,6 & 38 & 37,8 & 38,3 & 38,4 & 38,5 & 38,5 \\
\hline & Média & 38,3 & 38,3 & 37,9 & 38,2 & 38,0 & 38,4 & 38,4 \\
\hline & DP & 0,59 & 0,57 & 0,28 & 0,37 & 0,48 & 0,66 & 0,32 \\
\hline
\end{tabular}

Fonte: (SANTOS, R. S. T. dos, 2017).

Legenda: Basal: avaliação antes do procedimento anestésico/cirúrgico; T1, T2, T4, T8, T12 e T24: 1, 2, 4, 8, 12 e 24 horas após a administração da medicação pós-operatória; DP: desvio padrão. 
APÊNDICE I - Escores de dor, em centímetros, obtidos pela Escala Analógica Visual (EAV) dos 15 cavalos distribuídos aleatoriamente nos 2 grupos do estudo durante os momentos avaliados na Fase 02 - FMVZ - São Paulo - 2017.

\section{Tempos de Avaliação}

$\begin{array}{ccccccccc} & & \text { Basal } & \text { T1 } & \text { T2 } & \text { T4 } & \text { T8 } & \text { T12 } & \text { T24 } \\ \text { Cavalo 1 } & 0,00 & 0,20 & 0,20 & 0,10 & 0,00 & 0,15 & 0,00 \\ \text { Cavalo 2 } & 0,00 & 0,00 & 0,15 & 0,40 & 0,30 & 0,50 & 0,00 \\ \text { Dipirona } & \text { Cavalo 3 } & 0,00 & 0,30 & 0,30 & 0,10 & 0,10 & 0,40 & 0,10 \\ & \text { Cavalo 4 } & 0,00 & 0,15 & 0,00 & 0,10 & 0,00 & 0,20 & 0,10 \\ & \text { Cavalo 5 } & 0,00 & 0.2 & 0,15 & 0,15 & 0,10 & 0,10 & 0,00 \\ & \text { Cavalo 6 } & 0,00 & 0,10 & 0,10 & 0,10 & 0,00 & 0,05 & 0,00 \\ & \text { Cavalo 7 } & 0,00 & 0,00 & 0,00 & 0,00 & 0,00 & 0,00 & 0,00 \\ \text { Cavalo 8 } & 0,00 & 0,00 & 0,00 & 0,00 & 0,00 & 0,00 & 0,00\end{array}$

$\begin{array}{llllllll}\text { Média } & 0,00 & 0,13 & 0,13 & 0,14 & 0,07 & 0,20 & 0,03 \\ \text { DP } & 0,00 & 0,12 & 0,11 & 0,12 & 0,11 & 0,18 & 0,05\end{array}$

$\begin{array}{ccccccccc} & \text { Cavalo 1 } & 0,00 & 0,05 & 0,10 & 0,20 & 0,50 & 0,50 & 0,20 \\ & \text { Cavalo 2 } & 0,00 & 0,10 & 0,20 & 0,15 & 0,15 & 0,10 & 0,05 \\ \text { Cavalo 3 } & 0,00 & 0,00 & 0,00 & 0,00 & 0,00 & 0,00 & 0,00 \\ \text { Flunixin } & \text { Cavalo 4 } & 0,00 & 0,10 & 0,20 & 0,10 & 0,15 & 0,10 & 0,10 \\ & \text { Cavalo 5 } & 0,00 & 0,25 & 0,20 & 0,30 & 0,20 & 0,30 & 0,20 \\ & \text { Cavalo 6 } & 0,00 & 0,10 & 0,00 & 0,00 & 0,00 & 0,00 & 0,00 \\ & \text { Cavalo 7 } & 0,00 & 0,10 & 0,10 & 0,00 & 0,10 & 0,10 & 0,05 \\ & & & & & & & & \end{array}$

Média

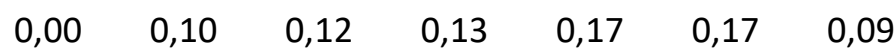


Fonte: (SANTOS, R. S. T. dos, 2017).

Legenda: Basal: avaliação antes do procedimento anestésico/cirúrgico; T1, T2, T4, T8, T12 e T24: 1, 2, 4, 8, 12 e 24 horas após a administração da medicação pós-operatória; DP: desvio padrão.

APÊNDICE J - Escores de dor obtidos pela Escala Multidimensional da UNESPBotucatu para avaliação de dor aguda pós-operatória em cavalos submetidos à castração (UNESP) dos 15 cavalos distribuídos aleatoriamente nos 2 grupos do estudo durante os momentos avaliados na fase 02 - FMVZ - São Paulo - 2017.

\begin{tabular}{|c|c|c|c|c|c|c|c|c|}
\hline & \multicolumn{8}{|c|}{ Tempos de Avaliação } \\
\hline & & Basal & T1 & T2 & T4 & T8 & T12 & T24 \\
\hline & Cavalo 1 & 4 & 3 & 3 & 3 & 2 & 3 & 3 \\
\hline & Cavalo 2 & 4 & 4 & 3 & 5 & 2 & 0 & 0 \\
\hline & Cavalo 3 & 1 & 1 & 1 & 1 & 1 & 1 & 1 \\
\hline \multirow[t]{10}{*}{ Dipirona } & Cavalo 4 & 0 & 5 & 1 & 1 & 0 & 1 & 1 \\
\hline & Cavalo 5 & 0 & 1 & 2 & 1 & 0 & 0 & 0 \\
\hline & Cavalo 6 & 0 & 0 & 2 & 2 & 2 & 1 & 0 \\
\hline & Cavalo 7 & 0 & 2 & 1 & 1 & 1 & 0 & 0 \\
\hline & Cavalo 8 & 0 & 1 & 0 & 0 & 0 & 0 & 0 \\
\hline & Média & 1,13 & 2,13 & 1,63 & 1,75 & 1,00 & 0,75 & 0,63 \\
\hline & DP & 1,81 & 1,73 & 1,06 & 1,58 & 0,93 & 1,04 & 1,06 \\
\hline & Cavalo 1 & 2 & 3 & 2 & 3 & 4 & 3 & 3 \\
\hline & Cavalo 2 & 0 & 2 & 0 & 0 & 0 & 0 & 0 \\
\hline & Cavalo 3 & 6 & 3 & 5 & 2 & 1 & 0 & 1 \\
\hline \multirow[t]{6}{*}{ Flunixin } & Cavalo 4 & 0 & 1 & 1 & 0 & 1 & 0 & 0 \\
\hline & Cavalo 5 & 0 & 1 & 0 & 0 & 0 & 1 & 1 \\
\hline & Cavalo 6 & 0 & 1 & 0 & 0 & 0 & 0 & 0 \\
\hline & Cavalo 7 & 0 & 0 & 0 & 0 & 0 & 1 & 0 \\
\hline & Média & 1,14 & 1,57 & 1,14 & 0,71 & 0,86 & 0,71 & 0,71 \\
\hline & DP & 2,27 & 1,13 & 1,86 & 1,25 & 1,46 & 1,11 & 1,11 \\
\hline
\end{tabular}

Fonte: (SANTOS, R. S. T. dos, 2017).

Legenda: Basal: avaliação antes do procedimento anestésico/cirúrgico; T1, T2, T4, T8, T12 e T24: 1, 2, 4, 8, 12 e 24 horas após a administração da medicação pós-operatória; DP: desvio padrão. 
APÊNDICE K - Escores de dor obtidos pela Escala de Expressões faciais para cavalos para avaliação de dor em cavalos (FACIAL) dos 15 cavalos distribuídos aleatoriamente nos 2 grupos do estudo durante os momentos avaliados na fase 02 - FMVZ - São Paulo - 2017.

\begin{tabular}{ccccccccc}
\hline \multicolumn{1}{c}{ Tempos de Avaliação } & & & & \\
\hline \multirow{5}{*}{ Dipirona } & \multicolumn{1}{c}{ Basal } & T1 & T2 & T4 & T8 & T12 & T24 \\
& Cavalo 1 & 0 & 1 & 1 & 1 & 1 & 1 & 0 \\
& Cavalo 2 & 1 & 0 & 0 & 1 & 0 & 0 & 0 \\
& Cavalo 3 & 0 & 2 & 1 & 1 & 1 & 1 & 1 \\
& Cavalo 4 & 0 & 0 & 0 & 0 & 0 & 0 & 0 \\
& Cavalo 5 & 0 & 1 & 0 & 0 & 0 & 0 & 0 \\
& Cavalo 6 & 0 & 0 & 1 & 0 & 0 & 0 & 0 \\
& Cavalo 7 & 0 & 2 & 0 & 0 & 0 & 0 & 0 \\
& Cavalo 8 & 0 & 0 & 0 & 0 & 0 & 0 & 0 \\
\hline \multirow{5}{*}{ Flunixin } & Média & 0,13 & 0,75 & 0,38 & 0,38 & 0,25 & 0,25 & 0,13 \\
& DP & 0,35 & 0,89 & 0,52 & 0,52 & 0,46 & 0,46 & 0,35 \\
\hline & & & & & & & & \\
& Cavalo 1 & 0 & 1 & 1 & 0 & 0 & 0 & 0 \\
& Cavalo 2 & 0 & 2 & 0 & 0 & 0 & 0 & 0 \\
& Cavalo 3 & 0 & 0 & 0 & 0 & 0 & 0 & 0 \\
& Cavalo 4 & 0 & 3 & 0 & 0 & 0 & 0 & 0 \\
& Cavalo 5 & 0 & 0 & 0 & 0 & 0 & 0 & 0 \\
& Cavalo 6 & 0 & 0 & 0 & 0 & 0 & 0 & 0 \\
& Cavalo 7 & 0 & 0 & 0 & 0 & 0 & 0 & 0 \\
\hline & Média & 0 & 0,86 & 0,14 & 0 & 0 & 0 & 0 \\
DP & 0 & 1,21 & 0,38 & 0 & 0 & 0 & 0 \\
\hline
\end{tabular}

Fonte: (SANTOS, R. S. T. dos, 2017).

Legenda: Basal: avaliação antes do procedimento anestésico/cirúrgico; T1, T2, T4, T8, T12 e T24: 1, 2, 4, 8, 12 e 24 horas após a administração da medicação pós-operatória; DP: desvio padrão. 
APÊNDICE L - Escores de Sedação dos 15 cavalos distribuídos aleatoriamente nos 2 grupos do estudo durante os momentos avaliados na fase 02 - FMVZ - São Paulo - 2017.

\begin{tabular}{ccccccccc}
\hline & & \multicolumn{7}{c}{ Tempos de Avaliação } \\
\hline \multirow{5}{*}{ Dipirona } & Cavalo 1 & 0 & 0 & 0 & 0 & 0 & 0 & 0 \\
& Cavalo 2 & 0 & 0 & 0 & 0 & 0 & 0 & 0 \\
& Cavalo 3 & 0 & 2 & 0 & 0 & 0 & 0 & 0 \\
& Cavalo 4 & 0 & 1 & 0 & 0 & 0 & 0 & 0 \\
& Cavalo 5 & 0 & 0 & 0 & 0 & 0 & 0 & 0 \\
& Cavalo 6 & 0 & 0 & 0 & 0 & 0 & 0 & 0 \\
& Cavalo 7 & 0 & 2 & 0 & 0 & 0 & 0 & 0 \\
& Cavalo 8 & 0 & 0 & 0 & 0 & 0 & 0 & 0 \\
\hline \multirow{5}{*}{ Flunixin } & Média & 0 & 0,63 & 0 & 0 & 0 & 0 & 0 \\
& DP & 0 & 0,92 & 0 & 0 & 0 & 0 & 0 \\
\hline & Cavalo 1 & 0 & 2 & 0 & 0 & 0 & 0 & 0 \\
& Cavalo 2 & 0 & 1 & 0 & 0 & 0 & 0 & 0 \\
& Cavalo 3 & 0 & 1 & 0 & 0 & 0 & 0 & 0 \\
& Cavalo 4 & 0 & 0 & 0 & 0 & 0 & 0 & 0 \\
& Cavalo 5 & 0 & 0 & 0 & 0 & 0 & 0 & 0 \\
& Cavalo 6 & 0 & 0 & 0 & 0 & 0 & 0 & 0 \\
& Cavalo 7 & 0 & 0 & 0 & 0 & 0 & 0 & 0 \\
\hline & Média & 0 & 0,57 & 0 & 0 & 0 & 0 & 0 \\
DP & 0 & 0,79 & 0 & 0 & 0 & 0 & 0 \\
\hline
\end{tabular}

Fonte: (SANTOS, R. S. T. dos, 2017).

Legenda: Basal: avaliação antes do procedimento anestésico/cirúrgico; T1, T2, T4, T8, T12 e T24: 1, 2, 4, 8, 12 e 24 horas após a administração da medicação pós-operatória; DP: desvio padrão. 
APÊNDICE M - Escores de Ataxia dos 15 cavalos distribuídos aleatoriamente nos 2 grupos do estudo durante os momentos avaliados na fase 02 - FMVZ - São Paulo - 2017.

\begin{tabular}{|c|c|c|c|c|c|c|c|c|}
\hline & \multicolumn{8}{|c|}{ Tempos de Avaliação } \\
\hline & & Basal & T1 & $\mathrm{T} 2$ & T4 & T8 & T12 & T24 \\
\hline & Cavalo 1 & 0 & 0 & 0 & 0 & 0 & 0 & 0 \\
\hline & Cavalo 2 & 0 & 0 & 0 & 0 & 0 & 0 & 0 \\
\hline & Cavalo 3 & 0 & 3 & 1 & 0 & 0 & 0 & 0 \\
\hline \multirow[t]{10}{*}{ Dipirona } & Cavalo 4 & 0 & 2 & 0 & 0 & 0 & 0 & 0 \\
\hline & Cavalo 5 & 0 & 1 & 0 & 0 & 0 & 0 & 0 \\
\hline & Cavalo 6 & 0 & 1 & 0 & 0 & 0 & 0 & 0 \\
\hline & Cavalo 7 & 0 & 3 & 1 & 0 & 0 & 0 & 0 \\
\hline & Cavalo 8 & 0 & 1 & 0 & 0 & 0 & 0 & 0 \\
\hline & Média & 0 & 1,38 & 0,25 & 0 & 0 & 0 & 0 \\
\hline & DP & 0 & 1,19 & 0,46 & 0 & 0 & 0 & 0 \\
\hline & Cavalo 1 & 0 & 2 & 0 & 0 & 0 & 0 & 0 \\
\hline & Cavalo 2 & 0 & 2 & 0 & 0 & 0 & 0 & 0 \\
\hline & Cavalo 3 & 0 & 1 & 0 & 0 & 0 & 0 & 0 \\
\hline \multirow[t]{6}{*}{ Flunixin } & Cavalo 4 & 0 & 1 & 0 & 0 & 0 & 0 & 0 \\
\hline & Cavalo 5 & 0 & 1 & 0 & 0 & 0 & 0 & 0 \\
\hline & Cavalo 6 & 0 & 1 & 0 & 0 & 0 & 0 & 0 \\
\hline & Cavalo 7 & 0 & 0 & 0 & 0 & 0 & 0 & 0 \\
\hline & Média & 0 & 1,14 & 0 & 0 & 0 & 0 & 0 \\
\hline & DP & 0 & 0,69 & 0 & 0 & 0 & 0 & 0 \\
\hline
\end{tabular}

Fonte: (SANTOS, R. S. T. dos, 2017).

Legenda: Basal: avaliação antes do procedimento anestésico/cirúrgico; T1, T2, T4, T8, T12 e T24: $1,2,4,8,12$ e 24 horas após a administração da medicação pós-operatória; DP: desvio padrão. 
APÊNDICE N - Tempos cirúrgicos, em minutos, dos 15 cavalos distribuídos aleatoriamente nos 2 grupos do estudo durante os momentos avaliados na fase 02 - FMVZ - São Paulo - 2017.

Tempo Cirúrgico $(\mathrm{min})$

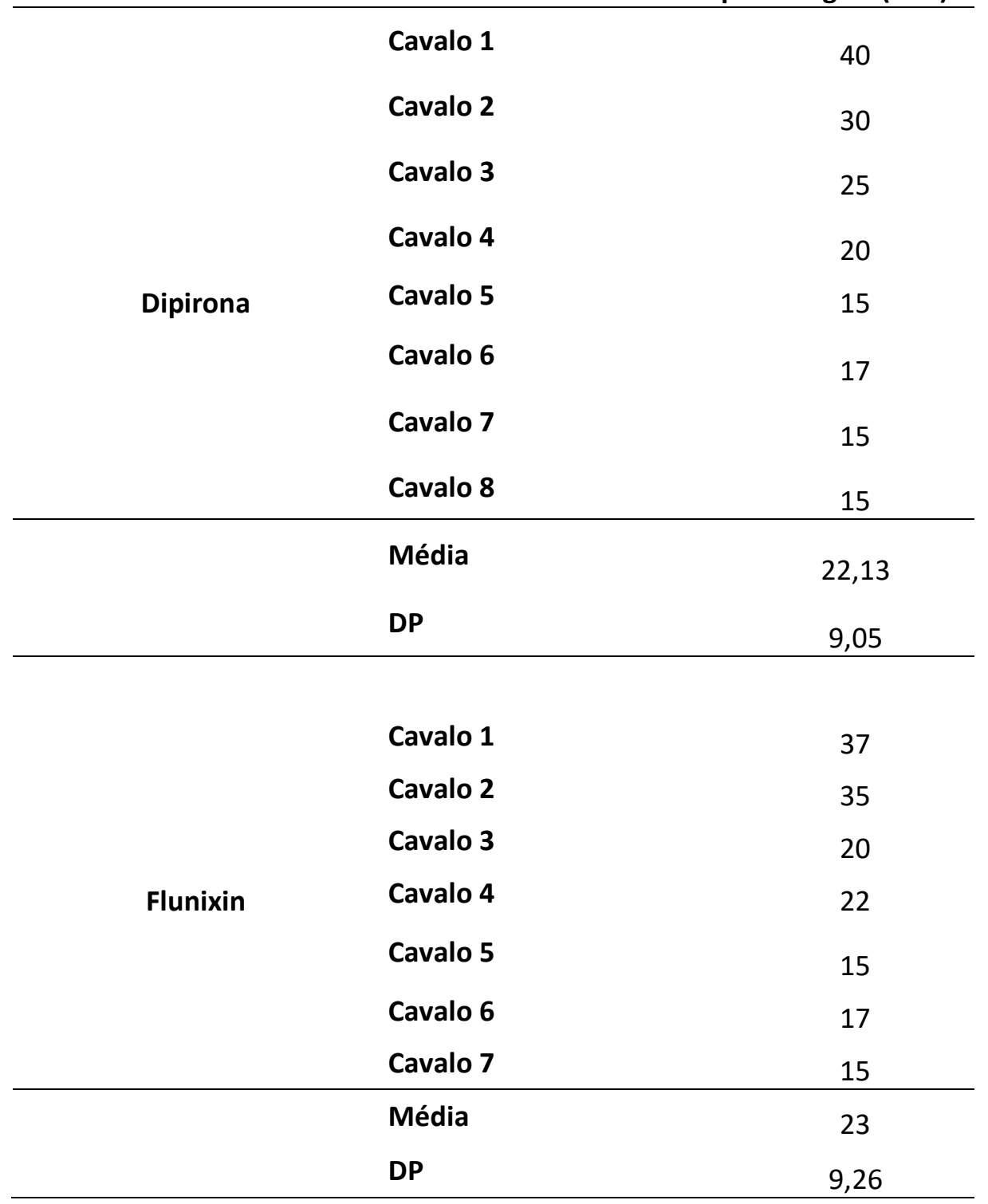

Fonte: (SANTOS, R. S. T. dos, 2017).

Legenda: Min: minutos; DP: desvio padrão. 


\section{ANEXOS}


ANEXO A- Escala Multidimensional da UNESP-Botucatu para avaliação de dor aguda pós-operatória em cavalos submetidos à castração.

\begin{tabular}{|c|c|c|}
\hline Variável & Descrição & Escore \\
\hline \multirow{4}{*}{ Posição na baia } & A cabeça do cavalo está para fora da baia & 0 \\
\hline & $\begin{array}{l}\text { O cavalo está dentro da baia, porém olhando para fora, } \\
\text { observando o ambiente }\end{array}$ & 1 \\
\hline & O cavalo está comendo & 0 \\
\hline & $\begin{array}{c}\text { O cavalo não está próximo da porta de saída e não } \\
\text { demonstra interesse no ambiente }\end{array}$ & 2 \\
\hline \multirow{3}{*}{ Locomoção } & O cavalo se move sozinho normalmente & 0 \\
\hline & $\begin{array}{c}\text { O cavalo não se move, ou fica relutante para se } \\
\text { movimentar }\end{array}$ & 1 \\
\hline & O cavlao está agitado, inquieto & 2 \\
\hline \multirow{3}{*}{$\begin{array}{l}\text { Locomoção quando puxado pelo } \\
\text { avaliador }\end{array}$} & O cavlo se move livremente quando é puxado & 0 \\
\hline & $\begin{array}{l}\text { O cavalo não se move ou fica relutante para se mover } \\
\text { quando é puxado }\end{array}$ & 1 \\
\hline & O cavalo está agitado, inquieto & 2 \\
\hline \multirow{3}{*}{$\begin{array}{c}\text { Resposta à palpação da área } \\
\text { dolorosa (aproximadamente } 3 \mathrm{~cm} \\
\text { nas laterais da ferida) }\end{array}$} & $\begin{array}{l}\text { Sem nenhuma resposta ou mudança frente à resposta } \\
\text { da palpação antes do procedimento }\end{array}$ & 0 \\
\hline & Reação leve à palpação da ferida cirúrgica & 1 \\
\hline & Reação violenta à palpação da ferida cirúrgica & 2 \\
\hline \multirow{2}{*}{ Olhar para o flanco } & O cavalo não olha para o flanco & 0 \\
\hline & O cavalo olha para o flanco & 1 \\
\hline \multirow{2}{*}{ Chutar o abdômen } & O cavalo não chuta o abdômen & 0 \\
\hline & O cavalo chuta o abdômen & 1 \\
\hline \multirow{3}{*}{ Levantar membros pélvicos } & Não levanta membros pélvicos & 0 \\
\hline & Levanta membros pélvicos & 1 \\
\hline & Levanta membros pélvicos e se alonga & 2 \\
\hline \multirow{3}{*}{ Movimento da cabeça } & A cabeça está erguida a maior parte do tempo & 0 \\
\hline & $\begin{array}{c}\text { Ocasionalmente faz movimentos laterais e/ou verticais } \\
\text { com a cabeça }\end{array}$ & 1 \\
\hline & $\begin{array}{l}\text { Constantemente faz movimentos laterais e/ou verticais } \\
\text { com a cabeça }\end{array}$ & 2 \\
\hline \multirow{2}{*}{ Patiar (membros torácicos) } & Quieto, sem patiar & 0 \\
\hline & Patiando & 1 \\
\hline \multirow{2}{*}{$\begin{array}{l}\text { FC (Comparada com valores } \\
\text { iniciais) }\end{array}$} & $25-50 \%$ de aumento & 1 \\
\hline & $>50 \%$ de aumento & 2 \\
\hline
\end{tabular}

Fonte: TAFFAREL et al., 2015. 
ANEXO B: Escala Multidimensional de expressões faciais em cavalos como ferramenta para avaliação de dor pós-castração de rotina.
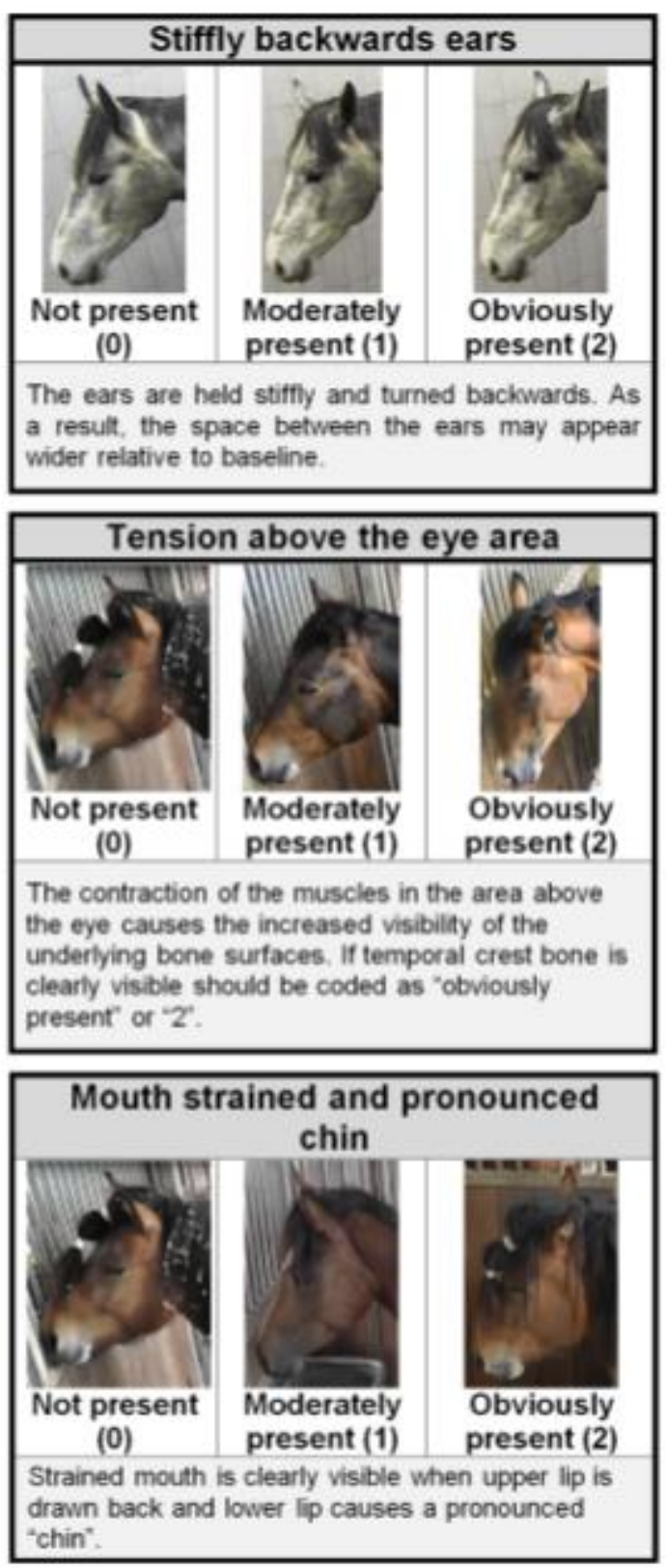
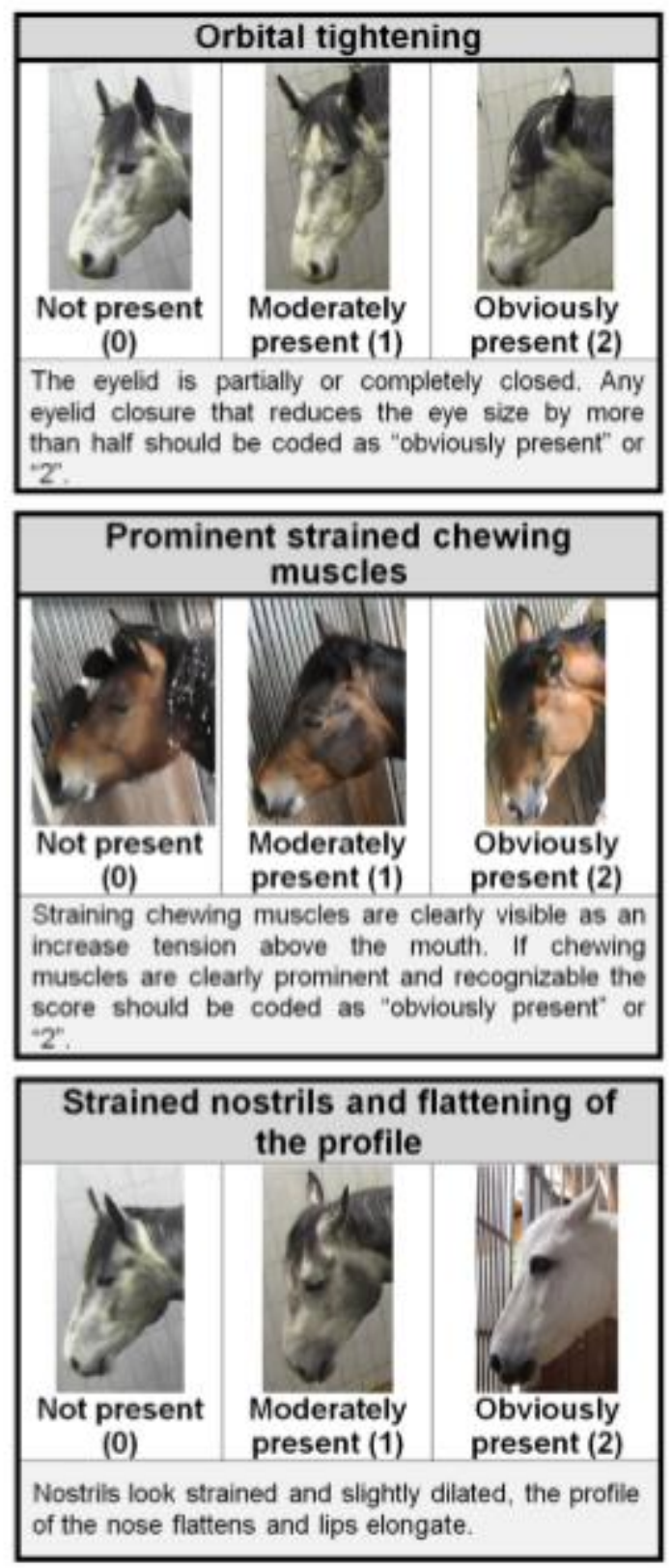

Fonte: DALLAS COSTA et al., 2014. 
ANEXO C: Escala Analógica Visual (EAV), em centímetros (cm), como ferramenta para avaliação de dor nos animais da fase 02 do experimento. $\mathrm{O}$ avaliador marca entre o zero, que representa animal sem dor, e $10 \mathrm{~cm}$, a pior dor possível.

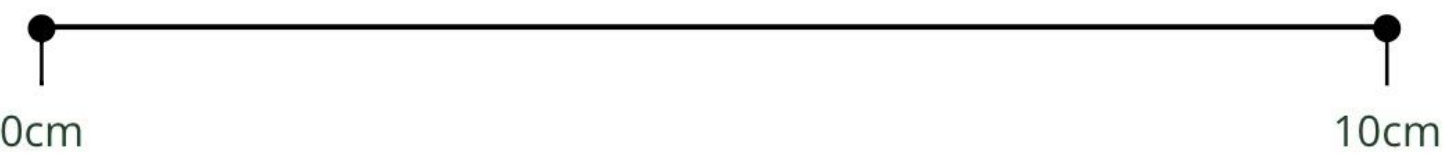


ANEXO D: Escala de Sedação utilizada para avaliar os animais da fase 02 do experimento.

\begin{tabular}{|l|l|}
\hline \multicolumn{2}{|c|}{ Sedação } \\
\hline $\mathbf{0}$ & $\begin{array}{l}\text { Sem sedação, postura normal, responde ao contato com o } \\
\text { avaliador. }\end{array}$ \\
\hline $\mathbf{1}$ & $\begin{array}{l}\text { Sedação leve, pouca movimentação de cabeça, relaxamento } \\
\text { de músculos faciais, lábio inferior pendente. }\end{array}$ \\
\hline $\mathbf{2}$ & $\begin{array}{l}\text { Sedação moderada, abaixamento de cabeça em direção ao } \\
\text { chão, balanço de membros pélvicos. }\end{array}$ \\
\hline $\mathbf{3}$ & Sedação intensa, tende a deitar-se. \\
\hline
\end{tabular}

Fonte: Adaptado de Taylor et al. (2013).

ANEXO D: Escala de ataxia utilizada para avaliar os animais da fase 02 do experimento.

\begin{tabular}{|l|l|}
\hline \multicolumn{2}{|c|}{ Ataxia } \\
\hline $\mathbf{0}$ & $\begin{array}{l}\text { Sem ataxia, permanece em estação e anda normalmente, apto } \\
\text { para realizar curvas fechadas. }\end{array}$ \\
\hline $\mathbf{1}$ & $\begin{array}{l}\text { Leve ataxia, animal consegue andar, porém há incoordenação } \\
\text { do membro. }\end{array}$ \\
\hline $\mathbf{2}$ & $\begin{array}{l}\text { Ataxia moderada, pode andar apenas com suporte, cambaleia } \\
\text { mas não cai. }\end{array}$ \\
\hline $\mathbf{3}$ & $\begin{array}{l}\text { Ataxia severa, animal anda com risco de queda, cambaleia e } \\
\text { cai quando realiza curvas. }\end{array}$ \\
\hline
\end{tabular}

Fonte: Adaptado de Taylor et al. (2013). 